Universidade de Brasília - UnB

Instituto de Ciências Humanas - IH

Departamento de Geografia - GEA

Programa de Pós Graduação em Geografia

UNIVERSIDADE DE BRASÍLIA

PÓS-GRADUÇÃO EM GEOGRAFIA

USO DE SÉRIES TEMPORAIS NDVI DO MODIS PARA

MAPEAMENTO DA COBERTURA VEGETAL NATURAL E EXÓTICA EM UMA REGIÃO DE TRANSIÇÃO CERRADO-CAATINGA

Natanael Antunes Abade

Dissertação de Mestrado

Brasília-DF, Abril de 2015. 
Universidade de Brasília - UnB

Instituto de Ciências Humanas - IH

Departamento de Geografia - GEA

Programa de Pós Graduação em Geografia

UNIVERSIDADE DE BRASÍLIA

PÓS-GRADUÇÃO EM GEOGRAFIA

\section{USO DE SÉRIES TEMPORAIS NDVI DO MODIS PARA \\ MAPEAMENTO DA COBERTURA VEGETAL NATURAL E EXÓTICA EM UMA REGIÃO DE TRANSIÇÃO CERRADO-CAATINGA}

Natanael Antunes Abade

Orientador: Prof. Dr. Osmar Abílio de Carvalho Júnior

Dissertação de Mestrado

Brasília-DF, Abril de 2015. 


\title{
USO DE SÉRIES TEMPORAIS NDVI DO MODIS PARA MAPEAMENTO DA COBERTURA VEGETAL NATURAL E EXÓTICA EM UMA REGIÃO DE TRANSIÇÃO CERRADO-CAATINGA
}

\author{
Natanael Antunes Abade
}

Dissertação de Mestrado submetida ao Departamento de Geografia da Universidade de Brasília, como parte dos requisitos para a obtenção do Grau de Mestre em Geografia, área de concentração Gestão Ambiental e Territorial, linha de pesquisa Geoprocessamento, opção Acadêmica.

Aprovado por:

Prof. Dr. Osmar Abílio de Carvalho Júnior (UnB)

Prof. Dr. Arnaldo Yoso Sakamoto (UFMS)

Prof. Dr. Jeater Waldemar Maciel Correa Santos (UFMT)

Brasília-DF, Abril de 2015. 
ABADE, NATANAEL ANTUNES

Uso de séries temporais NDVI do MODIS para mapeamento da cobertura vegetal natural e exótica em uma região de transição Cerrado-Caatinga, 70 p., (UnB-IH-GEA, Mestre, Gestão Ambiental e Territorial, 2015).

Dissertação de Mestrado - Universidade de Brasília. Instituto de Humanas, Departamento de Geografia.

1. Séries Temporais

3. Mapeamento de Vegetação

I. UnB-IH-GEA
2. MODIS

4. Sensoriamento Remoto

É concebido à Universidade de Brasília permissão para reproduzir cópias desta dissertação e emprestar ou vender tais cópias somente para propósitos acadêmicos e científicos. O autor reserva outros direitos de publicação e nenhuma parte desta dissertação de mestrado pode ser reproduzida sem a autorização por escrito do autor.

Natanael Antunes Abade 


\section{AGRADECIMENTOS}

Ao meu orientador, Dr. Osmar Abílio de Carvalho Júnior, grande professor e cientista, pelo seu profissionalismo e disposição para esclarecer dúvidas e compartilhar conhecimentos preciosos.

Aos professores do curso de Pós-graduação em Geografia Roberto Arnaldo Trancoso Gomes e Renato Fontes Guimarães, que sempre se mostraram presentes e dispostos a colaborar na construção deste trabalho.

Agradeço ao Instituto do Meio Ambiente e dos Recursos Hídricos do Distrito Federal - Brasília Ambiental (IBRAM), pela concessão de licença remunerada, ao curso de PósGraduação em Geografia e à gestão do Laboratório de Sistemas de Informações Espaciais (LSIE), por terem disponibilizado a estrutura necessária ao processamento dos dados.

Aos meus colegas de IBRAM Alisson, Amanda, Ana Gabriela, Daniel, Dilberto, Fernando, José Flávio, Juliana e Tatiane, verdadeiros amigos que garantiram o apoio que tanto precisei para conseguir finalizar esta dissertação.

Aos colegas de LSIE Sandro, Míriam, Verônica, Paulo Henrique, Cristiane, Potira, Ricardo Aranha e Wilma, pelos momentos de angústia, de risadas, de troca de conhecimentos e pela amizade construída.

Ao meu professor do curso Técnico em Agropecuária, Wilson Alves Moreira, por ter feito acreditar que a educação muda a vida das pessoas. Ela realmente mudou a minha.

À minha família e em especial à minha amada esposa Neyrilanne, à minha filhinha Natália e à minha mãe Elvira. Desculpem-me pela ausência e muito, muito obrigado mesmo pela paciência e amor incondicionais. É por vocês e para vocês que tenho, dia após dia, tentado me tornar um pessoa melhor, na plenitude do que isso significa! 


\section{RESUMO}

O acompanhamento orbital da flora brasileira tem como marco inicial o projeto Radam na década de 1970. Na época foram utilizados dados do Side-Looking Airborne Radar (SLAR). Outros programas visando conhecer e monitorar o estado de conservação dos biomas do Brasil foram conduzidos nos últimos anos. Cita-se dentre eles o Programa de Cálculo de Desflorestamento da Amazônia (PRODES), a Detecção em Tempo Real (DETER), o Projeto de Conservação e Utilização Sustentável da Diversidade Biológica Brasileira (PROBIO) e o Projeto de Monitoramento do Desmatamento nos Biomas Brasileiros por Satélite (PMDBBS). Além dessas iniciativas governamentais, pesquisas vêm sendo conduzidas por instituições de cunho acadêmico-científico nacionais e internacionais. Todavia, a maioria dos esforços até então conduzidos ou foram orientados ao ecossistema Amazônico ou lançaram mão de técnicas apoiadas em imagens monotemporais, cuja resolução espaço-temporal não é compatível com a atual dinâmica de mudança da paisagem. Diante dessa realidade, desenvolveu-se este trabalho visando estudar uma região de transição de ecossistemas semiáridos (Cerrado-Caatinga), localizada no norte do estado de Minas Gerais e sudoeste da Bahia. Trata-se de um local de biodiversidade riquíssima, composta por uma flora complexa e que ainda não foi muito bem estudada. Sua paisagem começa agora a sofrer alterações por conta do crescimento significativo de atividades antrópicas ligadas à agricultura, alavancadas pela concretização de grandes projetos de irrigação criados entre as décadas de 1970 e 1990 . Para atingir tal objetivo, foi aplicado um conjunto de metodologias que envolveu: o uso de séries temporais NDVI-MODIS, compreendendo o período de 2011 a 2013, oriundas do produto MOD09Q1; das técnicas filtragem de mediana e Savitzky-Golay; seleção de assinaturas temporais de classes de uso da terra e cobertura vegetal; e classificação das séries temporais através dos algoritmos de similaridade e distância Spectral Angle Mapper (SAM), Spectral Correlation Mapper (SCM) e Euclidian Distance Measure (ED). Os melhores resultados foram obtidos com o uso do classificador ED sobre a série temporal NDVIMODIS, alcançando índices de Exatidão Global e Kappa, superiores a 82\% e 0,75. Entretanto, mais estudos devem ser feios visando à distinção das fitofisionomias de porte arbustivo-herbáceo do domínio Cerrado, bem como das lavouras cultivadas nas propriedades agrícolas familiares, presentes em grande número à margem esquerda do rio São Francisco.

Palavas-chave: Monitoramento da Vegetação, Brasil, Semiárido, Séries Temporais, NDVIMODIS, Transição Cerrado-Caatinga 


\begin{abstract}
The orbital monitoring of Brazilian flora began in the 1970s with Radam project, when were used data of the Side-Looking Airborne Radar (SLAR). Other programs were conducted in order to know and monitor the conservation status of Brazil's biomes. The Programa de Cálculo de Desflorestamento da Amazônia (PRODES), the Detecção em Tempo Real (DETER), the Projeto de Conservação e Utilização Sustentável da Diversidade Biológica Brasileira (PROBIO) and Projeto de Monitoramento do Desmatamento nos Biomas Brasileiros por Satélite (PMDBBS) were some such initiatives. In addition to government actions, research is being conducted by institutions of national and international academic and scientific nature. However, most efforts were directed to the Amazon ecosystem or used techniques supported by monotemporal images, resolution space-times is not compatible with the current dynamics of change of the landscape. Given this reality, we developed this work aiming to study a transition region of semi-arid ecosystems (Cerrado-Caatinga), located in the north of Minas Gerais and Bahia southwest, Brazil. This place has rich biodiversity, consisting of a complex flora and that has not been well studied. Its landscape begins to undergo changes due to significant growth of human activities related to agriculture, leveraged by the realization of major irrigation projects created between the 1970s and 1990s. Thus, we used the following method: use of NDVI-MODIS time-series from 2011 to 2013, deriving from the MOD09Q1 product; use of median and Savitzky-Golay filters; selection of temporal-signature references of land use and vegetation cover and use of classifiers similarity and distance Spectral Angle Mapper (SAM), Spectral Correlation Mapper (SCM) and Euclidian Distance Measure (ED).The results were satisfactory especially when using the classifier ED on time series NDVI-MODIS, reaching levels of agreement, Global Accuracy and Kappa, more than $82 \%$ and 0.75 . However, more studies should be made to identify the shrub and herbaceous vegetation types of the Cerrado biome and the crops grown on farms of small extent, present in large numbers on the left of São Francisco river.
\end{abstract}

Keywords: Vegetation monitoring, Brazil, Semiarid, Time Series NDVI-MODIS, Transition Cerrado-Caatinga 


\section{SUMÁRIO}

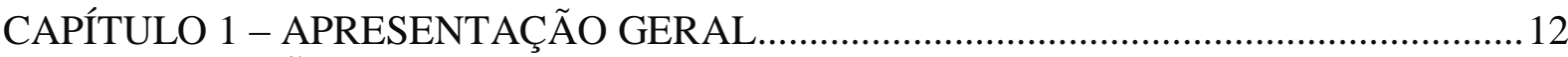

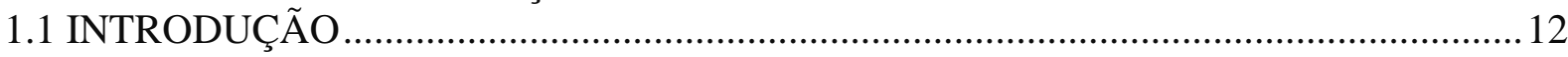

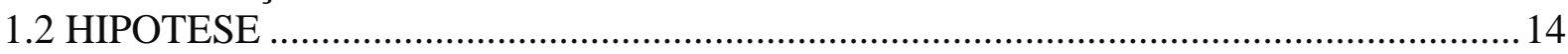

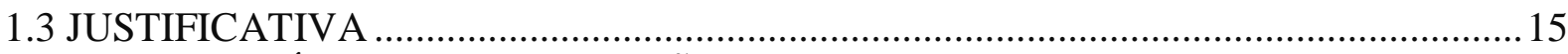

1.4 CARACTERÍSTICAS E APLICAÇÕES DO SENSOR MODIS .....................................15

1.5 UTILIZAÇÃO DE FILTROS DE RUÍDOS EM SÉRIES TEMPORAIS NDVI .............19

1.6 DETECÇÃ

1.7 CARACTERÍSTICAS DA VEGETAÇÃO NATIVA NAS REGIÕES NORTE DE

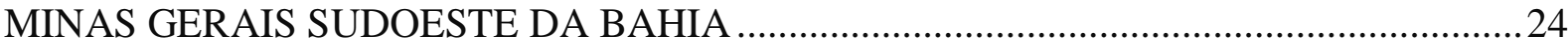

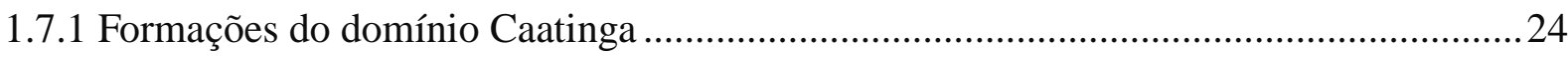

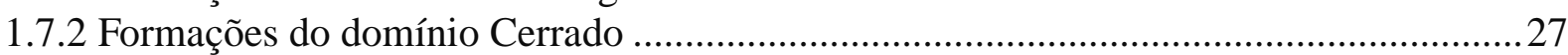

1.8 FATORES PROMOTORES DESENVOLVIMENTO DA AGRICULTURA NAS

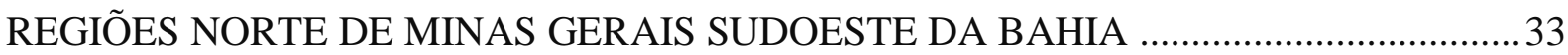

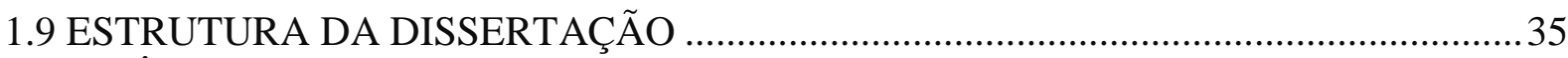

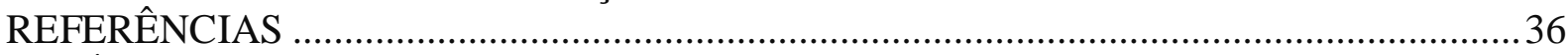

CAPÍTULO 2 - COMPARATIVE ANALYSIS OF DISTANCE AND SIMILARITY MEASURES FOR TIME-SERIES CLASSIFICATION AT THE BRAZILIAN CERRADO-

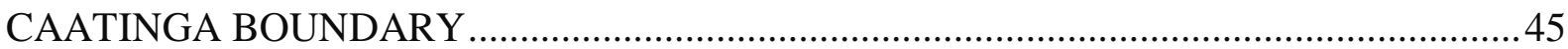

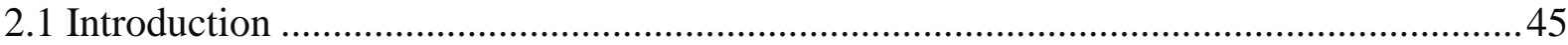

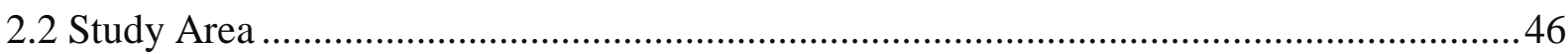

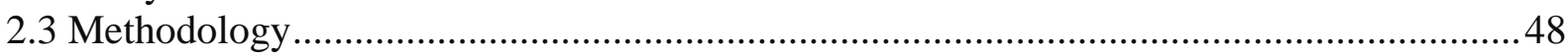

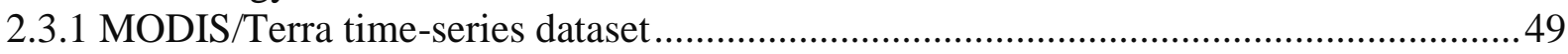

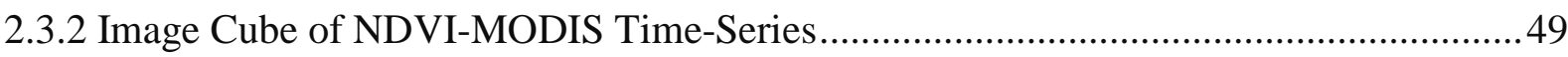

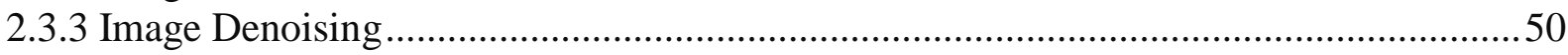

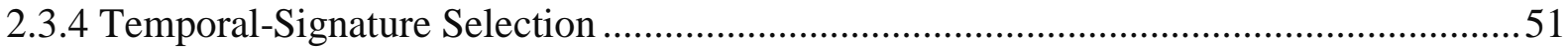

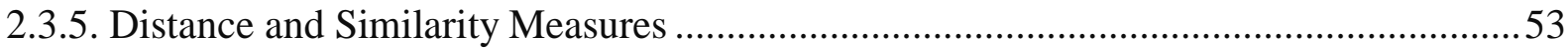

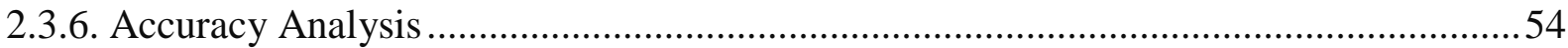

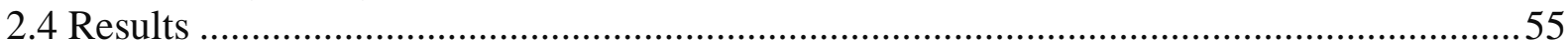

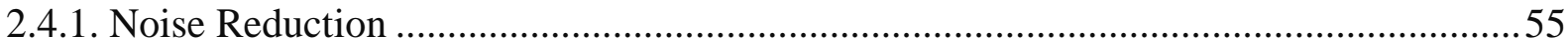

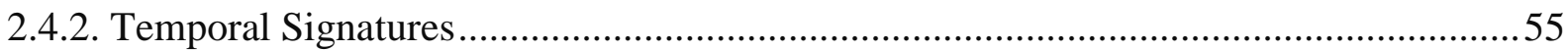

2.4.3. Classification of the MODIS-NDVI Time-Series and MNF Signal Components .........57

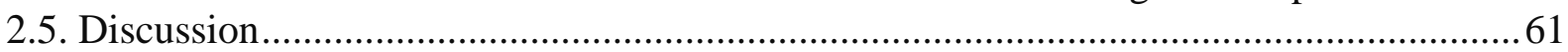

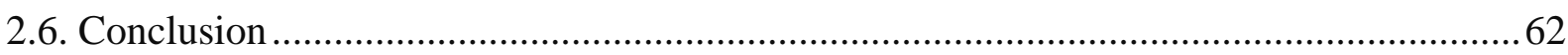

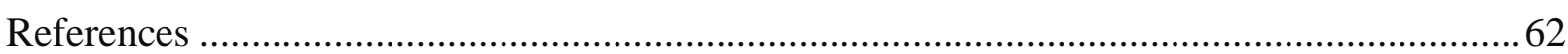

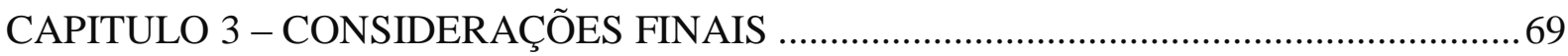




\title{
LISTA DE FIGURAS
}

\author{
Capítulo 1
}

Figura 1.1 - Sequência metodológica para identificação dos membros finais em série temporais NDVI, conforme Bordman; Kruse (1994) .........................................................24 Figura 1.2 - Diagrama de perfil (1) e de cobertura arbórea (2) de florestas semidecídua (a) e decídua (b) nas estações de chuva e de seca. Cada diagrama representa faixas de terreno com cerca de $26 \mathrm{~m}$ de comprimento por $10 \mathrm{~m}$ de largura. $\mathrm{CA}=\%$ de cobertura arbórea...............26 Figura 1.3 - Diagrama do perfil (1) e da cobertura arbórea (2) de um Campo Limpo representado na faixa de $40 \mathrm{~m}$ de comprimento por $10 \mathrm{~m}$ de largura, onde a porção (a) mostra a vegetação em local seco, (b) em local úmido e (c) em local mal drenado com murundus. ..30 Figura 1.4 - Diagrama de perfil (1) e cobertura arbórea (2) de um Campo Sujo representando uma faixa de $40 \mathrm{~m}$ de comprimento por $10 \mathrm{~m}$ de largura, onde a porção (a) mostra a vegetação em local seco, (b) em local úmido e (c) em local mal drenado com murundus. Figura 1.5 - Diagrama de perfil (1) e cobertura arbórea (2) de um Campo Rupestre representando uma faixa de $40 \mathrm{~m}$ de comprimento por $10 \mathrm{~m}$ de largura. ................................31 Figura 1.6 - Diagrama de perfil (1) e de cobertura arbórea (2) dos subtipos da fitofisionomia Cerrado stricto:sensu. (a) Cerrado Denso, (b) Cerrado Típico, (c) Cerrado Ralo. ..................32 Figura 1.7 - Estrutura da Dissertação.

\section{Capítulo 2}

Figure 2.1. Location map of the study area.

Figure 2.2. Spatial distribution of Caatinga and Cerrado in the study area............................48

Figure 2.3. Methodological flowchart of the digital image processing..................................49

Figure 2.4. 3D time series data cube of the study area.......................................................50

Figure 2.5. Eigenvalues plot from MNF transformation. The fraction signal is concentrated in

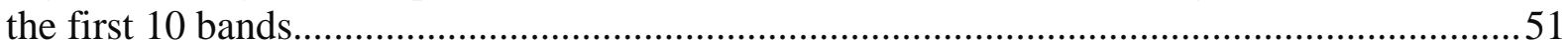
Figure 2.6. Procedure for the temporal-signature selection of land use and vegetal cover, considering both MODIS-NDVI data dimension and the actual dimension of image from signal components of the MNF transform.

Figure 2.7. (a) Landsat-5 TM image of September 12, 2011, color composite with 453 (RGB) and (b) high-resolution images from Google Earth of 2013.

Figure 2.8. MODIS NDVI time series, (a) original data with the presence of noise, (b) time

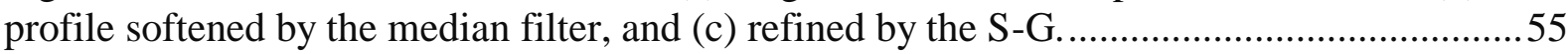
Figure 2.9. Temporal signatures from MODIS-NDVI time series and the MNF signal components: (a) Deciduous Seasonal Forest, (b) Semi-deciduous Seasonal Forest, (c) Savannah Woodland (Cerrado stricto sensu), (d) Grassland formations, (e) Pasture, (f) Annual

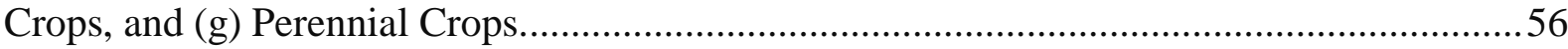
Figure 2.10. Classified maps elaborate from one (a) or three temporal curves (b), considering the other factors remain constant: Euclidian distance, six classes (land-use and land-cover), and NDVI-MODIS input data. Color composite (RGB) 12-28-44 of NDVI-MODIS images (c), 1-2-4 signal fraction of the MNF (d) and 4-5-3 Landsat-TM (e).

Figure 2.11. Classified images considering two types of input data (NDVI-MODIS time series and MNF signal components), three types of similarity and distance measures (SAM SCM and ED), and the more specific set of use classes (eight classes). 


\section{LISTA DE TABELAS}

\section{Capítulo 1}

Tabela 1.1 - Abrangência espectral e espacial das 36 bandas do sensor MODIS. 16

Tabela 1.2 - Produtos específicos do sensor MODIS disponibilizados gratuitamente pela NASA. 17

Tabela 1.3 - Conjunto de dados utilizados no estudo de séries temporais NDVI. 21 Tabela 1.4 - Área em produção, volume de produção e valor dos produtos agrícolas comercializados no perímetro irrigado de Gorutuba. 35

\section{Capítulo 2}

Table 2.1. Classes of land use and land cover used in the classification of MODIS NDVI time series.

Table 2.2. Accuracy assessment for the classifications from two types of input data (NDVIMODIS time series and MNF signal components), three classification measures (SAM SCM and ED) and the two classification with six and eight classes. 


\section{LISTA DE ABREVIATURAS E SIGLAS}

AG Asymmetric Gaussian

ALME Análise Linear de Mistura Espectral

AMF Adaptative Median Filter

APC Análise dos Principais Componentes

ASWM Adaptive Switching Median Filter

AVHRR Advanced Very High Resolution Radiometer

BISE Best Index Slope Extraction

BNB Banco do Nordeste do Brasil

BRDF Bidirectional Reflectance Distribution Function

CBERS China-Brazil Earth Resources Satellite

CHESF Companhia Hidrelétrica do São Francisco

CODEVASF Companhia de Desenvolvimento dos Vales do São Francisco e do Parnaíba

CW Changing-Weight Filter

DBA Decision Base Algorithm

DBUTMF Decision Based Unsymmetric Trimmed Median Filter

DETER Detecção em Tempo Real

DNOCS Departamento Nacional de Obras Contra as Secas

ED Euclidian Distance Measure

ENVI Environment for the Visualization of Images

EVI Enhanced Vegetation Index

FFT Fast Fourier Transform

GES DAAC Goddard Space Flight Center Earth Sciences Distributed Active Archive Center

GIMMS Global Inventory Modeling and Map Studies

HDF Hierarchy Data Format

IBAMA Instituto Brasileiro do Meio Ambiente e dos Recursos Naturais Renováveis

IBGE Instituto Brasileiro de Geografia e Estatística

IDR Interpolation for Data Reconstruction

IEF Instituto Estadual de Florestas de Minas Gerais

INPA Instituto Nacional de Pesquisas da Amazônia

INPE Instituto Nacional de Pesquisas Espaciais

IV Índice de Vegetação

LANDSAT Land Remote Sensing Satellite

LIDAR Light Detection and Ranging 
MBISE Modified Best Index Slope Extraction

MD Minimum Distance

MMA Ministério do Meio Ambiente

MNF Minimum Noise Fraction

MODIS Moderate Resolution Imaging Spectroradiometer

MRT MODIS Reprojection Tools

MVI Mean Value Iteration Filter

NAPC Noise-Adjusted Principal Components

NASA National Aeronautics and Space Administration

NDVI Normalized Difference Vegetation Index

NIR Near Infrared

NOAA National Oceanic and Atmospheric Administration

PECG Parque Estadual Caminho dos Gerais

PMDBBS Projeto de Monitoramento do Desmatamento nos Biomas Brasileiros por Satélite

PNUD Programa das Nações Unidas para o Desenvolvimento

PPI Pixel Purity Index

PROBIO Projeto de Conservação e Utilização Sustentável da Diversidade Biológica Brasileira

PRODES Programa de Cálculo de Desflorestamento da Amazônia

RMSE Root-Mean Squared Error

SAM Spectral Angle Mapper

SCM Spectral Correlation Mapper

SG Savitzky-Golay

SIDRA Sistema IBGE de Recuperação Eletrônica

SIG Sistemas de Informações Geográficas

SLAR Side-Looking Airbone Radar

SPG Sistemas de Posiconamento Global

SUVALE Superintendência do Vale São Francisco

TDF Tropical Dry Forest

TDRSS Tracking and Data Relay Satellite System

TM Thematic Mapper

UFLA Universidade Federal de Lavras

UnB Universidade de Brasília

WGS84 World Geodetic System 84

WS Whittaker Smoother 


\section{CAPÍTULO 1 - APRESENTAÇÃO GERAL}

\subsection{INTRODUÇÃO}

O primeiro levantamento sistemático da cobertura vegetal no Brasil foi iniciado em 1971 a partir do projeto Radam. O objetivo era, principalmente, conhecer a vegetação, a geologia e a natureza dos solos da Amazônia e do Nordeste Brasileiro, usando um método pouco convencional naquela época: Side-Looking Airborne Radar (SLAR) (BRUNNSCHWEILER, 1980; COURA, 2007). A incumbência pelo mapeamento integrado de recursos naturais passou a ser do projeto RadamBrasil a partir de julho de 1975, quando o levantamento por radar foi aplicado para o restante do território brasileiro (AB'SABER, 2002).

O interesse em obter dados sistemáticos sobre a vegetação nativa, em especial sobre o estado de conservação dos ecossistemas brasileiros, continuou através das ações diversas conduzidas pelo Instituto Nacional de Pesquisas Espaciais (INPE). O Programa de Cálculo de Desflorestamento da Amazônia (PRODES), em conjunto com o sistema de Detecção em Tempo Real (DETER), tem monitorado e disponibilizado informações sobre os desmatamentos ocorridos na Floresta Amazônica desde a década de 1980. Outra ação, o Projeto de Conservação e Utilização Sustentável da Diversidade Biológica Brasileira (PROBIO), concluiu o mapeamento dos remanescentes da cobertura vegetal nos biomas brasileiros em 2006 (FERREIRA et al., 2008; LIMA et al., 2012).

Em 2009, o Ministério do Meio Ambiente (MMA) e o Instituto Brasileiro do Meio Ambiente e dos Recursos Naturais Renováveis (IBAMA), contando com o apoio do Programa das Nações Unidas para o Desenvolvimento (PNUD), iniciaram o Projeto de Monitoramento do Desmatamento nos Biomas Brasileiros por Satélite (PMDBBS). Com essa iniciativa, as entidades responsáveis esperam garantir o monitoramento anual, a partir de 2002, dos desmatamentos ocorridos nos biomas extra-amazônicos, utilizando dados dos sensores a bordo dos satélites Land Remote Sensing Satellite (LANDSAT) e China-Brazil Earth Resources Satellite (CBERS), trabalho similar àquele iniciado pelo INPE em 1988 na Amazônia (IBAMA, 2014).

Em períodos mais recentes, as políticas públicas e as obrigações que vem sendo assumidas pelo governo brasileiro perante a comunidade internacional levam a crer que o conhecimento e a preservação da vegetação nativa brasileira passam a ter ainda mais 
relevância (SCARANO et al., 2012a). Um fato que retratou isso foi a reafirmação, durante a realização da Conferência das Nações Unidas sobre o Desenvolvimento Sustentável na cidade do Rio de Janeiro, em 2012 (MINAYO, 2012), do compromisso de cumprir as ações prioritárias da Agenda 21, dentre elas a preservação dos recursos naturais, a redução das emissões de gases do efeito estufa e a redução dos desmatamentos (BARBIER, 2012; SCARANO et al., 2012b).

Essa postura tem feito crescer a demanda por informações confiáveis acerca das modificações de uso do solo, dos limites geográficos e do estado de preservação da flora dos biomas brasileiros de tal forma que, as comunidades científicas e as lideranças políticas não podem mais prescindir de mapas atualizados que permitam fazer o controle dos mecanismos promotores das modificações (SÁNCHEZ-AZOFEIFA et al., 2003; CLARCK et al., 2012).

Apesar da necessidade de um melhor entendimento dos processos de alteração da vegetação nativa e consequentemente do uso do solo em um mundo que vem passando por rápidas mudanças, ainda há uma surpreendente falta de dados adequados sobre o tema. As informações não são produzidas com precisão e consistência suficientes. A maioria dos mapas existentes, ou que se pretende gerar, tem como base a aplicação de um conjunto de técnicas inadequadas ao processamento de imagens de satélite ou lançam mão de produtos de imagens monotemporais cuja resolução espaço-temporal não permite análises adequadas (CLARCK et al., 2012).

O projeto bancado pela parceria MMA/IBAMA é um exemplo, apesar do seu pioneirismo em fornecer dados anuais sobre o estado de conservação dos biomas brasileiros que não estão sobre a área de influência da floresta Amazônica, ele está amparado em imagens de baixa resolução temporal (LANDSAT e CBERS). Evidentemente não se pode negar que há uma longa tradição no uso dessas imagens, no entanto, a alta probabilidade de cobertura de nuvens e a forte sazonalidade climática que ocorrem especialmente em zonas tropicais tornam a utilização desses dados limitada (SANO et al., 2007; ARAI et al., 2011; ZHOU et al., 2013).

Tais imagens não são aptas à verificação de inflexões temporais ocorridas em períodos de tempo mais curtos, decorrentes das características fenológicas típicas da vegetação ou da marcante dinâmica espaço-temporal que ocorre em áreas de produção agrícola. Além disso, o processo de produção de informações derivadas desses dados ainda é composto de etapas manuais demoradas, conforme pode ser verificado nos trabalhos desenvolvidos por Menke et al. (2009), Numata et al. (2009), Sano et al. (2010), e pelo Instituto Estadual de Florestas de Minas Gerais (IEF), que em conjunto com a Universidade Federal de Lavras (UFLA), tem 
promovido o monitoramento da vegetação nativa do estado de Minas Gerais desde 2003 (CARVALHO e SCOLFORO, 2008).

Uma das medidas utilizadas para superar as dificuldades encontradas ao se utilizar imagens de menor resolução temporal para a identificação da vegetação, seja nativa ou exótica, e consequentemente para se obter mapas corretos referentes a mudanças de cobertura é a utilização de assinaturas temporais provenientes do Normalized Difference Vegetation Index (NDVI) (CARVALHO JÚNIOR et al., 2009; SANTANA et al., 2010; COUTO JÚNIOR et al., 2011; BALDI et al., 2014). Esse índice permite a identificação de padrões fenológicos da vegetação que se mostram diretamente relacionados com elementos fundamentais das dinâmicas sazonais da baixa atmosfera (REED et al., 1994). Tal capacidade conduz a inferências relativas à vegetação e seu ambiente, proporcionando o conhecimento relativo aos padrões de uso da superfície terrestre e suas interações climáticas (SCHWARTZ et al., 1999).

Contudo, deve-se destacar que há restrições quanto ao uso de séries temporais do índice de vegetação NDVI, isso devido principalmente à ocorrência de interferências oriundas da distribuição bidirecional de reflectância (BRDF), da variação radiométrica (oscilações do sensor, fatores de distribuição da reflectância) ou ruídos (MOTOHKA et al., 2011; GENG et al., 2014; OLIVEIRA et al., 2014). Diante dessa realidade, é imprescindível, antes da identificação e caracterização dos ecossistemas, desenvolver e aplicar técnicas que reduzam a influência de ruídos existentes em séries temporais (CHEN et al., 2004; CARVALHO JÚNIOR et al., 2012).

\subsection{HIPOTESE}

O mapeamento da vegetação nativa em uma região onde ocorre a transição de ecossistemas (Cerrado e Caatinga) e a diferenciação dela em relação a outras formas de vegetação exótica, decorrentes do desenvolvimento de atividades antrópicas, pode ser feita através da utilização de assinaturas temporais de índices de vegetação provenientes do sensor MODIS, conjugado com o emprego de técnicas de diminuição de ruído e de algoritmos de classificação espectral automatizada. 


\subsection{JUSTIFICATIVA}

Em regiões de características semiáridas nas quais o forte comportamento sazonal da vegetação não é identificado de forma adequada através de técnicas tradicionais de processamento de imagens orbitais, a utilização de assinaturas temporais do Normalized Difference Vegetation Index (NDVI) apresenta-se como uma das soluções a essa deficiência. Tal premissa é particularmente verdadeira em se tratando da região de fronteira que abrange o norte de Minas Gerais e o sudoeste do estado da Bahia, onde a sazonalidade ocorre concomitante a uma riqueza de formação vegetal, caracterizada pela ocorrência da transição de floresta para Caatinga e inclusões de Caatinga e Cerrado.

Considerando a posição de liderança assumida pelo Brasil perante a comunidade internacional a partir da última edição da Conferência das Nações Unidas sobre o Desenvolvimento Sustentável, é de suma importância que o país desenvolva e aplique técnicas que propiciem a identificação e o monitoramento da sua flora nativa remanescente (localizações, dimensões territoriais e estágios de conservação frente à expansão de atividades tais como a agropecuária). Estas técnicas devem ser orientadas principalmente às regiões semiáridas, isso porque apesar da sua riqueza de espécies, equivalente a das zonas tropicais úmidas, esses locais carecem de dados científicos consistentes. Somente através do conhecimento pleno das atuais condições dos biomas brasileiros, inclusive em escala microrregional, é que se terá condições de aplicar as políticas públicas e privadas voltadas à sustentabilidade.

\subsection{CARACTERÍSTICAS E APLICAÇÕES DO SENSOR MODIS}

O MODIS é o principal instrumento a bordo dos satélites TERRA e AQUA, lançados em dezembro de 1999 e maio de 2002, respectivamente. Trata-se de radiômetro-imageador que possui alta resolução temporal, com uma cobertura global quase que diária (a cada 1-2 dias) e cujas resoluções espectral (36 bandas), radiométrica (12 bits) e espacial ( $250 \mathrm{~m}, 500 \mathrm{~m}$ e $1000 \mathrm{~m}$ ) foram selecionadas para obter dados de radiância da atmosfera, do oceano e da terra (JUSTICE et al., 2002; RUDORFF et al., 2007).

As características desse sensor são baseadas em diversos outros instrumentos, tais como o Advanced Very High Resolution Radiometer (AVHRR), a bordo dos satélites da série National Oceanic and Atmospheric Administration (NOAA), e o Thematic Mapper (TM), presente na série LANDSAT. Assim, para o imageamento terrestre, por exemplo, o modelo do 
sensor MODIS combinou tanto características do AVHRR, quanto do LANDSAT/TM, as quais foram adicionadas das bandas espectrais do infravermelho médio (HUETE et al., 1997).

As 36 bandas espectrais do MODIS estão localizadas em comprimentos de onda que vão do visível ao infravermelho termal (Tabela 1.1), elas foram projetadas de tal forma que evitam as bandas de absorção atmosférica, facilitando a observação de propriedades das nuvens, a dinâmica e as propriedades da vegetação na cobertura terrestre e a temperatura da superfície dos oceanos (STRAHLER et al., 1999). As primeiras 19 bandas estão entre $405 \mathrm{~nm}$ e $2155 \mathrm{~nm}$, de forma que as bandas 1-7 estão direcionadas a aplicações terrestres; as bandas 8-16 a observações oceânicas e as bandas 17-19 a medições atmosféricas. As bandas 20 - 36, com exceção da banda 26, cobrem a porção termal do espectro (3660 nm a $14385 \mathrm{~nm}$ ).

Tabela 1.1 - Abrangência espectral e espacial das 36 bandas do sensor MODIS.

\begin{tabular}{|c|c|c|c|}
\hline Uso Primário & Banda & Comprimento de Onda (nm) & Resolução Espacial (m) \\
\hline \multirow{2}{*}{ prorpriedades da terra/nuvens/aerosol } & 1 & $620-670$ & \multirow{2}{*}{250} \\
\hline & 2 & $841-876$ & \\
\hline \multirow{5}{*}{ prorpriedades da terra/nuvens/aerosol } & 3 & $459-479$ & \multirow{5}{*}{500} \\
\hline & 4 & $545-565$ & \\
\hline & 5 & $1230-1250$ & \\
\hline & 6 & $1628-1652$ & \\
\hline & 7 & $2105-2155$ & \\
\hline \multirow{9}{*}{$\begin{array}{c}\text { cor do } \\
\text { oceano/fitoplancton/biogeoquímica }\end{array}$} & 8 & $405-420$ & \multirow{9}{*}{1000} \\
\hline & 9 & $438-448$ & \\
\hline & 10 & $483-493$ & \\
\hline & 11 & $526-536$ & \\
\hline & 12 & $546-566$ & \\
\hline & 13 & $662-672$ & \\
\hline & 14 & $673-683$ & \\
\hline & 15 & $743-753$ & \\
\hline & 16 & $862-877$ & \\
\hline \multirow{3}{*}{ vapor de água na atmosfera } & 17 & $890-920$ & \multirow{3}{*}{1000} \\
\hline & 18 & $931-941$ & \\
\hline & 19 & $915-965$ & \\
\hline \multirow{4}{*}{ temperatura nuvens/superfície } & 20 & $3660-3840$ & \multirow{4}{*}{1000} \\
\hline & 21 & $3929-3989$ & \\
\hline & 22 & $3929-3989$ & \\
\hline & 23 & $4020-4080$ & \\
\hline \multirow{2}{*}{ temperatura atmosférica } & 24 & $4433-4498$ & \multirow{2}{*}{1000} \\
\hline & 25 & $4482-4549$ & \\
\hline \multirow{3}{*}{ vapor de água em nuvens cirrus } & 26 & $1360-1390$ & \multirow{3}{*}{1000} \\
\hline & 27 & $6535-6895$ & \\
\hline & 28 & $7175-7475$ & \\
\hline propriedades das nuvens & 29 & $8400-8700$ & 1000 \\
\hline ozônio & 30 & $9580-9880$ & 1000 \\
\hline \multirow{2}{*}{ temperatura nuvens/superfície } & 31 & $10780-11280$ & \multirow{2}{*}{1000} \\
\hline & 32 & $11770-12270$ & \\
\hline \multirow{4}{*}{ nuvens no topo da atmosfera } & 33 & $13185-13485$ & \multirow{4}{*}{1000} \\
\hline & 34 & $13485-13785$ & \\
\hline & 35 & $13785-14085$ & \\
\hline & 36 & $14085-14385$ & \\
\hline
\end{tabular}


Os produtos do MODIS (Tabela 1.2) são ofertados gratuitamente pela National Aeronautics and Space Administration (NASA) ao usuário final. Eles são armazenados no formato específico, o Hierarchy Data Format (HDF), e quando adquiridos já se encontram georreferenciados e corrigidos de efeitos atmosféricos como nuvens, aerossóis, entre outros (ANDERSON et al., 2003). Esses produtos são gerados em intervalos diversos que variam desde oito dias a um mês, ou ainda em temporadas que chegam a um ano, e são mais adequados ao uso por pesquisadores interessados em efeitos sazonais (PARKINSON et al., 2000).

Tabela 1.2 - Produtos específicos do sensor MODIS disponibilizados gratuitamente pela NASA.

\begin{tabular}{|c|c|}
\hline Calibração & Produto \\
\hline MOD 01 & Nível 1-A \\
\hline MOD 02 & Nível 1-B \\
\hline MOD 03 & Geolocalização \\
\hline Atmosfera & Produto \\
\hline MOD 04 & Aerosol \\
\hline MOD 05 & Vapor d'água \\
\hline MOD 06 & Nuvens \\
\hline MOD 07 & Perfis Atmosféricos \\
\hline MOD 08 & Grade Atmosférica \\
\hline MOD 35 & Máscara de Nuvens \\
\hline Terra & Produto \\
\hline MOD 09 & Reflectância de Superfície \\
\hline MOD 11 & Temperatura e Emissividade da Superfície Terrestre \\
\hline MOD 12 & Cobertura / Mudança de Cobertura da Terra \\
\hline MOD 13 & Índices de Vegetação \\
\hline MOD 14 & Anomalias Termais, Incêndios e Queimada de Biomassa \\
\hline MOD 15 & Índice de área foliar e Fração da Radiação Fotossinteticamente Ativa \\
\hline MOD 16 & Evapotranspiração \\
\hline MOD 17 & Rede Fotossintética e Produtividade Primária \\
\hline MOD 43 & Reflectância de Superfície \\
\hline MOD 44 & Conversão da Cobertura Vegetal \\
\hline Criosfera & Produto \\
\hline MOD 10 & Cobertura de Gelo \\
\hline MOD 29 & Cobertura de Gelo no Oceano \\
\hline Oceano & Produto \\
\hline MOD 18 & Radiância Normalizada da Água \\
\hline MOD 19 & Concentração de Pigmentos \\
\hline MOD 20 & Fluorescencia de Clorofila \\
\hline MOD 21 & Concentração de Pigmentos de Clorofila-A \\
\hline MOD 22 & Radiação Fotossinteticamente Disponível \\
\hline MOD 23 & Concentração de Sólidos Suspensos \\
\hline MOD 24 & Concentração de Matéria Orgânica \\
\hline MOD 25 & Concentração de Coccolith \\
\hline MOD 26 & Coeficiente de Atenuação da Água do Oceano \\
\hline MOD 27 & Produtividade Primária do Oceano \\
\hline MOD 28 & Temperatura da Superfície do Oceano \\
\hline MOD 36 & Coeficiente de Absorção Total \\
\hline MOD 37 & Propriedades do Aerosol do Oceano \\
\hline MOD 39 & Água Clara Epsilon \\
\hline
\end{tabular}


Cabe esclarecer que os intervalos de geração dos produtos nem sempre são iguais ao de obtenção de dados pelo sensor. A aquisição de dados pelo sensor é diária, todavia, a disponibilização das informações adquiridas obedece a períodos compatíveis com o produto ofertado. No caso específico do MOD09 e MOD13, que disponibilizam dados de refletância e de índices de vegetação, a cada 8 e 16 dias, respectivamente, são disponibilizados novas informações, que resultam da composição das melhores imagens adquiridas diariamente pelo instrumento durante aqueles intervalos de tempo (HUETE et al., 2002; JUSTICE et al., 2002).

Assim como os demais instrumentos a bordo dos satélites TERRA e AQUA, os dados MODIS são enviados para estações terrestres em White Sands, Novo México. Posteriormente eles são processados no Goddard Space Flight Center e divididos em cinco níveis (0 a 4), que variam de acordo com o grau de tratamento, detalhados abaixo, conforme Justice et al. (2002):

$\checkmark$ Nível 0: este nível retrata a imagem em seu estado bruto, sem tratamento de espécie alguma. Não é disponível ao usuário e não consta na lista de produtos padrões;

$\checkmark$ Nível 1 (1A): contém uma base de dados de 36 canais do MODIS, é utilizado como dado de entrada para geolocalização, calibração e processamento. Indicadores de qualidade são adicionados aos dados para indicar a perda de pixels ruins. Medidas no visível, infravermelho próximo e médio são feitas apenas durante o dia, enquanto que as medidas na faixa do infravermelho termal são feitas tanto de dia, quanto à noite;

$\checkmark$ Nível 1 (1B): os produtos contém os dados de calibração e geolocalização para as 36 bandas geradas pelo nível 1A. As radiâncias são em $\mathrm{W} /\left(\mathrm{m}^{2} . \mu \mathrm{m} . \mathrm{sr}\right)$. Em adição, o BRDF (reflectância bidirecional) pode ser determinado para bandas reflectivas solares $(1-19,26)$ através do conhecimento da irradiação solar (por exemplo, determinação de dados MODIS e a geometria de iluminação do alvo. Dados adicionais são fornecidos, incluindo as estimativas de qualidade, de erro e dados de calibração;

$\checkmark$ Nível 2: os produtos deste nível são derivados de radiâncias calibradas de prévios produtos MODIS. Os produtos conhecidos como nível 2G (L2G) são gerados a partir de um conjunto de dados de um simples dia do nível 2, reorganizados e armazenados em uma grade baseada na Terra (eath-based grid), preservando todas as amostras dos dados originais do nível 2. Cabe salientar que, a menor quantidade de dados processados em um determinado período é definida nos níveis 1 e 2 como granular (granule) e correspondem à aproximadamente 5 minutos de imageamento. O MODIS imagea 288 "grânulos" a cada 24 horas, sendo que sua cobertura equivale a uma área aproximada de $2340 \mathrm{Km}$ (acrosstrack) por $2030 \mathrm{Km}$ (along-track); 
$\checkmark$ Nível 3: neste nível os produtos são espacialmente reamostrados e temporariamente compostos para produzir uma simples estimativa das variáveis geofísicas para cada grade de localização. As escalas de tempo dos produtos destes níveis variam de um simples dia para um ano inteiro;

$\checkmark$ Nível 4: os produtos deste nível são gerados pela incorporação dos dados MODIS em modelos para se estimar as variáveis geofísicas.

A utilização dos produtos do MODIS tem proporcionado a avaliação das mudanças terrestres e suas consequências para a vida na terra, ampliando a visão sistêmica e integrada para a compreensão dos processos. Baldi et al. (2014), por exemplo, conseguiram quantificar as ligações entre os padrões de paisagem, o funcionamento da vegetação e os usuários de terra agrícola numa região de Chaco Seco no territórios de Chiquitania, que abrange partes da Argentina, Bolívia e Paraguai, usando dentre outros produtos, séries temporais NDVI do MODIS. Assim como Couto Júnior et al. (2013), que desenvolveram o seu trabalho na região Oeste do estado da Bahia, onde predomina o ecossistema Cerrado, aqueles autores distinguiram áreas de agricultura mais intensiva de locais onde a produção é tradicional a partir da avaliação do contraste de sazonalidade. Identificaram-se padrões sazonais extremos, valores de NDVI mais altos e mais baixos, nas áreas de agricultura intensiva e valores intermediários, mais uniformes, nos locais ocupados por comunidades tradicionais, onde a modificação do uso do solo, ao longo do tempo, é lenta visando tão somente à subsistência.

Outros trabalhos utilizando dados MODIS demonstraram como a expansão da atividade agrícola e a ocorrência de queimadas sobre áreas de vegetação natural e seminatural têm gradativamente modificado a paisagem (ARAÚJO et al., 2012; FERREIRA et al., 2013; PORTILLO-QUINTERO et al., 2013). Entretanto, apesar do sucesso da sua aplicação, a riqueza de informações provenientes da alta resolução temporal deste sensor traz consigo interferências de naturezas diversas que estão presentes inclusive em dados de índices de vegetação. A ocorrência dessas interferências implica na necessidade de aplicação de técnicas de tratamento de imagens visando à qualidade dos produtos que se pretende gerar.

\subsection{UTILIZAÇÃO DE FILTROS DE RUÍDOS EM SÉRIES TEMPORAIS NDVI}

Os índices de área foliar, calculados a partir da combinação da reflectância de bandas (matemática de bandas), são amplamente utilizados nos trabalhos de análise de parâmetros biofísicos relacionados ao ecossistema terrestre. Destaca-se dentre eles o NDVI cuja 
composição em séries temporais tem sido ferramenta útil para estudar o clima, a dinâmica da vegetação, a mudança de cobertura da terra e a distribuição de animais (GENG et al., 2014).

Embora os conjuntos de dados NDVI sejam pré-processados com o objetivo de minimizar os ruídos oriundos da calibração do sensor, de erros de quantização digital, de condições de solo e atmosféricas, parte dessas interferências ainda estão presentes nos conjuntos de dados disponibilizados para download, inclusive naqueles provenientes do sensor MODIS (MOTOHKA et al., 2011). Diante dessa realidade, dados de séries temporais NDVI precisam ser analisados antes da sua utilização (MIGLANI et al., 2011).

Mesmo que alguns trabalhos tenham sido desenvolvidos sem a reconstrução das séries temporais NDVI (LISENBERG et al., 2007; SOUZA et al., 2010; CLARK et al., 2012), é reconhecidamente indispensável a aplicação de técnicas de filtragem para eliminação de ruídos e consequente reconstrução da série temporal e obtenção de dados de melhor qualidade, haja vista que séries NDVI são suscetíveis a ocorrência de vários componentes de ruído residual, resultando em um comportamento temporal irregular e muitas quedas acentuadas nos valores dos dados estudados (GITELSON et al., 2014; OLIVEIRA et al., 2014).

Várias metodologias têm sido utilizadas para reduzir ruídos em séries temporais de índices de vegetação antes da utilização dos dados para estimativa das características fenológicas da vegetação. Dentre elas, as elencadas por Oliveira et al. (2014) incluem o filtro 4253H, o Savitzky-Golay (SG), o mean value iteration filter (MVI), o best index slope extraction (BISE), o Whittaker smoother (WS), a double logistic (DL) e a fast Fourier transform (FFT).

O mean value iteration filter (MVI) foi desenvolvido para diminuir o ruído e permitir a reconstrução de NDVI de séries temporais de alta qualidade. Segundo Ma e Veroustraete (2006), esse algoritmo apresentou um bom desempenho quando comparado com outros métodos existentes, tais como o modified best index slope extraction (MBISE) e a FFT.

Geng et al. (2014) avaliaram a capacidade de redução de ruído de oito metodologias distintas em diferentes tipos de dados multitemporais NDVI. O objetivo destes autores foi determinar a melhor técnica de reconstrução para variadas formações vegetais adquiridas da bacia do rio Heihe, na China, por quatro sensores de satélite (Tabela 1.3). Estas técnicas incluem o MBISE, o SG, o MVI, o asymmetric Gaussian (AG), a DL, o changing- weight filter (CW), a interpolation for data reconstruction (IDR) e o WS. Eles concluíram que a escolha do método de correção de ruído varia de acordo com os diferentes tipos de vegetação e com as fontes de dados NDVI. Entretanto, o SG tem o melhor desempenho para a maioria 
das situações, apresentando-se como uma ótima técnica tanto no estudo de pastagens e culturas agrícolas quanto para a avaliação de áreas ocupadas por arbustos, sendo esta a mais destacada.

Miglani et al. (2011) estudaram o efeito de algoritmos de suavização transformada FFT e SG, em diferentes tamanhos de janela, sobre espectros de vegetação do sensor Hyperion. De acordo com esses autores, técnicas de redução de ruído como a transformada de Fourier não são capazes de produzir um resultado razoável. Todavia, o método SG pareceu ser mais promissor em estudos de vegetação quando o tamanho da janela de filtragem varia entre 7 e 11, com base em root-mean saqured error (RMSE).

Tabela 1.3 - Conjunto de dados utilizados no estudo de séries temporais NDVI.

\begin{tabular}{ccccc}
\hline Produtos & $\begin{array}{c}\text { Período } \\
\text { (Tempo) }\end{array}$ & $\begin{array}{c}\text { Resolução } \\
\text { Temporal }\end{array}$ & $\begin{array}{c}\text { Resolução } \\
\text { Espacial }\end{array}$ & Sensores \\
\hline GIMMS & Jan.1982-Dez. 2006 & 15 dias & $8 \mathrm{Km}$ & AVHRR \\
Pathfinder & $\begin{array}{c}\text { Jul. 1981-Jul. 1994 } \\
\text { Jul. 1995-Dez. 2000 }\end{array}$ & 10 dias & $8 \mathrm{Km}$ & AVHRR \\
$\begin{array}{c}\text { SPOT } \\
\text { VEGETATION } \\
\text { (S10) }\end{array}$ & Abr. 1998-Abr. 2013 & 10 dias & $1 \mathrm{Km}$ & $\begin{array}{c}\text { SPOT } \\
\text { MOD13A2 }\end{array}$ \\
Fev. 2000-Fev. 2013 & 16 dias & $1 \mathrm{Km}$ & Terra/MODIS \\
\hline
\end{tabular}

FONTE: Adaptada de Geng et al. (2014).

Outra metodologia de correção de ruído que tem alcançado bons resultados em regiões de domínio de biomas com características semiáridas no Brasil (Cerrado e Caatinga) é aquela empregada por Carvalho Júnior et al. (2008, 2009) e Couto Júnior et al. (2013). Trata-se de procedimento que envolve três etapas: (I) aplicação de um filtro móvel de mediana; (II) separação da fração sinal pelo emprego da transformação Minimum Noise Fraction (MNF); (III) restituição dos dados NDVI utilizando a fração sinal.

O filtro de mediana é um caso particular da $\boldsymbol{i}^{\text {ésima }}$ ordem estatística de uma série de números reais, utilizando uma janela móvel sobre a assinatura temporal e gerando valores de mediana (ATAMAN et al., 1981). Organizando as observações em ordem crescente, a mediana gera o valor central da janela, requerendo operações não lineares simples. Considerando um ordenamento estatístico de " $N$ " números reais, " $x(i)$ " ... " $x(n)$ ", onde " $N$ " representa a janela do filtro digital, se o valor mínimo é " $x(1)$ ", o máximo " $x(n)$ ", sua mediana será “ $M((N+1) / 2)$ ".

O MNF é um procedimento estatístico no âmbito da Análise dos Principais Componentes (APC) que concilia tanto os procedimentos de segregação da componente ruído como também de redução da dimensionalidade dos dados (GREEN et al., 1988). O MNF 
projeta dados de entrada (uma imagem multidimensional) para um novo espaço que é dividido em duas partes, a primeira está associada ao sinal e a segunda é dominada pelo ruído que afeta a imagem (AMATO et al., 2009). Usando apenas o primeiro subespaço dos dados, é feita a identificação pela qualidade da imagem e pelo gráfico de autovalores das bandas relativas ao sinal e ao ruído (ponto de inflexão), em seguida, apenas as bandas do sinal sofrem a transformação inversa do MNF, restituindo assim uma imagem de qualidade melhorada.

\subsection{DETECÇÃO DE MEMBROS FINAIS EM IMAGENS}

A mistura espectral é consequência da mistura de materiais com diferentes propriedades espectrais dentro de um único pixel da imagem medido pelo sistema imageador (BOARDMAN e KRUSE, 2011). Este fenômeno é muito comum em imagens de baixa e média resolução espacial, devido à dimensão da área imageada e dos seus respetivos pixels, sendo pouco provável a ocorrência de um pixel puro, mesmo quando o alvo são formações vegetais extensas e uniformes (MIKHEEVA et al., 2012).

A Análise Linear de Mistura Espectral (ALME) é usada em larga escala, havendo muitos trabalhos que descrevem uma grande variedade de abordagens e aplicações (SHIMABUKURO et al., 1998; MIKHEEVA et al., 2012; SON et al., 2012). A ALME fundamenta-se no pressuposto de que a resposta espectral de um pixel, numa banda qualquer (bandas $1,2, \ldots, m$ ) é a combinação linear dos diversos materiais contidos na superfície. Deste modo, conhecendo-se as respostas espectrais dos componentes, a abundância destes pode ser estimada de forma individual por meio da geração de imagens fração (SHIMABUKURO e SMITH, 1991).

O modelo linear de mistura espectral pode ser escrito da seguinte forma (SHIMABUKURO et al., 1998):

$$
r_{i}=a \times \operatorname{veg}_{i}+b x \text { solo }_{i}+a ́ g u a+e_{i}
$$

onde, " $r$ " é a resposta do pixel na banda i da imagem; " $a$ ", " $b$ " e " $c$ " são proporções de vegetação, solo e sombra (ou água) que compõem o pixel; "veg.", "solo" e "sombra" correspondem as respostas espectrais de cada uma dessas componentes citadas; " $e_{i}$ " é o erro de estimação intrínseco para cada banda " $i$ ".

Normalmente a ALME requer uma grande intervenção humana. Para identificar a proporção dos materiais em cada pixel é necessária a existência de um conjunto de espectros 
de referência oriundos de espectrorradiometria de campo, de dados médios escolhidos pelo analista a partir de conhecimento prévio da região de interesse ou de bibliotecas espectrais pré-existentes, também construídas a partir de intenso trabalho de campo. Além disso, a seleção dos membros finais contidos nos dados investigados é feita manualmente a partir do conhecimento subjetivo do analista (LUMME, 2004; BOARDMAN e KRUSE, 2011).

Para superar os inconvenientes inerentes à seleção manual de membros finais, foi desenvolvido um método para a análise de mistura espectral denominado geométrica do convexo, ou modelo simplex. A geometria do convexo estabelece um arranjo espacial para os pixels da imagem que proporciona determinar a porcentagem existente de cada membro final (BOARDMAN e KRUSE, 2011).

Uma das abordagens desenvolvidas para o uso do modelo simplex foi apresentada por Bordman e Kruse (1994). Esses pesquisadores estabeleceram metodologia para a detecção de membros finais (Figura 1.1) na qual é utilizado apenas o conjunto de dados presentes na própria imagem avaliada, tal técnica é denominada de modelo simplex de volume mínimo e a diferença dela para os demais modelos simplex fica por conta dos dados que formam o convexo, conforme detalhado por Carvalho Júnior et al., 2003:

$\checkmark$ Volume mínimo: o simplex está circunscrito dentro do conjunto dos dados presentes na imagem;

$\checkmark$ Volume máximo: o simplex é estabelecido pelos espectros verdadeiros obtidos em campo ou presentes em bibliotecas;

$\checkmark$ Volume intermediário: o simplex fica em posição intermediária entre o volume mínimo e o volume máximo.

O modelo simplex de volume mínimo tem possibilitado a identificação automática de membros finais em trabalhos que utilizam dados de sensores com alta e média resolução espectral (CARVALHO JÚNIOR et al., 2008; COUTO JÚNIOR et al., 2013; BLANCO et al., 2014). Esse procedimento consiste em uma etapa exploratória que permite uma primeira avaliação dos materiais existentes na área. Tornando-se importante para locais pouco estudados, tais como as regiões de ocorrência de biomas abertos (Cerrado e Caatinga) (SÁNCHEZ-AZOFEIFA et al., 2003; FURLEY e METCALFE, 2007; WERNECK et al., 2011), onde podem aparecer espectros inexistentes nas bibliotecas espectrais disponíveis. Além disso, esse procedimento permite identificar e avaliar os efeitos relativos aos fatores físicos ambientais presentes na imagem (CARVALHO JÚNIOR et al., 2003). 


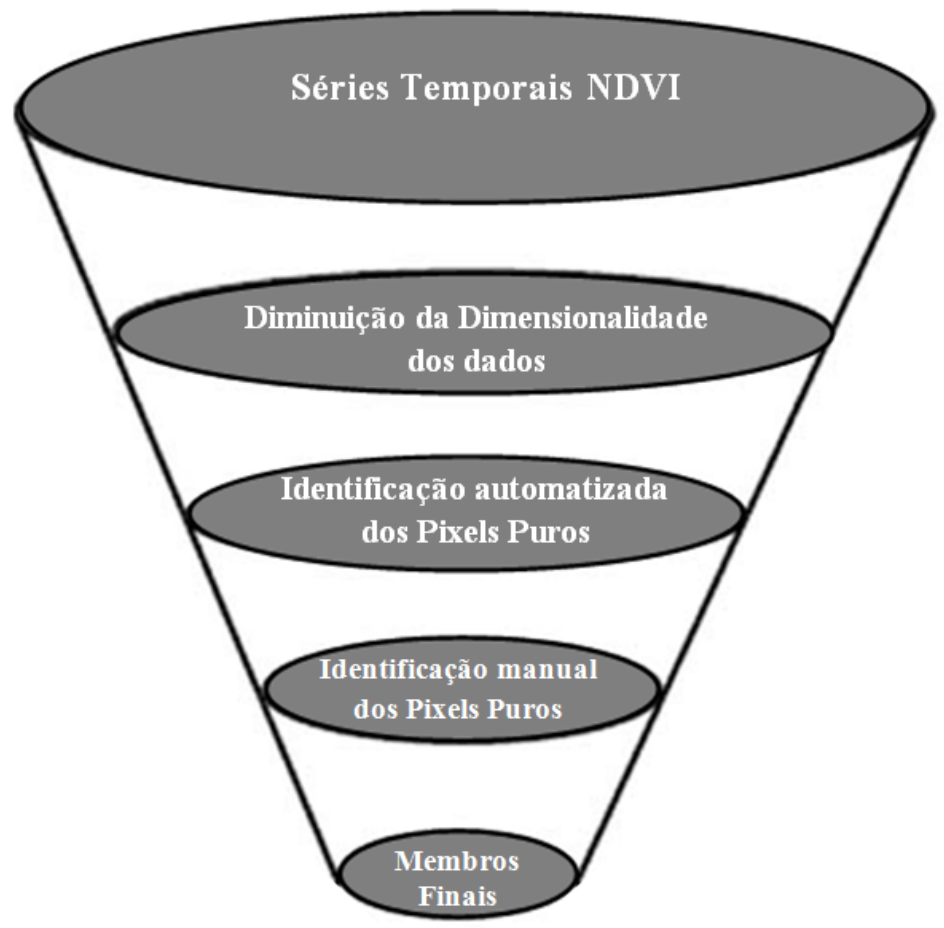

Figura 1.1. - Sequência metodológica para identificação dos membros finais em série temporais NDVI, conforme Bordman; Kruse (1994).

\subsection{CARACTERÍSTICAS DA VEGETAÇÃO NATIVA NAS REGIÕES NORTE DE MINAS GERAIS SUDOESTE DA BAHIA}

A região que abrange o norte de Minas Gerais e o sudoeste da Bahia está inserida em uma área de transição de ecossistemas do Cerrado e da Caatinga. Em graus variados, nota-se a dominância de uma formação sobre a outra, dando origem a fitofisionomias bem distintas, considerando o porte dos indivíduos e a composição das espécies (SANTOS et al., 2007). Entre as fitofisionomias encontradas destacam-se a Floresta Estacional Decidual, a Floresta Estacional Semidecidual, que na região estão sob o domínio Caatinga, o Campo Limpo, o Campo Sujo, o Campo Rupestre e o Cerrado stricto sensu, do domínio Cerrado (LISENBERG et al., 2007; CARVALHO e SCOLFORO, 2008).

\subsubsection{Formações do domínio Caatinga}

As Florestas Estacionais Deciduais e as Florestas Estacionais Semideciduais estão distribuídas pelas Américas Central de do Sul. Elas são compostas por remanescentes de uma área mais extensa que se formou no auge do Pleistoceno e se estendia até as regiões do Amazonas e dos Andes. Assim, sua distribuição pode estar relacionada com a retração de 
extensas áreas contínuas que, após terem atingido sua extensão máxima durante o final da última glaciação do Pleistoceno, quando o clima era mais seco e frio, instalaram-se em regiões onde as condições edáficas eram favoráveis (PENNINGTON et al., 2000; WERNECK, 2011).

A ocorrência dessas formações está normalmente associada à sazonalidade climática em regiões com pluviosidade anual inferior a cerca de $1.800 \mathrm{~mm}$, com estiagem acentuada durante 5 a 6 meses, quando a precipitação total é menor do que $100 \mathrm{~mm}$ (PENNINGTON et al., 2000). Elas formam o "Corredor Estacional”, que é composto por três núcleos principais com base na distribuição da espécie Anadenathera colubrina (Angico), são eles: Núcleo Caatingas, formado pelas caatingas do nordeste brasileiro; Núcleo Missiones, formado pelo sistema hidrográfico Paraguai-Paranã e o Núcleo Piedmont, formado pela área a sudoeste da Bolívia e a noroeste da Argentina (PRADO et al., 2000). Em termos de fisionomia e composição florística, existe um continuum entre as formações estacionais e as áreas de savana florestada (Cerradões), que é considerado um estágio intermediário entre floresta e savana (DAMASCENO JÚNIOR et al., 2009).

No Brasil, as Florestas Estacionais ocorrem naturalmente na forma de manchas, distribuídas ao longo da sua porção central (Mato Grosso do Sul, Mato Grosso, Goiás, Tocantins norte de Minas Gerais e Bahia). Elas também são encontradas na região sul do Brasil e abrangem, portanto, uma amplitude climática que permitem a sua presença em uma extensa faixa territorial do país, em diferentes fitorregiões, ao longo dos biomas Mata Atlântica, Cerrado e Caatinga (RIBEIRO e WALTER, 2008).

A Floresta Estacional Decidual apresenta dossel superior a $6 \mathrm{~m}$, quando estão sobre afloramentos rochosos, e a $15 \mathrm{~m}$ de altura, quando em solos mais profundos. Suas árvores emergentes podem chegar a $30 \mathrm{~m}$ e deciduidade dessa formação varia de $50 \%$ a $70 \%$ da massa foliar do dossel na época seca (CARVALHO e SCOLFORO, 2008). Na Floresta Estacional Semidecidual o porte da vegetação é superior a $4 \mathrm{~m}$, no caso de florestas de altitude sobre solos rasos ou litólicos, e a $25 \mathrm{~m}$ de altura, em solos mais profundos. As árvores emergentes dessa fitofisionomia atingem até $40 \mathrm{~m}$ e deciduidade foliar do dossel vai de $20 \%$ até $70 \%$ (CARVALHO e SCOLFORO, 2008).

Ambas as fitofisionomias são constituídas na sua grande maioria por árvores eretas com alguns indivíduos emergentes. Na época chuvosa as copas se tocam, formando uma cobertura arbórea de 70\% a 95\% do terreno (RIBEIRO e WALTER, 2008) (Figura 1.2). 

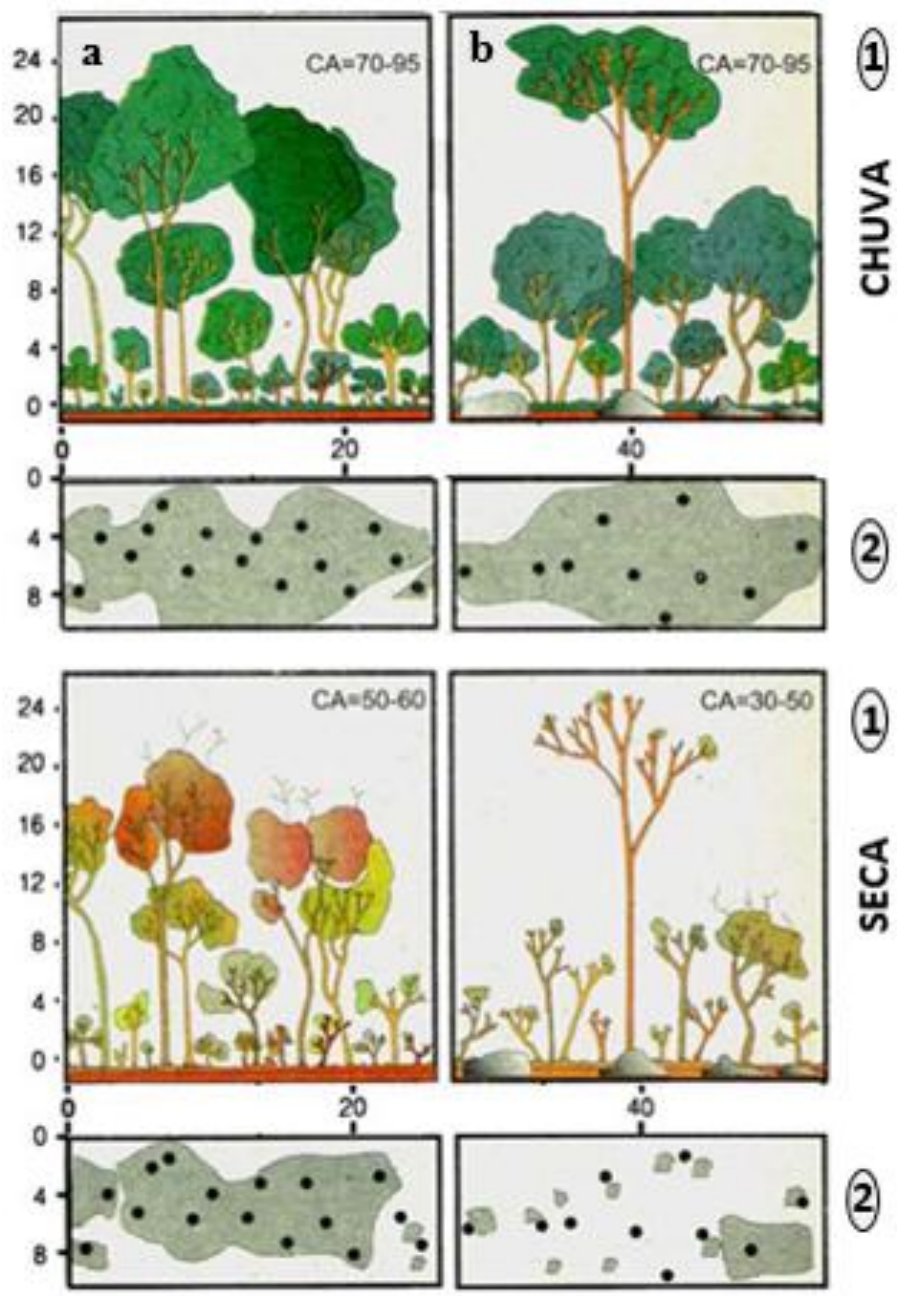

\section{(1)}

Figura 1.2 - Diagrama de perfil (1) e de cobertura arbórea (2) de florestas semidecídua (a) e decídua (b) nas estações de chuva e de seca. Cada diagrama representa faixas de terreno com cerca de $26 \mathrm{~m}$ de comprimento por $10 \mathrm{~m}$ de largura. $\mathrm{CA}=\%$ de cobertura arbórea.

FONTE: Adaptado de Ribeiro e Walter (2008).

Tanto Oliveira-Filho et al. (2006) quanto Haidar et al. (2013) verificaram que o gradiente florístico existente entre áreas de Floresta Estacional Semidecidual e Decidual da América do Sul está relacionado com o decréscimo da disponibilidade das chuvas, precipitação média anual e da capacidade de retenção hídrica dos solos.

Em Tocantins, por exemplo, as amostras de Floresta Estacional Decidual estão associadas à menor precipitação média anual (1.200 a $1.400 \mathrm{~mm}$. ano $\left.^{-1}\right)$ e a maior estiagem, que pode atingir sete meses (DIAS et al., 2008), além de ocorrerem sobre solos rasos e afloramentos de rocha de elevada fertilidade, mas de baixa capacidade de retenção hídrica (NASCIMENTO et al., 2004). Por outro lado, as Florestas Estacionais Semideciduais na região centro-sul daquele estado estão relacionadas a níveis de precipitação que oscilam de 1.500 a 1.800 mm.ano ${ }^{-1}$ e o substrato em geral é cascalhento ou argiloso, com boa capacidade de retenção hídrica (HAIDAR et al., 2013).

No Mato Grosso do Sul, as Florestas Estacionais, principalmente as deciduais, são mais abundantes nos morros de entorno do que nas áreas de planície. Segundo Damasceno 
Júnior et al., 2009, essas formações estão restritas a lugares onde ocorrem solos do tipo Vertissolo e Plintossolo, que são ricos em bases.

A disponibilidade hídrica e as condições edáficas também definem a fitogeografia na região de influência da bacia do rio São Francisco, entre os estados de Minas Gerais e Bahia. Neste local as Florestas Estacionais Deciduais, também conhecidas como Mata Seca, estão relacionadas a afloramentos calcários e, em virtude desta associação, à existência de solos rasos, porém com elevada disponibilidade de nutrientes (SANTOS et al., 2007; GONZAGA et al., 2013). Ocorrem em altitudes inferiores a 800 m, na depressão São Franciscana, próxima às margens da Cadeia do Espinhaço e normalmente são dissociados de cursos d'água (ZAPPI et al., 2008).

Todavia, a riqueza de espécies da formação decidual e sua ambientação aos mais variados ambientes, permitem a presença de alguns dos seus representantes típicos inclusive em ambientes ciliares, conforme foi verificado por Durães et al., 2014 em estudo ao longo do rio Cedro, em Montes Claros, norte de Minas Gerais.

Adicionalmente às Matas Secas, na região que abrange parte do norte de Minas Gerais e do sudoeste da Bahia, ocorrem Florestas Estacionais Semideciduais. Elas possuem características perenifólias e semiperenifólias, floristicamente similares à Mata Seca, sendo a transição entre essas duas formações praticamente imperceptível na região, diferenciando-se apenas pela estrutura da fitofisionomia semidecidual, que em geral é mais densa e está associada aos cursos d'água (SANTOS e VIEIRA, 2005; DURÃES et al., 2014).

\subsubsection{Formações do domínio Cerrado}

As origens do bioma Cerrado, que atualmente ocupa aproximadamente 2 milhões de $\mathrm{Km}^{2}$ do território brasileiro, fazendo fronteira com a Amazônia, a Caatinga e a Mata Atlântica tem sido amplamente discutida (PINHEIRO e MONTEIRO, 2010). Todavia, apesar da ausência de um senso comum, há convergência de entendimento quanto a alguns dos fatores que contribuíram para sua origem e permanência na atualidade. Na América do Sul, por exemplo, as mudanças climáticas ocorridas em épocas geológicas distintas (Piloceno e Pleistoceno) foram preponderantes para o desenvolvimento desse ecossistema (RULL, 2008).

No período Terciário e durante toda a fase do quaternário, alterações na ocupação da paisagem por savanas e florestas foram condicionadas à disponibilidade de água. Quanto maior a umidade ambiental, maior a presença de florestas, do contrário, quando ocorria o 
declínio da ocorrência de chuva, prevaleciam as formações de savana (MAYLE, 2004; PENNIGTON, 2009).

Além dos fatores climáticos, a adaptação à periodicidade de incêndios e a solos distróficos, ricos em alumínio, pobres em bases trocáveis, com baixos teores de matéria orgânica, pH reduzido, profundos e com alta capacidade de drenagem, acabaram definindo a origem evolutiva do bioma Cerrado e suas fitofisionomias (PINHEIRO e MONTEIRO, 2010; PIVELLO et al., 2010; OLIVERAS et al., 2013). A convergência destes fatores exerceu uma forte pressão seletiva sobre as espécies vegetais, o que acabou consolidando a composição e a estrutura da comunidade arbórea e arbustiva do Cerrado na atualidade (OLIVEIRA FILHO e RATTER, 2002).

A classificação dessa estrutura vegetal em grupos de características semelhantes (fitofisionomias) tem sido um grande desafio imposto aos pesquisadores da vegetação do Cerrado, isso porque em muitos casos não é possível fazer a separação com nitidez das suas formações, que em muitas situações formam um gradiente estrutural contínuo (OLIVEIRA FILHO e RATTER, 2002; RIBEIRO e WALTER, 2008). Além disso, a identificação das fitofisionomias fica prejudicada por conta das alterações que a vegetação sofre ao longo do tempo em um mesmo local (alterações sucessionais), devido à frequência e intensidade de impactos como o fogo e o pastoreio (DURIGAN, 2009; PINHEIRO e DURIGAN, 2012).

Todavia, desenvolver critérios claros para classificação das fitofisionomias é necessário para dar suporte tanto ao mapeamento de tipos de vegetação em escala detalhada quanto para estudos ecológicos, que muitas vezes, dependem da exata descrição da estrutura da comunidade para que sejam compreendidos. Pinheiro e Durigan, 2012, por exemplo, indicam que é possível classificar as fitofisionomias de porte arbóreo do Cerrado em um dado momento no tempo, considerando-se como centro de classes os valores médios dos descritores quantitativos, área basal, cobertura das copas, diâmetro das árvores.

Ribeiro e Walter (2008) propuseram uma classificação para diferenciar os principais tipos fisionômicos do Cerrado, de acordo com estrutura, formas de crescimento dominantes, possíveis mudanças estacionais, fatores edáficos e composição florística. Ainda que a classificação não se baseie em dados quantitativos, tem sido utilizada por diversos autores em virtude do seu pragmatismo (PINHEIRO e DURIGAN, 2012).

No total são descritos onze tipos de vegetação para o bioma, enquadrado em formações florestais (Mata Ciliar, Mata de Galeria, Mata Seca e Cerradão), com predominância de árvores formando um estrato contínuo; savânicas (Cerrado stricto sensu, Parque de Cerrado, Palmeiral e Vereda), em que estão presentes árvores esparsas sobre o 
estrato graminoso; e campestres (Campo Sujo, Campo Limpo e Campo Rupestre), onde não ocorre vegetação de porte arbóreo. Considerando outros subtipos, neste sistema são reconhecidos 23 fitofisionomias distintas (BASTOS e FERREIRA, 2010), das quais quatro integram a paisagem da região que está à leste do rio São Francisco e a Oeste do conjunto de Montanhas da Cadeia do Espinhaço, no norte de Minas Gerais e sudoeste da Bahia (LISENBERG et al., 2007; CARVALHO e SCOLFORO, 2008). Elas são descritas a seguir, conforme Ribeiro e Walter, 2008:

Campo Limpo: tipo de vegetação predominantemente herbáceo, com raros arbustos e ausência completa de árvores. Pode ser encontrado em diversas posições topográficas, com diferentes variações no grau de umidade, profundidade e fertilidade do solo. Entretanto, é encontrado com mais frequência nas encostas, nas chapadas, nos olhos d'água, circundando as Veredas e na borda das Matas de Galeria. Pode ocorrer em solos com características variadas de coloração (desde amarelo claro, avermelhada, ao vermelho-escuro) textura (arenosos a argilosa, ou muito argilosa e bem frenados) e graus variados de permeabilidade (penetração de água), tais como: Neossolos Litólicos, Cambissolos e Plitossolos Pétricos.

O Campo Limpo, assim como o campo sujo, também apresenta variações dependentes de particularidades ambientais, determinadas pela umidade do solo e topografia. Na presença de um reservatório subterrâneo de água (lençol freático) profundo ocorre o Campo Limpo Seco, mas se o lençol freático é alto, há o Campo Limpo Úmido, cada qual com sua flora específica. Quando aparecem os murundus (microrrelevos), tem-se o Campo Limpo com Murundus (Figura 1.3).

Campo Sujo: é um tipo físionômico exclusivamente arbustivo-herbáceo, com arbustos e subarbustos esparsos cujas plantas são menos desenvolvidas que as árvores do Cerrado stricto sensu. Este tipo de vegetação é encontrado em solos rasos, eventualmente com pequenos afloramentos rochosos de pouca extensão (sem caracterizar Campo Rupestre), ou ainda em solos profundos e de baixa fertilidade (álicos ou distróficos).

Em função de particularidades ambientais, o Campo Sujo pode apresentar três subtipos fisionômicos distintos. $\mathrm{Na}$ presença de reservatório subterrâneo de água (lençol freático) profundo, ocorre o Campo Sujo Seco. Se o lenço freático é alto, próximo da superfície do solo, há o Campo Sujo Úmido. Quando na área ocorrem microrrelevos mais elevados (murundus), tem-se o Campo Sujo com Murundus (Figura 1.4). 


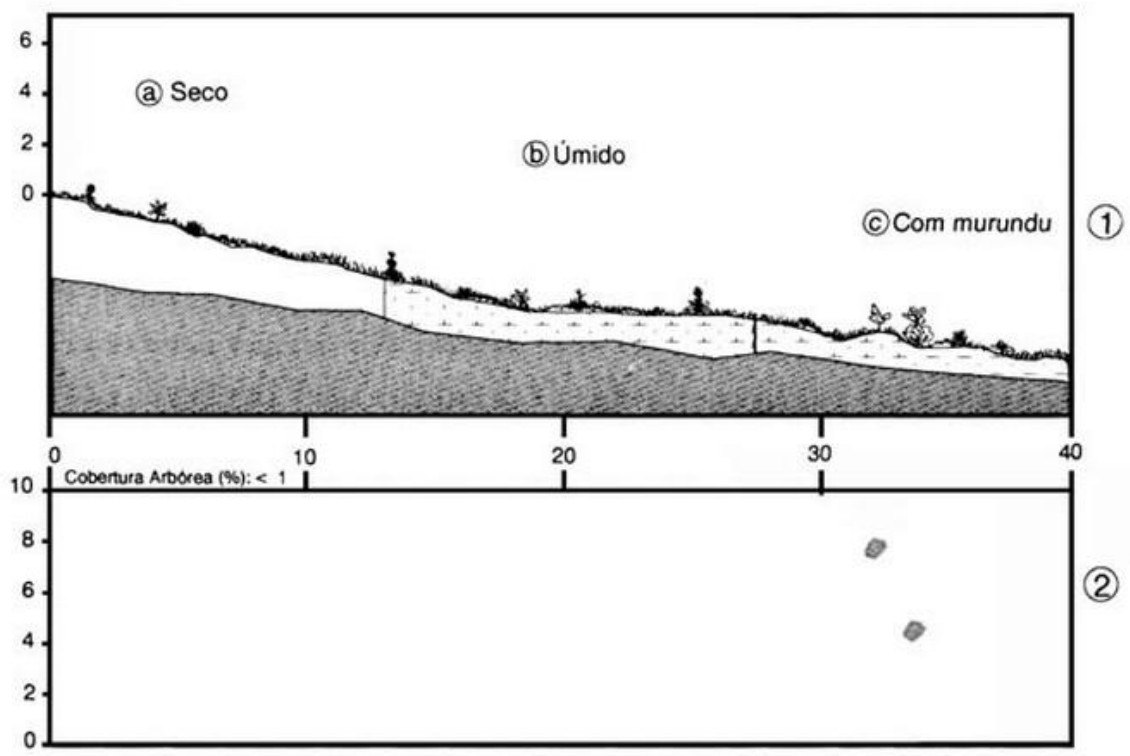

Figura 1.3 - Diagrama do perfil (1) e da cobertura arbórea (2) de um Campo Limpo representado na faixa de $40 \mathrm{~m}$ de comprimento por $10 \mathrm{~m}$ de largura, onde a porção (a) mostra a vegetação em local seco, (b) em local úmido e (c) em local mal drenado com murundus.

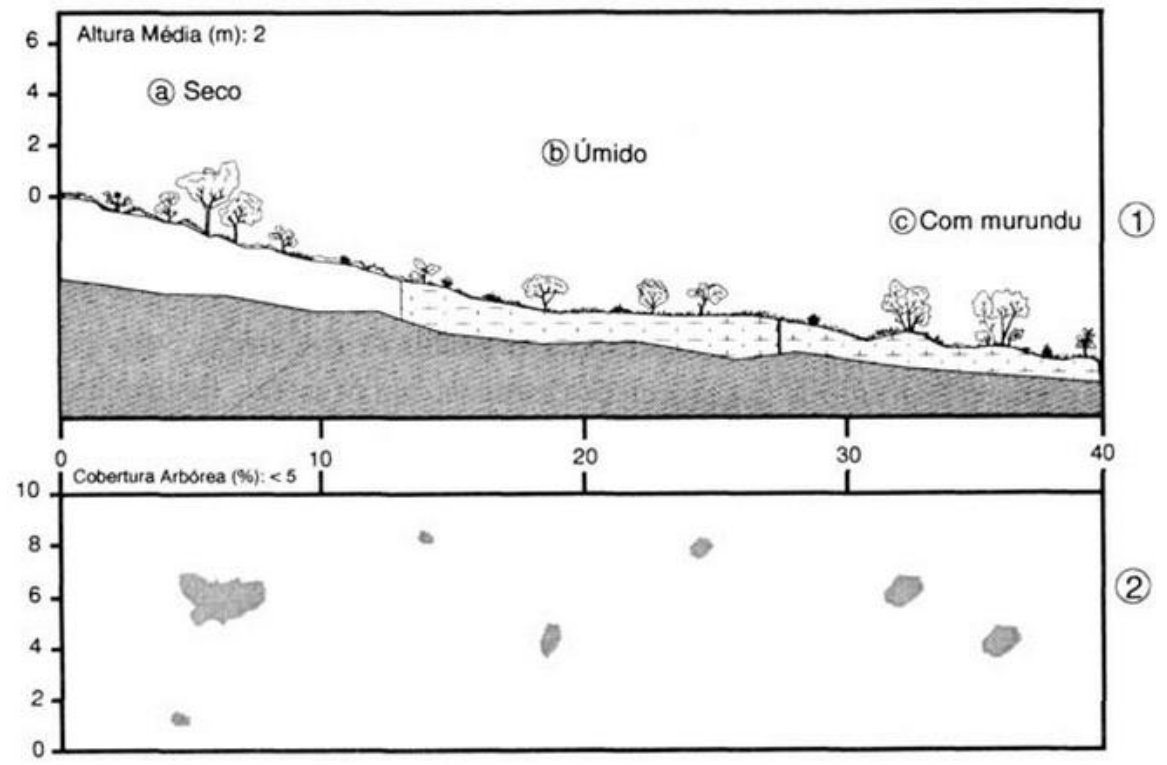

Figura 1.4 - Diagrama de perfil (1) e cobertura arbórea (2) de um Campo Sujo representando uma faixa de $40 \mathrm{~m}$ de comprimento por $10 \mathrm{~m}$ de largura, onde a porção (a) mostra a vegetação em local seco, (b) em local úmido e (c) em local mal drenado com murundus.

Campo Rupestre: trata-se de formação vegetação predominantemente herbáceoarbustiva, com a presença eventual de pequenas árvores pouco desenvolvidas de até dois metros de altura. Abrange um complexo de vegetação que agrupa paisagens em microrrelevos com espécies típicas, ocupando trechos de afloramentos rochosos. Geralmente ocorrem em altitudes superiores a $900 \mathrm{~m}$, ocasionalmente a partir de $700 \mathrm{~m}$, em áreas onde há ventos constantes e variações extremas de temperatura, com dias quentes e noites frias. 
Este tipo de vegetação ocorre geralmente em solos ácidos, pobres em nutrientes ou nas frestas dos afloramentos rochosos. Em geral, a disponibilidade de água no solo é restrita, pois as águas pluviais escoam rapidamente para os rios, devido a pouca profundidade e reduzida capacidade de retenção do solo.

A composição da flora em áreas de Campo Rupestre pode variar muito em poucos metros de distância, e a densidade das áreas depende do substrato, da profundidade e fertilidade do solo, da disponibilidade de água, da posição topográfica, etc. Nos afloramentos rochosos, por exemplo, as árvores concentram-se nas fendas das rochas, onde a densidade pode ser muito distinta. Há locais em que os arbustos praticamente dominam a paisagem, enquanto em outros a flora herbácea predomina. Também são comuns agrupamentos de uma única espécie, cuja presença é condicionada, entre outros fatores, pela umidade disponível no solo. Algumas espécies podem crescer diretamente sobre as rochas (rupícolas), sem que haja solo, como ocorre com algumas Aráceas e Orquidáceas (Figura 1.5).

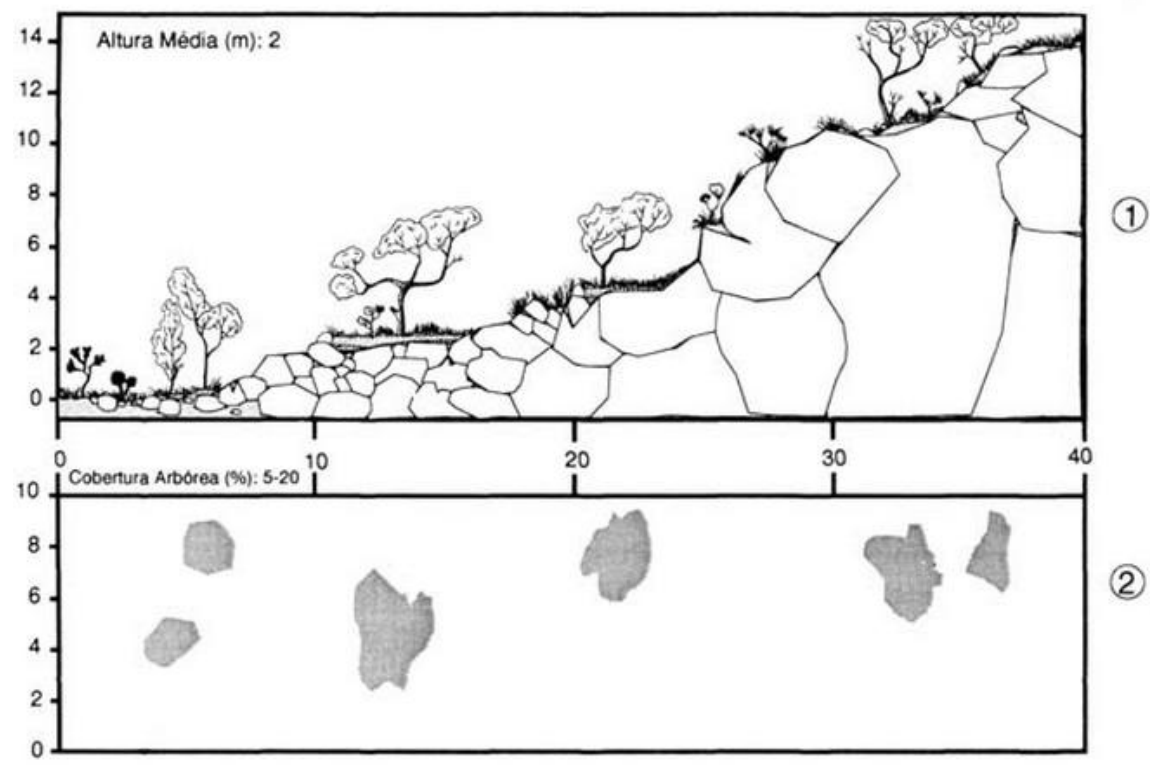

Figura 1.5 - Diagrama de perfil (1) e cobertura arbórea (2) de um Campo Rupestre representando uma faixa de $40 \mathrm{~m}$ de comprimento por $10 \mathrm{~m}$ de largura.

Cerrado stricto sensu: caracteriza-se pela presença de árvores baixas, inclinadas, tortuosas, com ramificações irregulares e retorcidas, e geralmente com evidencias de queimadas. Os arbustos e subarbustos encontram-se espalhados, com algumas espécies apresentando órgãos subterrâneos perenes (xilopódios), que permitem a rebrota após queima ou corte. Na época chuvosa as camadas subarbustiva e herbácea tornam-se exuberantes, devido ao seu rápido crescimento. 
Os troncos das plantas lenhosas em geral possuem cascas com cortiça espessa, fendida ou sulcada, e gemas apicais (responsáveis pelo crescimento dos vegetais) de muitas espécies são protegidas por densa quantidade de pelos. As folhas em geral são rígidas e com consistência de couro. Esses caracteres indicam adaptação a condições de seca.

Devido à complexidade dos fatores condicionantes (clima, fertilidade do solo, quantidade de chuvas, etc.) originaram-se subdivisões fisionômicas do Cerrado stricto sensu, sendo as principais o Cerrado Denso, o Cerrado Típico, o Cerrado Ralo. Elas refletem variações na forma dos agrupamentos e no espaçamento entre as árvores. A gradação de densidade das árvores é decrescente do Cerrado Denso ao Cerrado Ralo (Figura 1.6).
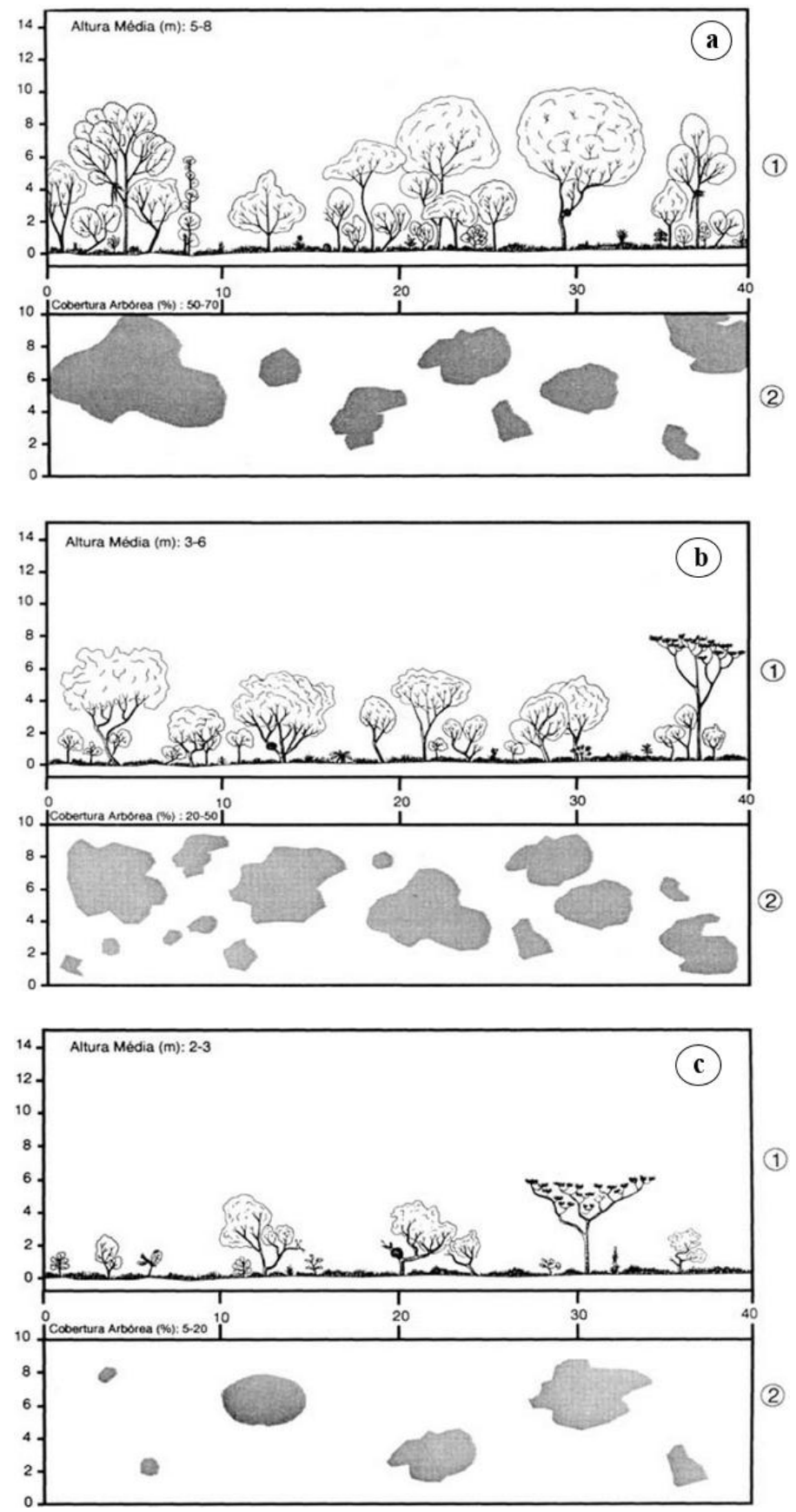

Figura 1.6 - Diagrama de perfil (1) e de cobertura arbórea (2) dos subtipos da fitofisionomia Cerrado stricto sensu. (a) Cerrado Denso, (b) Cerrado Típico, (c) Cerrado Ralo. 


\subsection{FATORES PROMOTORES DESENVOLVIMENTO DA AGRICULTURA NAS REGIÕES NORTE DE MINAS GERAIS SUDOESTE DA BAHIA}

A década de 1970 foi marcada por uma série de medidas adotadas pelo governo federal visando modernizar a agricultura no Polígono das Secas, região que abrange oito estados de Alagoas, Bahia, Ceará, Paraíba, Pernambuco, Piauí, Rio Grande do Norte, Sergipe, e a porção norte do estado de Minas Gerais (BRASIL, 2005). Além da criação da Companhia de Desenvolvimento dos Vales do São Francisco e do Parnaíba (CODVASF) em 1974, vários planos como POLONORDESTE (1974), o PROTERRA (1971) e o Projeto Sertanejo (1976) foram lançados (COELHO NETO, 2005).

Tais ações representam o desdobramento da política iniciada no final dos anos 1940, com a criação de órgãos como Departamento Nacional de Obras Contra as Secas (DNOCS) e da Companhia Hidrelétrica do São Francisco (CHESF) em 1948. Além desses órgãos surgiram a Superintendência do Vale do São Francisco (SUVALE) em 1967 e o Banco do Nordeste (BNB), cuja função é captar recursos para o desenvolvimento do Polígono das Secas (COELHO NETO, 2005; DOURADO e MESQUITA, 2012).

Nesse contexto, o poder público financiou a implantação de projetos de irrigação na região, dotando frações desse território de infraestrutura (barragens, açudes, canais de irrigação, adutoras, rodovias). Isso possibilitou o início do desenvolvimento de atividades agrícolas (produção de frutas tropicais, por exemplo) com vistas a atender a demanda dos mercados do centro-sul do país, bem como o mercado internacional. Em função dessas ações, a região semiárida brasileira transformou-se numa grande produtora frutícola, assumindo lugar de destaque no cenário nacional, visto que além dos fatores naturais terra e luminosidade e humanos, disponibilidade de mão de obra em abundância, passou-se a ter disponibilidade de água para as lavouras (DOURADO, 2014).

Com uma atividade agrícola ainda dominada pela pecuária extensiva e pela silvicultura (ESPÍRITO SANTO et al., 2009), a implantação dos projetos de irrigação também tem proporcionado uma mudança de paradigma para a região que abrange o norte do estado de Minas Gerais e sudoeste do estado da Bahia, localiza no extremo sul do Polígono das Secas brasileiro (REIS et al., 2012a). Destacam-se nestes locais os Projetos de Irrigação Vale do Rio Brumado, Formoso A/H, Jaíba e Gorutuba (DOURADO e MESQUITA, 2012; REIS et al., 2012a; BRASIL, 2013; DOURADO, 2014; CODEVASF, 2015).

O Projeto de Irrigação do Vale do Rio Brumado foi concebido em 1976 com intuito de promover a irrigação de aproximadamente 5.153 ha, ele está localizado às margens do rio 
Brumado, em Livramento de Nossa Senhora, no sudoeste da Bahia. Atualmente o perímetro irrigado é bem maior devido principalmente à expansão das lavouras de manga, que chegam a ocupar uma área de 8.000 ha, levando a microrregião de Brumado a se tornar a segunda maior produtora de frutas do estado da Bahia com 90 mil t. ano ${ }^{-1}$, ficando atrás apenas da região de Juazeiro (DOURADO e MESQUITA, 2012).

O perímetro irrigado de Formoso está situado no município de Bom Jesus da Lapa, em área compreendida entre a margem esquerda do Rio São Francisco e a margem direita do rio Corrente. A infraestrutura de uso comum do perímetro foi construída em duas etapas: Formoso A e Formoso H. A assentamento dos lotes no Formoso A teve início em 1989 e, em 1999 no Formoso H. O perímetro apresenta uma área irrigável de 12.028 ha, com um total de 1.144 lotes, sendo 1.031 de agricultores familiares e 143 de produtores empresariais (DOURADO e MESQUITA, 2010; BRASIL, 2013).

A região irrigada de Formoso é responsável pela maior produção de bananas da região Nordeste do Brasil, são 171 mil t. ano ${ }^{-1}$. Apesar de a banana ser o produto de maior importância do perímetro, está ocorrendo a expansão de áreas plantadas com citrus (laranja, tangerina e limão). Culturas temporárias como feijão, milho e mandioca também são exploradas, atingindo a produção de mais de 10 mil toneladas no ano de 2012 (BRASIL, 2013).

O Projeto Jaíba foi iniciado em 1975 e está localizado nos municípios de Jaíba, Matias Cardoso e Verdelândia, no estado de Minas Gerais, à margem direita do rio São Francisco, na região do vale do médio São Francisco (REIS et al., 2012b). Esse projeto foi previsto para ter uma área total de 107.600 ha, dos quais 65.800 ha seriam irrigados. Dividiu-se a sua implantação em quatro etapas, contudo, apenas as etapas I e II, que correspondem a 70,9\% da área total do projeto, estão em pleno funcionamento (CODEVASF, 2015).

Grande parte da área cultivada do Perímetro do Jaíba é destinada à fruticultura, com destaque para as produções de uva, limão, banana e manga. As produções de milho e cana também são significativas e somadas à fruticultura resultam numa produção total superior a 1,3 milhões de toneladas por ano. Os agricultores familiares são os maiores responsáveis por essa produção, juntos eles cultivam 58\% das lavouras do perímetro irrigado (REIS et al., 2012b; CODEVASF, 2015).

O Projeto de Irrigação Gorutuba foi implantado em 1978 e localiza-se em Nova Porteirinha e Janaúba, norte de Minas Gerais, às margens do rio Gorutuba. O projeto abrange uma área de 7.172 ha, sendo 4.818 ha irrigáveis (REIS et al., 2012a). A agricultura familiar tem destacada importância no projeto. São 426 famílias trabalhando em áreas médias de 5 a 
10 ha. As principais culturas do perímetro são banana, manga, acerola, citros, goiaba, uva, milho, maracujá, arroz, feijão, hortaliças e sementes, sendo a banana a cultura predominante (EMATER, 2006).

Na Tabela 1.4 são apresentados a área em produção, o volume e produção e o valor comercializado no Perímetro Irrigado de Gorutuba, durante o período de 1995 a 2005.

Tabela 1.4 - Área em produção, volume de produção e valor dos produtos agrícolas comercializados no perímetro irrigado de Gorutuba.

\begin{tabular}{cccc}
\hline Ano & Área em produção (ha) & Produção obtida (t) & Comercializado (Mil R\$) \\
\hline 1995 & 2151 & 23611 & 10813,75 \\
1996 & 2408 & 27422 & 9809,01 \\
1997 & 2772 & 38498 & 7375,41 \\
1998 & - & - & - \\
1999 & 2732 & 36102 & 8692,24 \\
2000 & 2799 & 42709 & 9775,83 \\
2001 & 2744 & 41392 & 10020,2 \\
2002 & 2729 & 45094 & 11883,19 \\
2003 & 3036 & 42071 & 14434,85 \\
2004 & 3226 & 44229 & 17758,89 \\
2005 & 2954 & 44312 & 15510,56 \\
\hline
\end{tabular}

FONTE: Adaptada de Reis et al. (2012a).

\subsection{ESTRUTURA DA DISSERTAÇÃO}

A presente dissertação está estrutura na forma de artigos científicos (Figura 1.7). A opção pela estrutura de artigos científicos visa facilitar a divulgação do conhecimento gerado neste estudo e fortalecer o programa de pós-graduação em Geografia da Universidade de Brasília (UnB).

O primeiro capítulo tem caráter introdutório e nele é feita uma abordagem geral sobre a flora nativa e os fatores promotores do desenvolvimento da agricultura na região de estudo. Destaca-se ainda a aplicação das séries temporais de índices de vegetação do sensor MODIS e das técnicas para realçar a resposta espectral de tais séries.

O segundo capítulo é composto por artigo que foi submetido ao periódico científico internacional Remote Sensing, cujo fator de impacto é 2,623. O artigo foi elaborado almejando comparar o desempenho de algoritmos de distância e similaridade na classificação de formações vegetais numa região de transição Cerrado-Caatinga.

No último capítulo são feitas as considerações finais a respeito deste trabalho. 


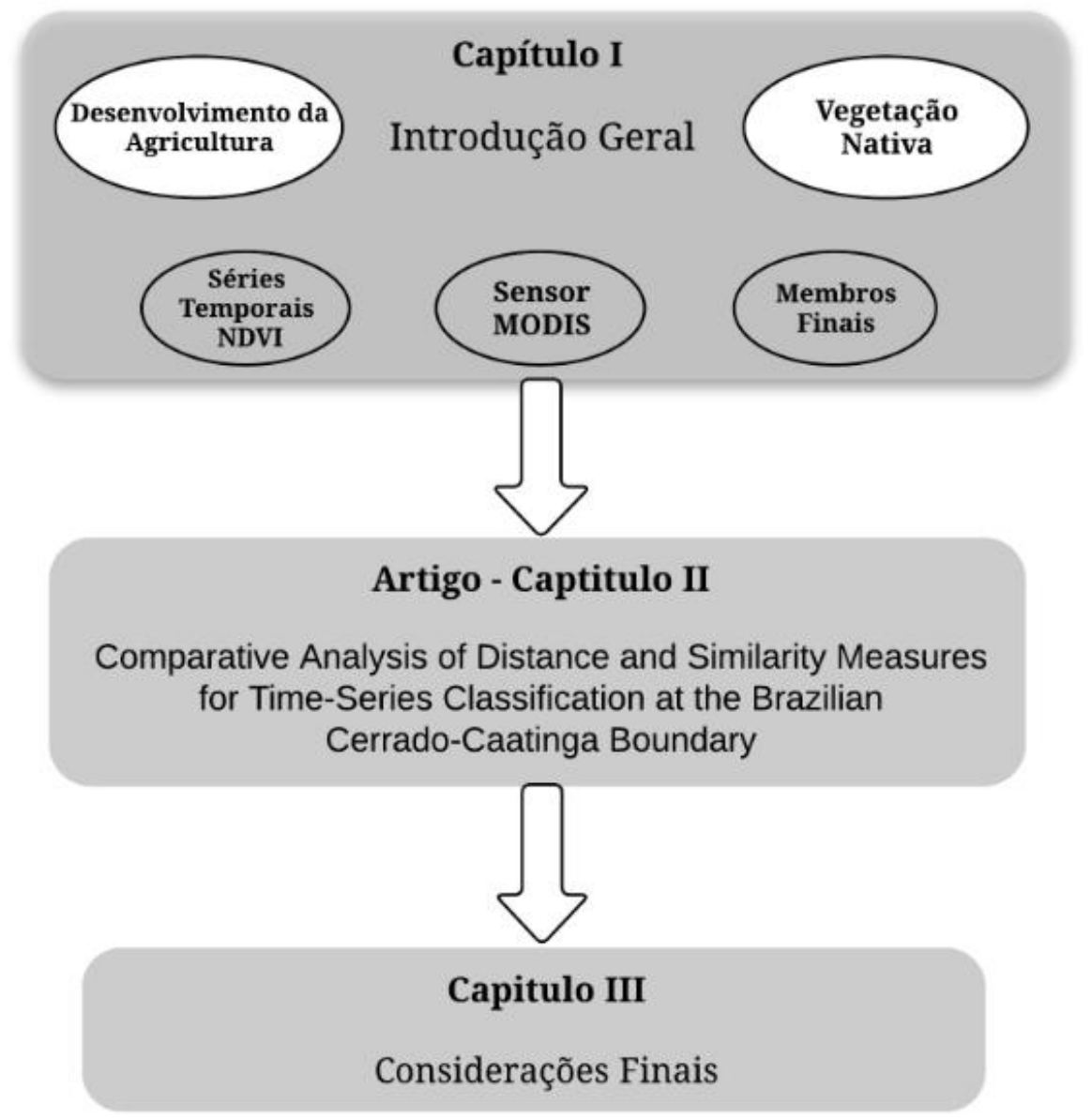

Figura 1.7 - Estrutura da Dissertação.

\section{REFERÊNCIAS}

AB'SABER, A.N. Bases para o estudo dos ecossistemas da Amazônia brasileira. Estudos Avançados, v.16, n.46, p. 7-30, 2002.

AMATO, U.; CAVALLI, R.M.; PALOMBO, A.; PIGNATTI, S.; SANTINI, F. Experimental approach to the selection of the componentes in the minimum noise fraction. IEEE Transactions on Geoscience Remote Sensing, v.47, n.1, p. 153-160, 2009.

ANDERSON, L.O; LATORRE, M.L.; SHIMABUKURO, Y.E.; ARAI, E.; CARVALHO JÚNIOR, O.A. Sensor MODIS: uma abordagem geral. São José dos Campos: Instituto Nacional de Pesquisas Espaciais-INPE, 2003. 86 p. (RPQ / 752).

ARAI, E.; SHIMABUKURO, Y.E.; PEREIRA, G.; VIJAYKUMAR, N.L. A multi-resolution multi-temporal for detecting and mapping deforestation in the Brazilian Amazon rainforest.

Remote Sensing, v.3, n.9, p. 1943-1956, 2011.

ARAÚJO, F.M.; FERREIRA, L.G.; ARANTES, A.R. Distribution patterns of burned areas in the brazilian biomes: an analysis based on satellite data for the 2002-2010 Period. Remote Sensing, v.4, n.7, p. 1929-1946, 2012. 
ATAMAN, E.; AATRE, V.K.; WONG, K.M. Some statistical properties of median filters. IEEE Transactions on Acoustics, Speech, and Signal Processing, v.29, p. 1073 - 1075, 1981.

BALDI, G.; HOUSPANOSSIAN, J.; MURRAY, F.; ROSALES, A.A.; RUEDA, C.V.; JOBBÁGY, E.G. Cultivating the dry forests of South America: diversity of land users and imprints on ecosystem functioning. Journal of Arid Environments, p. 1-13, 2014. DOI: 10. 1016/j.jaridenv.2014.05.027.

BARBIER, E.B. The green economy post Rio+20. Science, v.338, p. 887-888, 2012.

BASTOS, L.A.; FERREIRA, I.M.; Composições fitofisionômicas do biomas Cerrado: estudo sobre o subsistema de Vereda. Espaço em Revista, v.12, n.1, p. 97-108, 2010.

BLANCO, P.D.; VALLE, H.F.; BOUZA, P.J.; METTERNICHT, G.I.; HARDTKE, L.A. Ecological site classification of semiarid rangelands: synergistic use of Landsat and Hyperion imagery. International Journal of observation and geoinformation, v.29, p. 11-21, 2014.

BOARDMAN, J.W.; KRUSE, F.A. Analysis of imaging spectrometer data using ndimensional geometry and a mixture-tuned matched filtering approach. IEEE Transactions on Geoscience Remote Sensing, v.49, n.11, p. 4138-4152, 2011.

BOARDMAN, J.W.; KRUSE, F.A. Automated spectral analysis: a geological example using AVIRIS data, northern Grapevine Mountains, Nevada. In: Proceedings of the ERIM-Tenth Thematic Conference on Geologic Remote Sensing, San Antonio, Texas, United States, 1994; p. I-407-I-418.

BRASIL. MINISTÉRIO DA INTEGRAÇÃO NACIONAL/SDR. Produção de banana no perímetro irrigado de Formoso é a maior do Nordeste, 2013. Disponível em: <www.integração.gov.br>. Acesso em: 05 jan. 2015.

BRASIL. MINISTÉRIO DA INTEGRAÇÃO NACIONAL/SDR. Relatório final do grupo de trabalho interministerial para redelimitação do semiárido nordestino e do Polígono das Secas. Brasília, DF, 2005. 117 p.

BRUNNSCHWEILER, J.D. On nature in Latin America: progress and problems of physical geography. In: Proceedings of The Conference of Latin Americanist Geographers (CLAG), Muncie, United States, 1980; v.8, p. 269-279.

CARVALHO JÚNIOR, O.A.; COELHO, M.A.N.; MARTINS, E.S.; GOMES, R.A.T.; COUTO JÚNIOR, A.F.; OLIVEIRA, S.N.; SANTANA, O.A. Mapeamento da vegetação na Floresta Atlântica usando o classificador de árvore de decisão para integrar dados de sensoriamento remoto e modelo digital de terreno. Revista Brasileira de Geofísica, v.26, n.3, p. 331-345, 2008.

CARVALHO JÚNIOR, O.A.; COUTO JÚNIOR, A.F.; SILVA, N.C.; MARTINS, E.S.; CARVALHO, A.P.F.; Gomes, R. A. T. Avaliação dos classificadores espectrais de Mínima Distância Euclidiana e Spectral Correlation Mapper em séries temporais NDVI-MODIS no campo de instrução militar de Formosa (GO). Revista Brasileira de Cartografia, v.61, p. 399-412, 2009. 
CARVALHO JÚNIOR, O.A.; SILVA, N.C.; CARVALHO, A.P.F.; COUTO JÚNIOR, A.F.; SILVA, R.S.; SHIMABUKURO, Y.E.; GUIMARÃES, R.F.; GOMES, R.A.T. Combining noise-adjusted principal components transform and median filter techniques for denoising MODIS temporal signatures. Revista Brasileira de Geofísica, v.30, n.2, p. 147-157, 2012.

CARVALHO JÚNIOR, O.A.C.; CARVALHO, A.P.F.; GUIMARÃES, R.F.; MENESES, P.R.; SHIMABUKURO, Y.E. Mistura espectral: (I) detecção dos membros finais utilizando a geometria do simplex. Espaço \& Geografia, v. 6, n.1, p. 147-173, 2003.

CARVALHO, L.M.T.; SCOLFORO, J. (Ed). Inventário florestal de Minas Gerais: monitoramento da flora nativa 2005-2007. Lavras: UFLA, 2008. 357 p.

CHEN, J.; JÖNSSON, P.; TAMURA, M.; GU, Z.; MATSUSHITA, B.; EKLUNDH, L. A simple method for reconstructing a high-quality NDVI time-series data set based on the Savitzky-Golay filter. Remote Sensing of Environment, v.91, n.3, p. 332-344, 2004.

CLARK, M.L.; AIDE, T.M.; RINER, G. Land change for all municipalities in Latin America and the Caribbean assessed from 250-m MODIS imagery (2011-2010). Remote Sensing of Environment, v.126, p. 84-103, 2012.

CODEVASF. COMPANHIA DE DESENVOLVIMENTO DOS VALES SÃO FRANCISCO E DO PARNAÍBA. Elenco de projetos. Disponível em: <http://www.codevasf.gov.br/principal/perimetros-irrigados/elenco/de/projetos>. Acesso em: 06 jan. 2015.

COELHO NETO, A.S. As especificidades da produção dos espaços irrigados no vale do São Francisco. In: Encontro de Geográfos da América Latina, X: 2005, São Paulo. Anais...USP: 2005. p. 3505-3522.

COURA, S.M.C. Mapeamento de vegetação do estado de Minas Gerais utilizando dados MODIS. 2007. 150 f. Dissertação (Mestrado) Instituto Nacional de Pesquisas Espaciais, São José dos Campos, São Paulo, 2007.

COUTO JÚNIOR, A.F.; CARVALHO JÚNIOR, O.A. MARTTINS, E.S.; VASCONCELOS, V. Characterization of the agriculture occupation in the Cerrado biome using MODIS timeseries. Revista Brasileira de Geofísica, v.31, n.3, p. 393-402, 2013.

COUTO JÚNIOR, A.F.; CARVALHO JÚNIOR, O.A.; MARTINS, E.S.; SANTANA, O.A.; SOUZA, V.V.; Encinas, J. I. Denoising and characterization of Cerrado physiognomies using MODIS times series. Revista Árvore, v.35, n.3, p. 699-705, 2011.

DAMASCENO JÚNIOR, G.A.; SILVA, J.S.V.; POTT, A.; POTT, V.J. Florestas estacionais no Pantanal: considerações florísticas e subsídios para conservação. Geografia, v.34, p. 697 707, 2009.

DIAS, R.R.; PEREIRA, E.Q.; SANTOS, L.F. Atlas do Tocantins: subsídios ao planejamento da gestão territorial. 5 Ed. Secretaria do Planejamento do Estado do Tocantins, Palmas, Tocantins, 2008. $62 \mathrm{p}$.

DOURADO, J.A.L. Projetos desenvolvimentistas nas terras do sem-fim: expansão do agronegócio e precarização do trabalho no semiárido baiano. Sociedade \& Natureza, v.26, n.1, p. 7-23, 2014. 
DOURADO, J.A.L.; MESQUITA, H.A. Modernização do campo: implantação do perímetro irrigado do vale do rio Brumado em Livramento de Nossa Senhora (BA) e as transformações nas relações de trabalho. OKARA: Geografia em debata, v.6, n.2, p. 220-239, 2012.

DOURADO, J.A.L.; MESQUITA, H.A. Projeto de irrigação do vale do rio Brumado e o processo de (di?)lapidação da agricultura de Livramento de Nossa Senhora. In: Encontro Nacional de Geógrafos, XVI: 2010, Porto Alegre, Anais...AGP: 2010. p. 1-10.

DURÃES, M.C.O.; SALES, N.L.P.; D’ANGELO NETO, S.; FIGUEIREDO, M.A.P. Levantamento florístico do estrato arbóreo de três fragmentos de floresta ciliar como subsídio à recomposição da vegetação do rio Cedro, Montes Claros-MG. Ciência Florestal, v.24, n.1, p. 47-58, 2014.

DURIGAN, G. Estrutura e diversidade de comunidades florestais. In: MARTINS, S.V. (Ed.). Ecologia de florestas tropicais do Brasil. Viçosa: Universidade Federal de Viçosa-UFV, 2009. p. 185-215.

EMATER. EMPRESA DE ASSISTÊNCIA TÉCNICA E EXTENSÃO RURAL DO ESTADO DE MINAS GERAIS. Relatório de atividades desenvolvidas no perímetro do Gorutuba. Nova Porteirinha, 2006.

ESPÍRITO SANTO, M.M.; SEVILHA, A.C.; ANAYA, F.C.; BARBOSA, R.; FERNANDES, G.W.; SÁNCHEZ-AZOFEIFA, G.A.; SCARIOT, A.; NORONHA, S.E.; SAMPAIO, C.A. Sustainability of tropical dry forests: two case studies in southeastern and central Brazil. Forest Ecology and Management, v.258, p. 922-930, 2009.

FERREIRA, L.G.; FERNANDEZ, L.E.; SANO, E.E.; FIELD, C.; SOUSA, S.B.; ARANTES, A.E.; ARAÚJO, F.M. Biophysical properties of cultivated pastures in the brazilian savanna biome: an analysis in the spatial-temporal domains based on ground and satellite data. Remote Sensing, v.5, n.1, p. 307-326, 2013.

FERREIRA, L.G.; FERREIRA, N.C.; FERREIRA, M.E. Sensoriamento remoto da vegetação: evolução e estado da arte. Acta Scientiarum Biological Sciences, v.30, n.4, p. 379-390, 2008.

FURLEY, P.A.; METCALFE, S.E. Dynamic changes in savanna and seasonally dry vegetation through time. Progress in Physical Geography, v.31, n.6, p. 633-642, 2007.

GENG, L.; MA, M.; WANG, X.; YU, W.; JIA, S.; WANG, H. Comparation of eight tecniques for reconstructing multi-satellite sensor time-series NDVI data sets in the Heihe river Bain, China. Remote Sensing, v.6, n.3, p. 2024-2049, 2014.

GITELSON, A.A.; PENG, Y.; HUEMMRICH, K.F. Relationship between fraction of radiation absorbed by photosynthesizing maize and soybean canopies and NDVI from remotely sensed data taken at close range and from MODIS $250 \mathrm{~m}$ resolution data. Remote Sensing of Environment, v.147, p. 108-120, 2014.

GONZAGA, A.P.; PINTO, J.R.R.; MACHADO, E.L.M.; FELFILI, J.M. Similaridade florística entre estratos da vegetação em quatro florestas estacionais deciduais na bacia do rio São Francisco. Rodriguésia, v.64, n.1, p. 11-19, 2013. 
GREEN, A.A.; BERMAN, M.; SWITZER, P.; CRAIG, M.D. A transformation for ordering multispectral data in terms of images quality with implications for noise removal. IEEE Transactions on Geoscience Remote Sensing, v.26, n.1, p. 65-74, 1988.

HAIDAR, R.F.; FAGG, J.M.F.; PINTO, J.R.R.; DIAS, R.R.; DAMASCO, G.; SILVA, L.C.R.; FAGG, C.W. Florestas estacionais e áreas de ecótono no estado do Tocantins, Brasil: parâmetros estruturais, classificação das fitofisionomias florestais e subsídios para conservação. Acta Amazonica, v.43, n.3, p. 261-290, 2013.

HUETE, A.; DIDAN, K.; MIURA, T.; RODRIGUEZ, E. P.; GAO, X.; FERREIRA, L. G. Overview of the radiometric and biophysical performance of the MODIS vegetation indices. Remote Sensing of Environment, v.83, n.1, p. 195-213, 2002.

HUETE, A.R.; LIU, H.Q.; BATCHILY, K.; VAN LEEUWEN, W. A comparison of vegetation indices over a global set of TM images for EOS-MODIS. Remote Sensing of Environment, v.59, n.3, p. 440-451, 1997.

IBAMA. INSTITUTO BRASILEIRO DO MEIO AMBIENTE E DOS RECURSOS NATURAIS RENOVÁVEIS. Projeto de monitoramento do desmatamento dos biomas brasileiros por satélite - PMDBBS. Disponível em: <sicom.ibama.gov.br/monitorabiomas>. Acesso em: 25 de jun. 2014.

JUSTICE, C.O.; TOWNSHEND, J.R.G.; VERMOTE, E.F.; MASUOKA, E.; WOLFE, R.E.; SALEOUS, N.; ROY, D.P.; MORISETTE, J.T. An overview of MODIS land data processing and product status. Remote Sensing of Environment, v.83, n.1, p. 3-15, 2002.

LATORRE, M.L.; ANDERSON, L.O.; SHIMABUKURO, Y.E.; CARVALHO JÚNIOR, O.A. Sensor Modis: características gerais e aplicações. Espaço \& Geografia, v.6, n.1, p. 91$121,2003$.

LIMA, A.; SILVA, T.S.F.; ARAGÃO, L.E.O.C.; FREITAS, R.M.F.; ADAMI, M.; FORMAGGIO, A.R.; SHIMABUKURO, Y.E. Land use and cover changes determine the spatial relationship between fire and deforestation in the brazilian Amazon. Applied Geography, v.34, p. 239-246, 2012.

LISENBERG, V.; PONZONI, F.J.; GALVÃO, L.S. Análise da dinâmica sazonal e separabilidade spectral de algumas fitofisionomias do Cerrado com índices de vegetação dos sensors MODIS/TERRA e AQUA. Revista Árvore, v.31, n.2, p. 295-305, 2007.

LUMME, J.H. Classification of vegetation and soil using imaging spectrometer data. In: Proceedings of the XXth ISPRS Congress, Istanbul, Turkey, 2004; v.35, Part B7.

MA, M.M.; VEROUSTRAETE, F. Reconstructing pathfinder AVHRR land NDVI timeseries data for the Northwest of China. Advances in Space Research, v.37, n.4, p. 835-840, 2006.

MAYLE, F.E. Assessment of the Neotropical dry forest refugia hypothesis in thelight of palaecological data and vegetation model simulations. Journal of Quaternary Science, v.19, p. 713-720, 2004.

MENKE, A.B.; CARVALHO JÚNIOR, O.A.; GOMES, R.A.T.; MARTINS, E.S.; OLIVEIRA, S.N. Análise das mudanças do uso agrícola da terra a partir de dados de 
sensoriamento multitemporal no município de Luís Eduardo Magalhães (BA - Brasil). Sociedade \& Natureza, v.21, n.3, p. 315-326, 2009.

MIGLANI, A.; RAY, S.S.; VASHISHTA, D.P.; PARIHAR, J.S. Comparasion of two data smoothing techniques for vegetation spectra derived from EO-1 Hyperion. Journal of the Indian Society of Remote Sensing, v.39, n.4, p. 443-453, 2011.

MIKHEEVA, A.; NOVICHIKHIN, A.; TUTUBALINA, O. Linear spectral mixture modelling of artic vegetation using ground spectroradiometry. Polar Record, v.48, n.244, p. 63-74, 2012.

MINAYO, M.C.S. Rio+20: challenges of development for health and sustainability. Environmental Health Perspectives, v.120, n.9, p. a340-a340, 2012.

MOTOHKA, T.; NASAHARA, K.N.; MURAKAMI, K.; NAGAI, S. Evaluation of sub-pixel cloud noises on MODIS daily spectral indices based on in situ measurements. Remote Sensing, v.3, n.8, p. 1644-1662, 2011.

NASCIMENTO, A.R.T.; FELFILI, J.M.; MEIRELLES, E.M. Florística e estrutura da comunidade arbórea de um remanescente de floresta estacional decidual de encosta, Monte Alegre, GO, Brasil. Acta Botanica Brasilica, v.18, n.1, p. 659-669, 2004.

NUMATA, I.; COCHRANE, M.A.; ROBERTS, D.A.; SOARES, J.V. Determining dynamics of spatial and temporal structures of forest edges in south western Amazonia. Forest Ecology and Management, v.258, n.11, p. 2547-2555, 2009.

OLIVEIRA, J.C.; EPIPHANIO, J.C.N.; RENNÓ, C.D. Windon regression: a spatial-temporal analysis to estimate pixels classified as low-quality in MODIS NDVI time series. Remote Sensing, v.6, n.4, p. 3123-3142, 2014.

OLIVEIRA-FILHO, A.T.; JARENKOW, J.A.; RODAL, M.J.N. Floristic relationships of seasonally dry forests of eastern South America based on tree distribution patterns. In: PENNIGTON, R.T.; LEWIS, G.P.; RATTER, J.A. (Eds.). Neotropical savannas and seasonally dry forests: plant diversity, biogeography, and conservation. Edinburg, U.K.: CRS Press, 2006, p. 159-192.

OLIVEIRA-FILHO, A.T.; RATTER, J.A. Vegetation physiognomies and woody flora of the Cerrado biome. In: OLIVEIRA, P.S.; MARQUIS, R.J. (Eds.). The cerrados of Brazil: ecology and natural history of a neotropical savanna. New York: Columbia University, Columbia University Press, 2002. p. 91-120.

OLIVERAS, I.; MEIRELLES, S.T.; HIRAKURI, V.L.; FREITAS, C.R.; MIRANDA, H.S.; PIVELLO, V.R. Effects off fire regimes on herbaceous biomass and nutrient dynamics in the Brazilian savanna. International Journal of Wildland Fire, v.22, p. 368-380, 2013.

PARKINSON, C.L.; GREENSTONE, R. EOS data products handbook. Greenbelt: NASA Goddard Space Flight Center, 2000, 253 p.

PENNIGTON, R.T. LAVIN, M.; OLIVEIRA-FILHO, A. Woody plant diversity, evolution, and ecology in the tropics: perspectives from seasonally dry tropical forests. Annual Review of Ecology, Evolution and Systematics, v.40, p. 437-457, 2009. 
PENNINGTON, R.T.; PRADO, D.E.; PENDRY, C.A. Neotropical seasonally dry forests and Quaternary vegetation changes. Journal of Biogeography, v.27, p. 261-273, 2000.

PINHEIRO, E.S.; DURIGAN, G. Diferenças florísticas e estruturais entre fitofisionomias do Cerrado em Assis, SP, Brasil. Revista Árvore, v. 36, n.1, p. 181-193, 2012.

PINHEIRO, M.H.O.; MONTEIRO, R. Contribution to the discussions on the origin of the Cerrado biome: Brazilian savanna. Brazilian Journal of Biology, v. 70, n.1, p. 95-102, 2010.

PIVELLO, V.R.; OLIVERAS, I.; MIRANDA, H.S.; HARIDASAN, M.; SATO, M.N.; MEIRELES, S.T. Effect of fires on soil nutrient availability in an open savanna in Central Brazil. Plant and Soil, v. 337, p. 111-123, 2010.

PORTILLO-QUINTERO, C.A.; SÁNCHEZ-AZOFEIFA, G.A.; ESPÍRITO-SANTO, M.M. Monioring deforestation with MODIS active fires in neotropical dry forests: an analysis of local-scale assessments in Mexico, Brazil and Bolivia. Journal of Arid Environments, v.97, p. 150-159, 2013.

PRADO, D.E. Seasonally dry forests of tropical South America: from frogotten ecosystems to a new phytogeographic unit. Edinburg Journal of Botany, v.57, n.3, p. 437-461, 2000.

REED, B.C.; BROWN, J.F.; VANDERZEE, D.; LOVELAND, T.R.; METCHANT, J.W.; OHLEN, D.O. Measuring phonological variability from satellite imagery. Journal of Vegetation Science, v.5, n.5, p. 703-714, 1994.

REIS, P.R.C.; SILVEIRA, S.F.R.; RODRIGUES, P.E.L. Avaliação da política nacional de irrigação: o método quase experimental de avaliação de impacto aplicado ao projeto Jaíba. Organizações Rurais \& Agroindustriais, v.14, n.3. p. 426-440, 2012 b.

REIS, P.R.C.; SILVEIRA, S.F.R.; RODRIGUES, P.E.L. Impactos da política nacional de irrigação sobre o desenvolvimento socioeconômico da região norte de Minas Gerais: uma avaliação do Projeto Gorutuba. Revista de Administração Pública, v.46, n.4, p. 1101-1130, 2012a.

RIBEIRO, J.F.; WALTER, B.M.T. As principais fitofisionomias do bioma Cerrado. In: Sano, S.M.; ALMEIDA, S.P.; RIBEIRO, J.F. (Eds.). Cerrado: ecologia e flora. Brasília: Empresa Brasileira de Pesquisa Agropecuária-EMBRAPA, 2008. p. 151-212.

RUDORFF, B.F.T.; SHIMABUKURO, Y.E.; CEBALLOS, J.C. Sensor MODIS e suas aplicações ambientais no Brasil. 1. ed. São José dos Campos: Parêntese, 2007. 425 p.

RULL, V. Speciation timing and Neotropical biodiversity: the Tertiary-Quaternary debate in the light of the molecular phylogenetic evidence. Molecular Ecology, v.17, n.11, p. 27222729, 2008.

SÁNCHEZ-AZOFEIFA， G.A.; CASTRO， K.L.; RIVARD， B.; KALASCKA， M.R.; HARRISS, R.C. Remote sensing research priorities in tropical dry forest environments. Biotrópica, v.35, n.2, p. 134-142, 2003.

SANO, E.E.; FERREIRA, L.G.; ASNER, G.P.; STEINKE, E.T. Spatial temporal probabilities of obtaining cloud-free Landsat images over the Brazilian tropical savanna. International Journal of Remote Sensing, v.28, n.12, p. 2739-2752, 2007. 
SANO, E.E.; ROSA, R.; BRITO, J.L.S.; FERREIRA, L.G. Land cover mapping of the tropical savanna region in Brazil. Environmental Monitoring and Assessment, v.166, n.1, p. 113-124, 2010.

SANTANA, O.A.S.; CARVALHO JÚNIOR, O.A.; PIMENTEL, C.M.M.; GOMES, R.A.T. G.; OLIVEIRA, S.N. Modelagem em espectros temporais NDVI-MODIS, no período de 2000 a 2008, na bacia do rio Paracatu, Brasil. Revista Brasileira de Geofísica, v.28, n.1, p. 47-60, 2010.

SANTOS, R.M.; VIEIRA, F.A. Estrutura e florística de um trecho de mata ciliar do rio Carinhanha no extremo norte de Minas Gerais, Brasil. Revista Científica Eletrônica de Engenharia Florestal, v.5, p. 1-13, 2005.

SANTOS, R.M.; VIEIRA, F.A.; FAGUNDES, M.; NUNES, Y.R.F.; GUSMÃO, F. Riqueza e similaridade florística de oito remanescentes florestais no norte de Minas Gerais, Brasil. Revista Árvore, v.31, n.1, p. 135-144, 2007.

SCARANO, F.R.; GUIMARÃES, G.; SILVA, J.M. Leady by example. Nature, v.486, p. 2526, $2012 b$.

SCARANO, F.R.; SILVA, J.M.C.; Guimarães, A.L.; RAIK, D.; BOLTZ, F. Brazil on the spot: Rio+20, sustainability and a role for science. Brazilian Journal Botany, v.35, n.2, p. 233-239, 2012a.

SCHWARTZ, M.; REED, B. Surface phenology and satellite sensor-derived onset of greenness: an initial comparison. International Journal of Remote Sensing, v.20, n.17, 3451-3457, 1999.

SHIMABUKURO, Y.E.; NOVO, E.M.; PONZONI, F.J. Índice de vegetação e modelo linear de mistura espectral no monitoramento da região pantanal. Pesquisa Agropecuária Brasileira, v.33, n.2, p.1729-1737, 1998.

SHIMABUKURO, Y.E.; SMITH, J.A. The least-squares mixing models to generate fraction images derived form remote sensing multispectral data. IEEE Transactions on Geoscience Remote Sensing, v.29, n.1, p. 16-20, 1991.

SON, N.T.; CHEN, C.F.; CHEN, C.R.; CHANG, L.Y.; THANH, B.X. Urban growth mapping from Landsat data using linear mixture model in Ho Chi Minh city, Vietnam. Journal of Applied Remote Sensing, v.6, p. 063543-1-063543-14, 2012.

SOUZA, A.A.; GALVÃO, L.S.; SANTOS, J.R. Relationships between Hyperion-derived vegetation indices, biophysical parameters, and elevation data in Brazilian savannah environment. Remote Sensing Letters, v.1, n.1, p. 55-64, 2010.

STRAHLER, A.; MUCHONEY, D.; BORAK, J.; FRIEDL, M.; GOPAL, S.; LAMBIN, E.; MOODY, A. MODIS land cover product, algorithm theoretical basis document (ATBD). Version 5.0. Boston: Center for Remote Sensing, Department of Geography, Boston University, 1999. $72 \mathrm{p}$.

WERNECK, F.P. The diversification of eastern South American open vegetation biomes: historical biogeography and perspectives. Quaternary Science Reviews, v.30, p. 1630-1648, 2011. 
ZAPPI, D. Fitofisionomia da Caatinga associada à Cadeia do Espinhaço. Megadiversidade, v.4, n. 1-2, p. 34-38, 2008.

ZHOU, F.; ZHANG, A. Methodology for estimating availability of cloud-free image composites: a case study for southern Canada. International Journal of Applied Earth Observation and Geoinformation, v.21, n.1, p. 17-31, 2013. 


\title{
CAPÍTULO 2 - COMPARATIVE ANALYSIS OF DISTANCE AND SIMILARITY MEASURES FOR TIME-SERIES CLASSIFICATION AT THE BRAZILIAN CERRADO-CAATINGA BOUNDARY
}

\begin{abstract}
This paper aims to map the main native and exotic vegetation that occur in the Caatinga-Cerrado transition zone in Central Brazil from MODIS-NDVI time series (product MOD09Q1). The study period was two years (2011-2013). The methodology can be subdivided into the following steps: (a) development of a 3D-cube composed by NDVIMODIS time series; (b) removal of noise; (c) selection of temporal-signature references of land use and vegetation cover; and (d) time-series classification. Different classifications of land use and land cover were evaluated considering several combinations of the following attributes: (a) number of temporal curves by class (single or multiple); (b) number of classes used in the classification (six or eight), (c) input data (NDVI-MODIS time series or signal components of the Minimum Noise Fraction transform), and (d) measure types. The mapping methods included the following measures: Euclidian Distance Measure (ED), Spectral Angle Mapper (SAM) and Spectral Correlation Mapper (SCM). The best result used the Euclidean distance on the NDVI-MODIS data, considering more than a reference curve per class and adopting six mapping classes. This configuration achieved Overall Accuracy of $82.25 \%$ and Kappa coefficient of 0.76. SAM and SCM similarity measures also obtained better levels of accuracy when applied to the signal components of the Minimum Noise Fraction (MNF). The results in this work demonstrates the potential of vegetation study in semiarid ecosystems from time series.
\end{abstract}

Keywords: Caatinga, Cerrado, Spectral Angle Mapper; Spectral Correlation Mapper, Euclidian Distance Measure; MODIS

\subsection{Introduction}

The studies about spatial distribution and the processes governing the Brazilian Cerrado-Caatinga transition have significant implications for the management of these biomes. The ecotones are key indicators of local and global changes, helping understand the landscape responses to changes in climate regimes and human influences. The Cerrado and Caatinga biomes have a high biodiversity adapted to the seasonal stress that coexists in a complex mosaic [1-4]. The transition zone has different vegetation types such as dry forest islands, gallery forests and savannah, containing variations in the number and sizes of the patches. However, anthropogenic alterations are growing in this environment causing landscape fragmentation and harming the ecological functioning.

The semi-arid ecosystems have been threatened worldwide, with an area reduction around $50 \%$ in the global scale [5]. Portillo-Quintero and Sanchez-Azofeifa [6] estimates that 66\% of dry tropical forests in Latin America have been deforested, mainly due to the agricultural expansion, having remained only fragmented landscapes. In Brazil, human activities altered about $48 \%$ of the Caatinga 
[7,8] and 53\% of the Cerrado [9]. These ecosystems have received less attention and research than tropical rainforests. As a result, there are still some questions about its extent, limit, biogeographical relationships, land use processes, among others [10,11].

Time-series of satellite imagery have great potential for vegetation monitoring in the semi-arid regions. In this context, the Moderate Resolution Imaging Spectroradiometer (MODIS) sensor instrument aboard the Terra and Aqua platforms [12] is widely used for terrestrial monitoring due to its high temporal resolution and high image quality for the radiometric and geometric properties. Moreover, several phenological researches have been developed from the vegetation indices of MODIS images, both in natural ecosystems [13-18] as in anthropic landscapes, for instance, agricultural crops [19-24], pastures [25], and eucalyptus plantations [26].

In the semi-arid environments, MODIS data are being applied to the studies of seasonality, phenology, fire events and conservation [27]. Hüttich et al. [28] distinguish savanna types in South Africa from the in-situ botanical survey combined with Landsat and MODIS images. Baldi et al. [29] quantifies the connections among landscape patterns, ecosystem functioning and agricultural use in the Dry Chaco and Chiquitania ecoregions, which covers parts of Argentina, Bolivia and Paraguay, using MODIS-NDVI time series. Portillo-Quintero et al. [30] study the correlation between MODIS Active Fires and forest cover change in the Tropical Dry Forest (TDF).

This paper aims to map the vegetation cover and land-use in the Brazilian Cerrado-Caatinga transition using phenological signatures from MODIS vegetation indices over the 2011-2013 period. However, different aspects used to identify the temporal features affect the classification performance. In this context, we evaluated and compared different characteristics for temporal-signature classification in order to identify the best-fit method: (a) number of temporal curves by class (single or multiple); (b) number of classes used in the classification (six or eight), (c) input data (NDVI-MODIS time series or signal components of the Minimum Noise Fraction transform), and (d) three measure types. The measures used to cluster similar phenological patterns were Spectral Angle Mapper (SAM), Spectral Correlation Mapper (SCM) and Euclidian Distance (ED).

\subsection{Study Area}

The study area is located at the southern Brazilian semi-arid region, between coordinates $14^{\circ} 33$ '50"

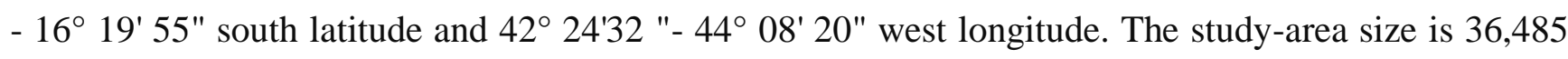
$\mathrm{km} 2$, of which $89.4 \%$ are located in the Minas Gerais state and the remainder is contained in the Bahia state (Figure 2.1).

The climate is tropical semi-arid with two well-defined seasons, dry (May to October) and rainy (November to April), with average annual rainfall around $818 \pm 242 \mathrm{~mm}$ and the average temperature ranging from $21^{\circ} \mathrm{C}$ to $25^{\circ} \mathrm{C}$ [31]. The geomorphology of the study area includes the São Francisco depression, highlands and the Espinhaço ranges and the main soil types are Entisols, Oxisols, Inceptisols and Gleysols [32].

The native vegetation is composed of six predominant phytophysiognomies, of which two derive from Caatinga domain (Deciduous Seasonal Forest and the Semi-Deciduous Seasonal Forest) and four of the Cerrado domain (Savannah Woodland and the following grasslands formations: Savannah Grassland, Shrub Savannah and Rupestrian Fields) [33]. The Cerrado predominates in the eastern part of the area, in the Espinhaço Range, while Caatinga occurs in the center and west of the area, at 
elevations below $800 \mathrm{~m}$ between the São Francisco River and the Espinhaço Range. Vegetation transition zones are also observed, as in the Parque Estadual Caminho dos Gerais (PECG), a protected area where prevails the Cerrado physiognomies [34] (mainly grassland) surrounded by Caatinga (Figure 2.2).
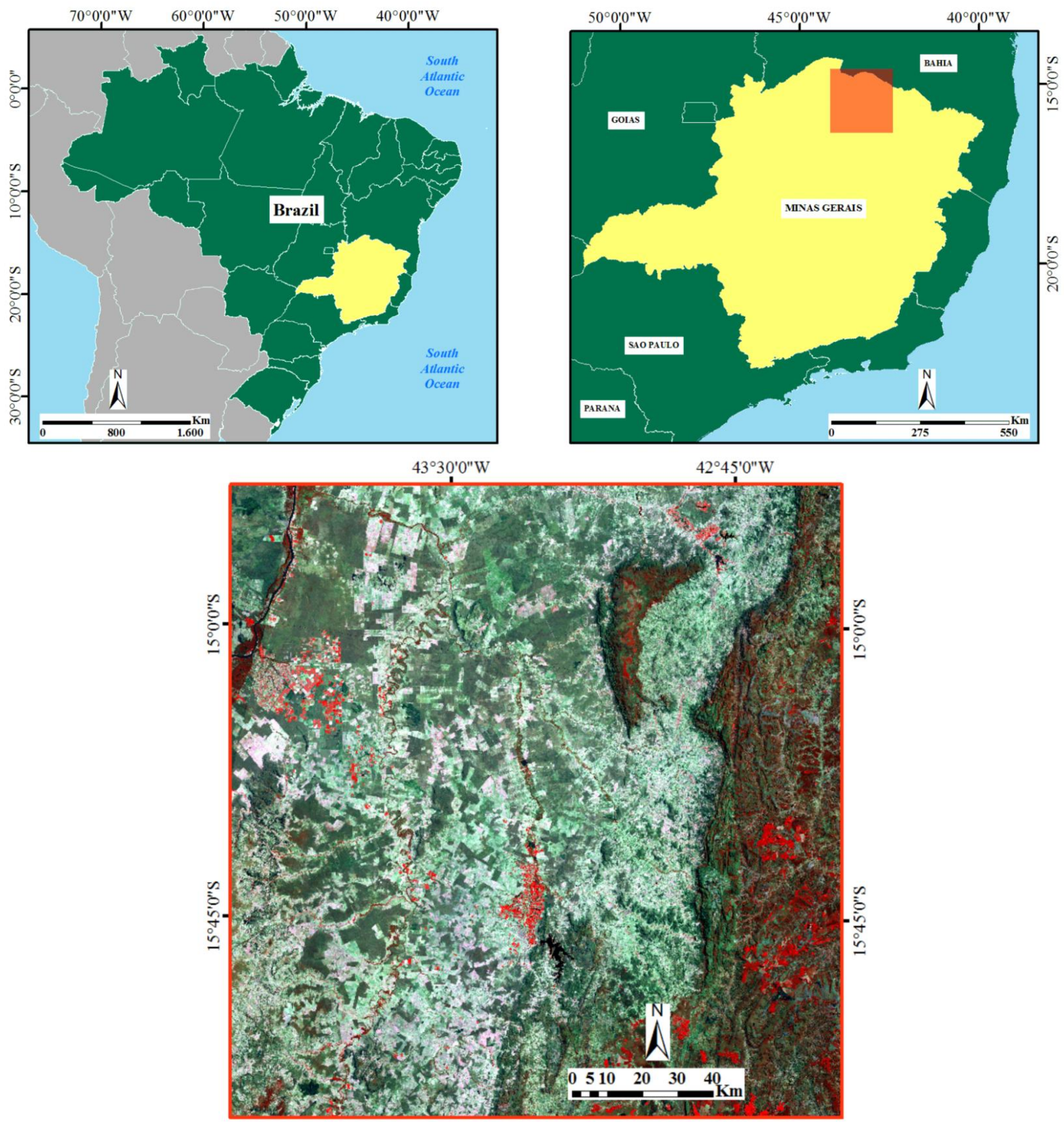

Figure 2.1. Location map of the study area.

In the Espinhaço Range, the Cerrado occurs on acid and dystrophic soils from quartzite rocks [35]. However, the vegetation is diverse, with the Savannah Woodland (Cerrado stricto sensu) on more developed and deep soils (e.g., Oxisol) and grasslands formations (Savannah Fields) on soils associated with rocky outcrops $[35,36]$.

The Caatinga region near the Espinhaço Range and the São Francisco River is due to particular combinations of soil type, terrain, and hillsides that act as barriers to regular rainfall [37]. The Caatinga physiognomies have species such as Cavanillesia umbellata (Barriguda), Myracrodruon 
urundeuva, Tabebuia impetiginosa, and Aspidsperma pyrifolim, occurring in soil erosion resulting from limestone or crystalline rocks of the Bambuí group [32]. Generally, the Caatinga does not have an herbaceous continuous coverage [38] and its presence indicates pasture for livestock [37].

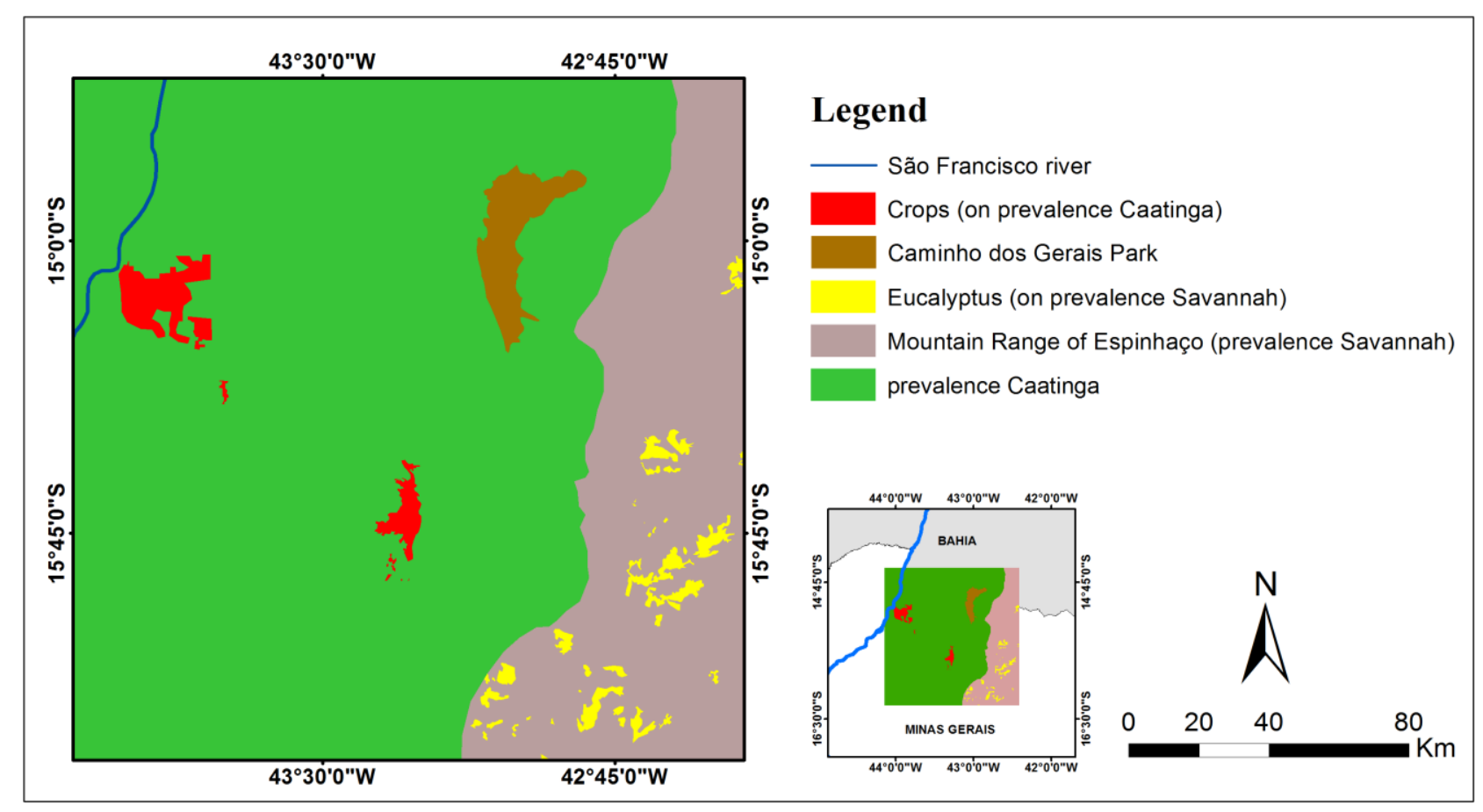

Figure 2.2. Spatial distribution of Caatinga and Cerrado in the study area.

The favorable soil conditions, mainly characterized by eutrophic soils, and water availability from the São Francisco River and its tributaries has allowed the installation of a technical agriculture, located in central and northwest of the study area. This agriculture area has annual crops (corn, cane sugar, sorghum, beans, and cotton) and perennial crops (banana, lemon, mango, and coffee) [39].

Therefore, extensive cattle and agricultural plantations, including a large irrigated area (Jaíba Project), have suppressed the native vegetation [33,40]. In the eastern of the study area, the Cerrado predominates due to the presence of low-fertility soil and water deficiency. These environmental conditions restrict the development of agriculture on site, specializing in planting the species of the genus Eucalyptus [37]. In addition, scientific studies that could contribute to the vegetation monitoring are scarce, hampering the conservation actions [41].

\subsection{Methodology}

The image processing included the following steps (Figure 2.3): (a) acquisition of MODIS images; (b) development of a 3D-cube composed by NDVI-MODIS time series; (c) removal of noise; (d) selection of temporal signatures; and (e) classification of time series using distance and similarity measures (Euclidian Distance Measure - ED, Spectral Angle Mapper - SAM and Spectral Correlation Mapper - SCM). 


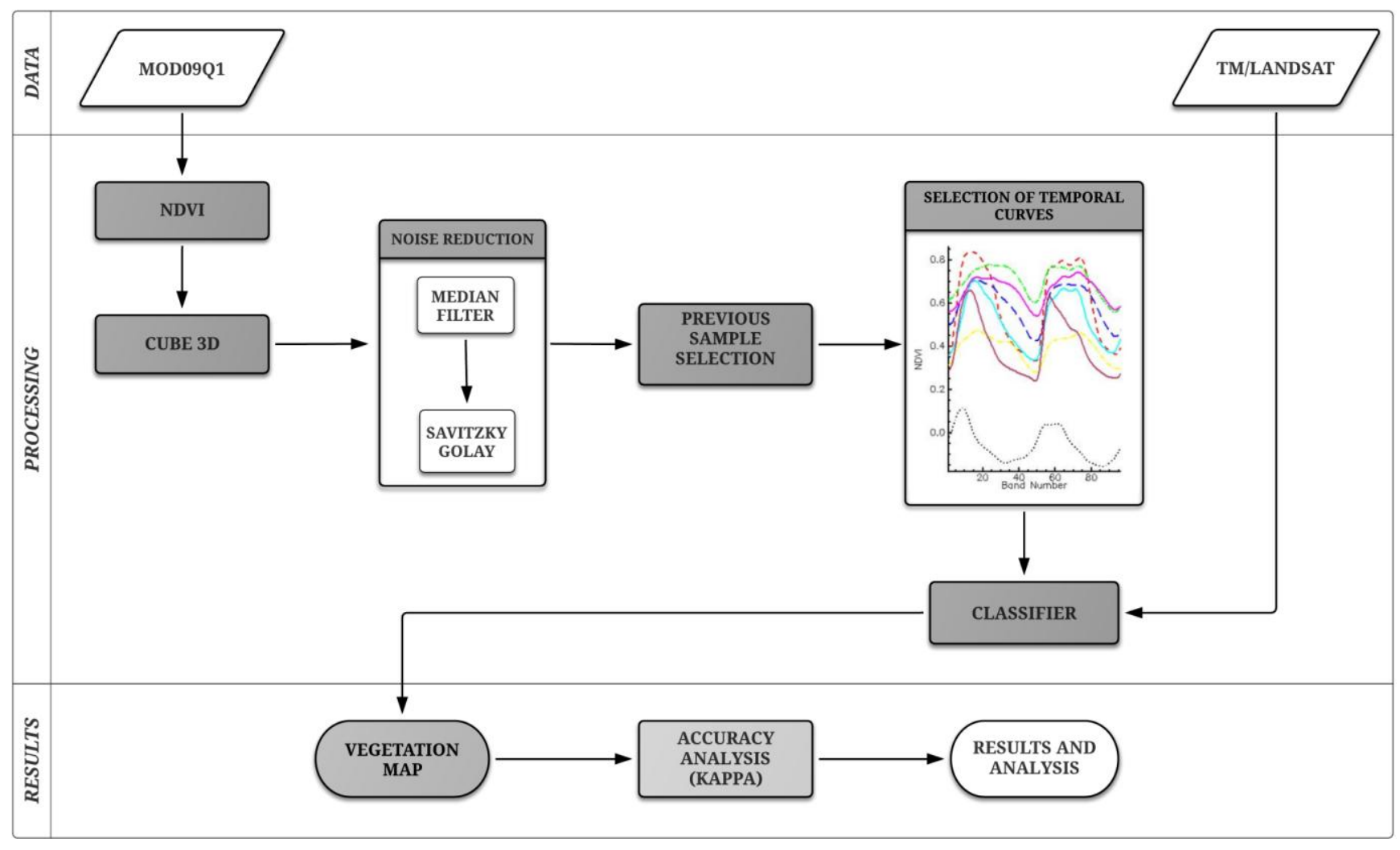

Figure 2.3. Methodological flowchart of the digital image processing.

\subsubsection{MODIS/Terra time-series dataset}

We used the 8-day MODIS/Terra MOD09Q1 product relative to surface reflectance data. This product provides the bands 1 and 2 relating to red $(620-670 \mathrm{~nm})$ and near infrared $(841-875 \mathrm{~nm})$, which are composited from all 8-day inputs at 250-meter resolution [42]. According Gundin-Garcia et al. [43], the MOD09Q1 product is best suited to the NDVI study than MOD13A1 and MOD13Q1 products because of its better spatial and temporal resolutions. The images were converted to geographical coordinates, datum World Geodetic System 84 (WGS84), using the MODIS Reprojection Tolls (MRT) program.

The NDVI-MODIS time series are able to identify the savanna types since the evaluation period is not less than two years [28]. In addition, the best results are obtained considering the dry season images that are largely cloud-free [28]. Thus, the long-term phenological observations, including the inter-seasonal variability, are useful for a detailed characterization of semi-arid vegetation $[28,44]$. In this work, the MODIS images were acquired for the period from September 2011 to October 2013, totaling 96 scenes. The initial and final date coincides with the peak of the dry season, when the deciduous vegetation loses its leaves [31,44].

\subsubsection{Image Cube of NDVI-MODIS Time-Series}

The Normalized Difference Vegetation Index (NDVI) was calculated from the MOD09Q1 bands according to the following equation [45]: 


$$
\text { NDVI }=\frac{\rho^{*} \text { NIR }-\rho^{*} \text { Red }}{\rho^{*} \text { NIR }+\rho^{*} \text { Red }}
$$

where " $\rho * N I R$ " (band 2) and " $\rho *$ Red" (band 1) are the reflectance values for the near infrared and red ranges, respectively. All MODIS NDVI-images over the 2011-2013 period were joined in a 3D image cube (Figure 2.4), where " $\mathrm{X}$ " and " $\mathrm{Y}$ " are related to geographical coordinates (longitude and latitude) and "Z" is the behavior of the target over time $[46,47]$.

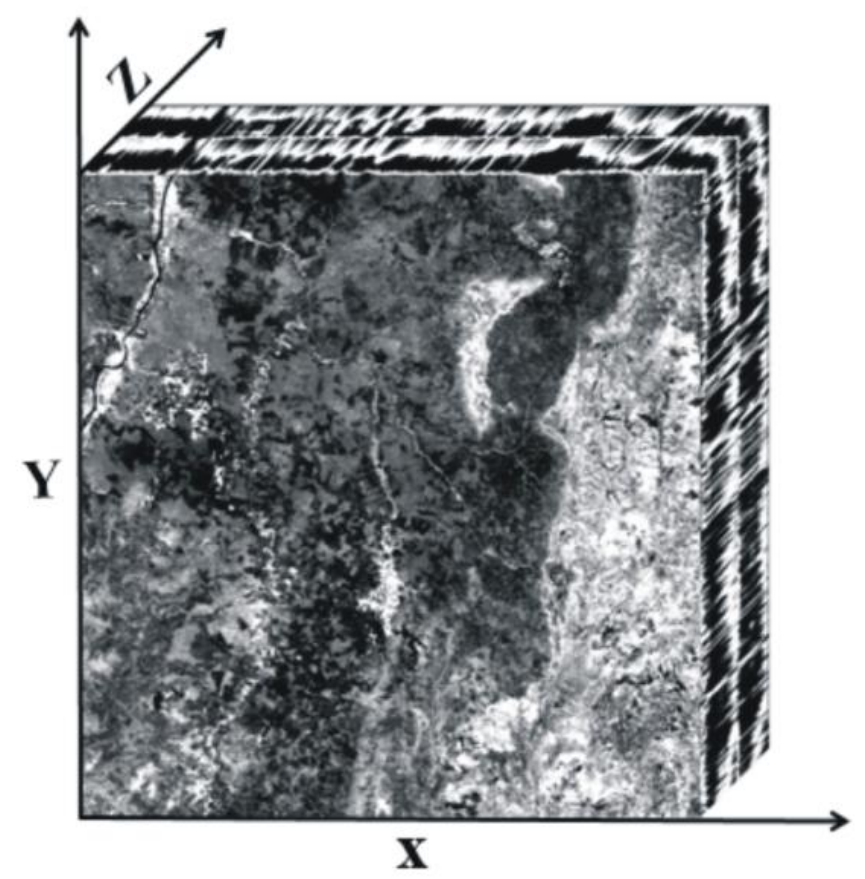

Figure 2.4. 3D time series data cube of the study area.

\subsubsection{Image Denoising}

Noise is very common in time series of NDVI images from the cloud cover, shade and instrumental defects, which affect the identification and quantification of ground targets. Thus, noise elimination is necessary to acquire a high-quality seasonal curve. In this work, we combined two filtering techniques: median filter and Savitzky-Golay (S-G) [48].

The median filter is a nonlinear smoothing technique that preserves signal edges or monotonic changes in trend and particularly removes impulse noise of short duration, which cannot be attained using linear algorithms [49]. The median filter performs a window moving over temporal curve and obtains the median value, a particular case of the order statistic (or rank statistic) of a finite set of real numbers, that is taken as the output. However, the temporal median filter is effective only at low noise densities, losing effectiveness and image details when the high noise-density interference in successive time series of images [50].

The S-G combines the effective noise removal and the waveform-peak preservation (height, shape and asymmetry) [51], adequate for the phenological analysis from remotely sensing data [52-54]. Geng et al. [55] compare eight techniques to filter NDVI time-series data and conclude that the S-G 
filter achieve best results for most situations. Thus, the combined techniques enable to develop a fast and accurate method for time series correction.

\subsubsection{Temporal-Signature Selection}

The convex geometry-based methods are widely used for isolating reference pixels within an image [56-58]. This technique was developed to detect endmembers, in order to be applied in the unmixing processing and spectral classification. In this study, the convex geometry was adapted for selecting reference signatures for time-series classification. In this approach, considering the following steps: (a) previous sample selection for the different classes, (b) use of Minimum Noise Fraction (MNF) transform [59] for the sample set of each class, and (c) identification of temporal signatures using the n-dimensional viewer.

The previous temporal-signature selection considered the following information: (a) land-cover map of Minas Gerais State produced by the State Forestry Institute and the University of Lavras [33]; (b) municipal agricultural production information from the Brazilian Institute of Geography and Statistics [39]; (c) high-resolution images from Google Earth; and (d) field-work data.

The MNF Transform is a method both to remove noise and to compress the image data into a little group of signal components [59]. MNF transform is a procedure similar to Principal Component Analysis (PCA) and consist of a linear transformation that maximizes the signal-to-noise ratio to order images, i.e. according to the image quality. This procedure is adequate to reduce the data redundancy from hyperspectral images [59], aerial gamma-ray survey [60], radar dataset [61] and a time series of remote sensing data [50]. Thus, the MNF is an efficient way to find a subspace with reduced dimensionality, in which reference data are appropriately selected. In the MNF space, the input data is divided into two parts, one associated with the signal components and the other to the noise components. Considering only the signal components, the size of data is drastically reduced. The fraction signal is identified from the evaluation of image quality and eigenvalues plot (Figure 2.5).

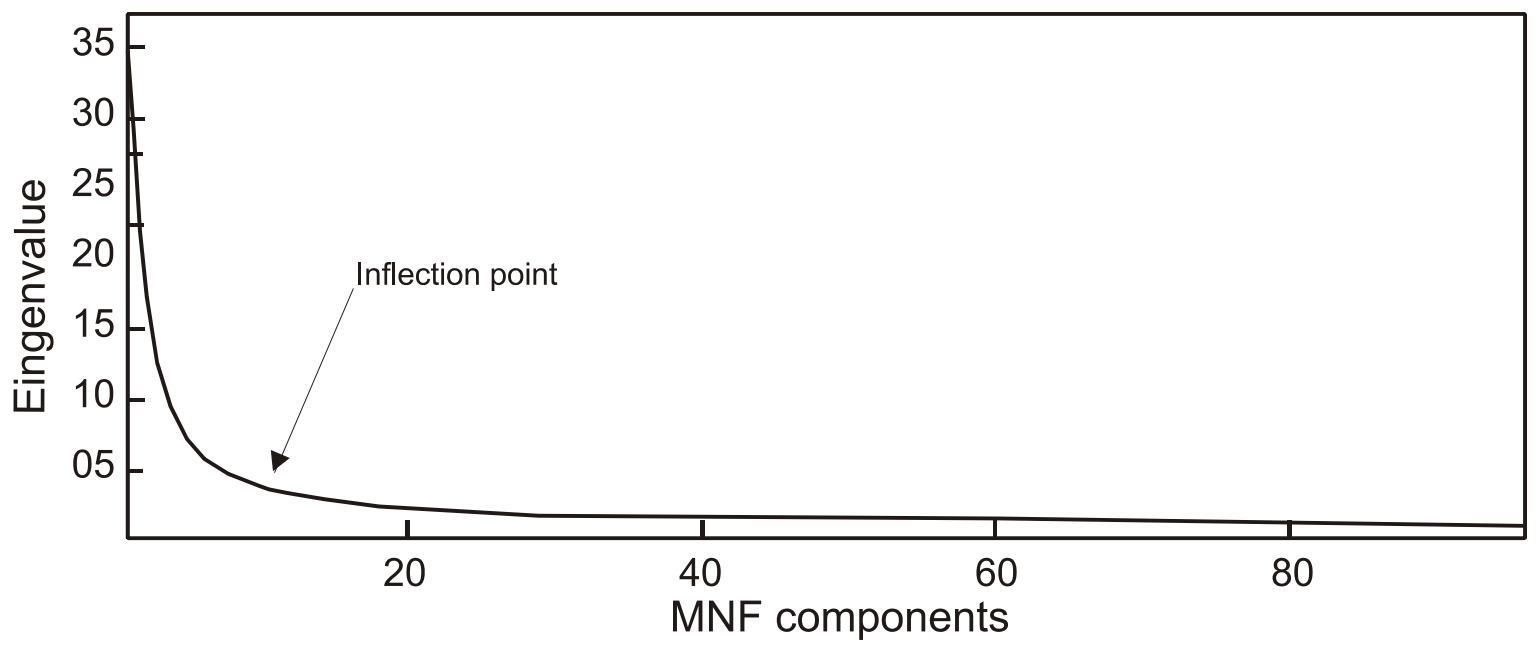

Figure 2.5. Eigenvalues plot from Minimum Noise Fraction (MNF) transformation. The fraction signal is concentrated in the first 10 bands.

Three temporal signatures were selected for each type of land-use/land-cover, using n-dimensional visualizer of the Environment for the Visualization of Images (ENVI). The reference data were 
collected for both MODIS-NDVI data and the signal components from MNF transform (Figure 2.6). In this algorithm, the three temporal curves for the same unit are used independently in classification generating three different classes, which are then clustered into the same class. This simple device allows us to consider for a same class slightly different time curves, causing a significant improvement in the time series classification. The temporal signatures show greater variation than the spectral signatures. The distinctive features of time series depend on the timing of seasonal climatic events susceptible to slight variations in time.

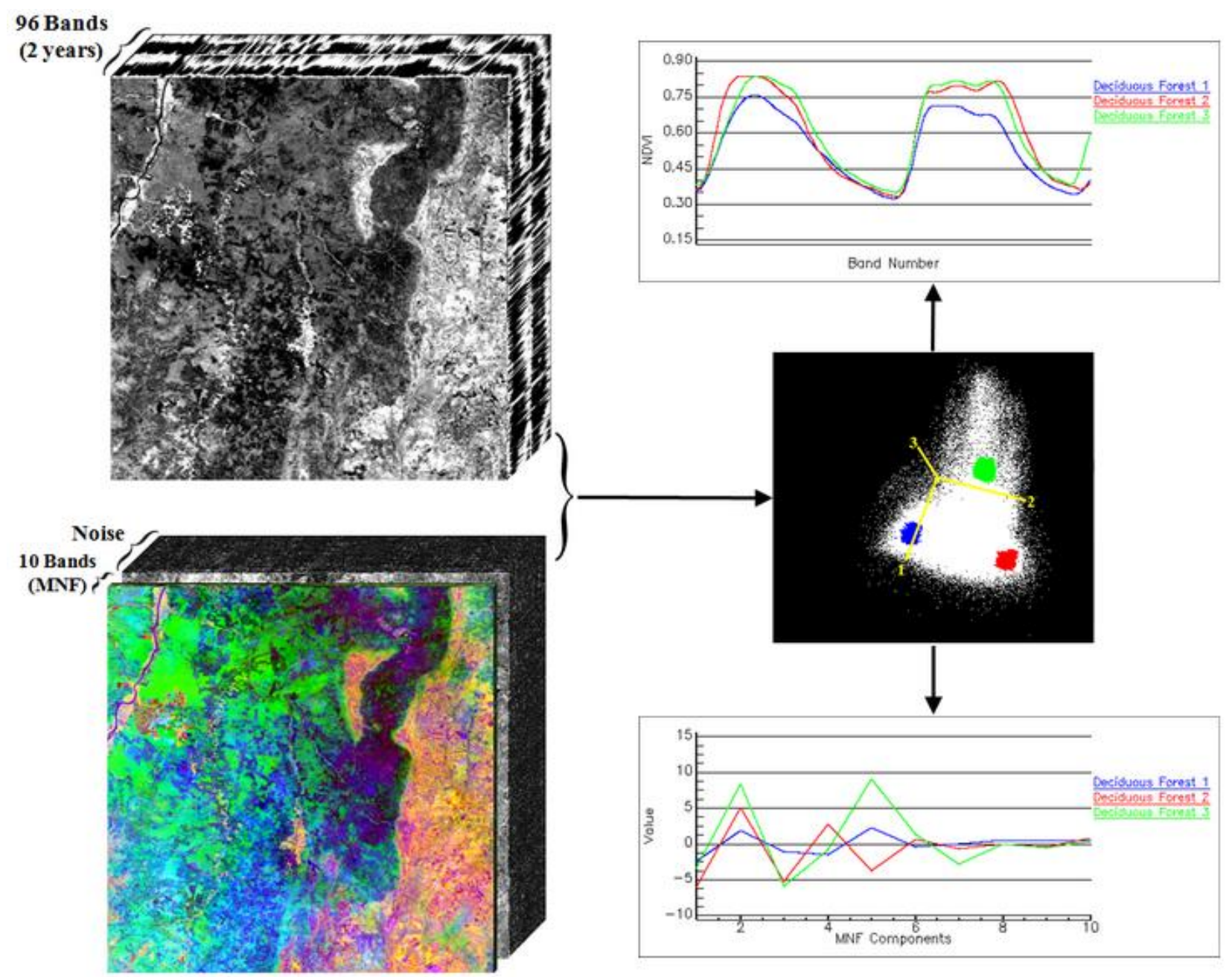

Figure 2.6. Procedure for the temporal-signature selection of land use and vegetal cover, considering both MODIS-NDVI data dimension and the actual dimension of image from signal components of the MNF transform.

The classification adopted the following classes: water; agricultural areas; pasture; Deciduous Forest; Semi-Deciduous Forest; and Savannah. In addition, a more detailed investigation in order to separate agricultural areas in annual and perennial crops as well as the savannas in woody and herbaceous formations (Table 2.1). 
Table 2.1. Classes of land use and land cover used in the classification of MODIS NDVI

\begin{tabular}{|c|c|c|c|}
\hline Sets & Specifications & $\begin{array}{c}\text { Total } \\
\text { Classes }\end{array}$ & Classes \\
\hline 1 & $\begin{array}{l}\text { Regional. } \\
\text { Annual and perennial crops are not } \\
\text { separated; Vegetation subtypes of } \\
\text { the Cerrado biome are not } \\
\text { separated. }\end{array}$ & 6 & $\begin{array}{l}\text { Water; Agricultural Areas }{ }^{1} \text {; } \text { Pasture }^{1} \text {; } \\
\text { Deciduous Seasonal Forest }{ }^{2} ; \text { Semi-deciduous } \\
\text { Seasonal Forest }{ }^{2} \text {; and Cerrado }{ }^{3} \text {. }\end{array}$ \\
\hline 2 & $\begin{array}{l}\text { Detailed. } \\
\text { Separate the annual and perennial } \\
\text { crops; } \\
\text { Separate woody and herbaceous } \\
\text { formations of the Cerrado biome. }\end{array}$ & 8 & $\begin{array}{l}\text { Water; Annual } \text { Crops }^{l} \text {; Perennial } \text { Crops }^{l} \text {; } \\
\text { Pasture ; Deciduous Seasonal Forest }{ }^{2} \text {; Semi- } \\
\text { deciduous Seasonal Forest }{ }^{2} \text { Savannah } \\
\text { Woodland (Cerrado stricto sensu) })^{3} \text {; and } \\
\text { Grasslands formations }{ }^{3} \text {. }\end{array}$ \\
\hline
\end{tabular}

${ }^{1}$ anthropic use; ${ }^{2}$ forms of occupation related to the Caatinga biome; ${ }^{3}$ forms of occupation related

to the Cerrado biome.

\subsubsection{Distance and Similarity Measures}

In the spectral classification, the similarity measures most frequently used are cosine correlation adopted in the Spectral Angle Mapper (SAM) [62] and the Pearson's correlation coefficient adopted in the Spectral Correlation Mapper (SCM) [63], while the main distance measure is the Euclidean Distance (ED) used in the Minimum Distance. The spectral measures provide different information about the target, which justifies conduct testing in order to determine the most appropriate procedure for a particular data type or target [64-66]. In this work, the similarity and distance measures are tested for time-series image classification.

The SAM method calculates the angle (expressed in radians $0-\pi$ ) formed between the temporal signature present in the pixel "X" and the reference "Y", described by the following formulation [62]:

$$
\mathrm{SAM}=\alpha=\cos ^{-1} \frac{\sum_{\mathrm{i}=0}^{\mathrm{N}} \mathrm{X}_{\mathrm{i}} \mathrm{Y}_{\mathrm{i}}}{\sqrt{\sum_{\mathrm{i}=0}^{\mathrm{N}}\left(\mathrm{X}_{\mathrm{i}}\right)^{2} \sum_{\mathrm{i}=0}^{\mathrm{N}}(\mathrm{Y})^{2}}}
$$

The variable " $\mathrm{i}$ " corresponds to the temporal band, ranging from one to the number of temporal bands "N". The higher the similarity between the temporal curves smaller the angle value. The SAM is unable to detect anti-correlated data and is invariant to bias factors.

The SCM is a modification of the SAM method, being invariant to the bias and gain factors, and enables to detect anti-correlated data. The SCM values range from -1 to 1 , where 1 means maximum correlation, 0 means they are completely uncorrelated, and -1 means they are perfect opposites. The major difference between the correlation methods is that SAM uses only values for X and Y, whereas SCM uses data centered by the means " $\overline{\mathrm{X}}$ " and "Y $"$ " [63]:

$$
\operatorname{SCM}=\frac{\sum(\mathrm{X}-\overline{\mathrm{X}})(\mathrm{Y}-\overline{\mathrm{Y}})}{\sqrt{\sum(\mathrm{X}-\overline{\mathrm{X}})^{2} \sum(\mathrm{Y}-\overline{\mathrm{Y}})^{2}}}
$$


The ED is a measure sensitive to the bias (additive) factor and gain (multiplicative) factor. The shorter the distance, the greater the possibility of temporal signature belongs to the reference group. The Euclidean distance is described by the equation:

$$
\mathrm{ED}=\sqrt{\sum_{\mathrm{i}=1}^{\mathrm{N}}\left(\mathrm{X}_{\mathrm{i}}^{\mathrm{t}_{1}}-\mathrm{Y}_{\mathrm{i}}^{\mathrm{t}_{2}}\right)^{2}}
$$

\subsubsection{Accuracy Analysis}

The Overall Accuracy and the Kappa coefficient were used for the accuracy assessment of land-use or land-cover classifications [66]. The calculation of these accuracy indices for the different methodological approaches used as ground truth 1510 points from the visual classification of Thematic Mapper (TM) from September 12, 2011 (Figure 2.7a). This classification was updated for 2013 from high-resolution data from Google Earth and fieldwork observations (Figure 2.7b). The areas of landuse change were not considered in the accuracy analysis. Overall Accuracy is the ratio of the number of pixels correctly classified by the total number of pixels. The Kappa index is a measure described by the following equation:

$$
\mathrm{K}=\frac{\mathrm{N} \sum_{\mathrm{i}=1}^{\mathrm{r}} \mathrm{x}_{\mathrm{ii}}-\sum_{\mathrm{i}=1}^{\mathrm{r}} \mathrm{x}_{\mathrm{i}+\mathrm{x}_{+\mathrm{i}}}}{\mathrm{N}^{2}-\sum_{\mathrm{i}=1}^{\mathrm{r}} \mathrm{x}_{\mathrm{i}+} \mathrm{x}_{+\mathrm{i}}}
$$

where " $r$ " is the number of rows in the error matrix, "xii" is the number of observation on row "i" and column " $\mathrm{i}$ ", " $\mathrm{xi}+$ " and " $\mathrm{x}+\mathrm{i}$ " are thus the marginal totals on row " $\mathrm{i}$ " and column " $\mathrm{i}$ ", respectively, and "N" is the total number of observations.

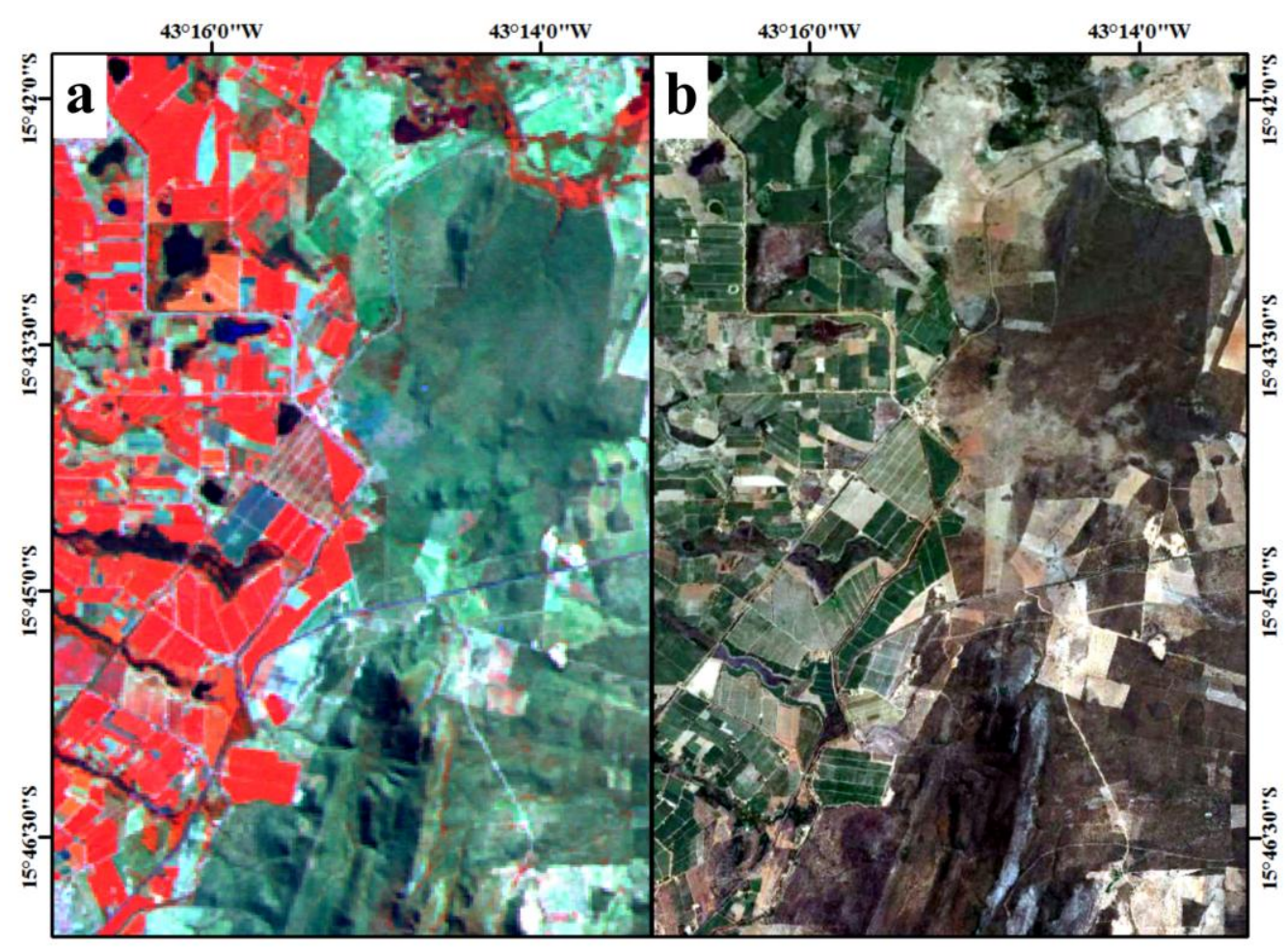

Figure 2.7. (a) Landsat-5 TM image of September 12, 2011, color composite with 453 (RGB) and (b) high-resolution images from Google Earth of 2013. 


\subsection{Results}

\subsubsection{Noise Reduction}

The combination of the median filter and SG exhibited good results in the noise elimination of the MODIS-NDVI time series. The median filter minimized the impulse noise such as cloud cover and shade. However, the median filter can generate some linear levels due to the repetition of values. The SG with a window size of nine [67] refined the result obtained by the median filter, smoothing the temporal profile without interfering with the maximum and minimum values and ensuring data integrity. Figure 2.8 shows the results from the application of filtering techniques in the time series.

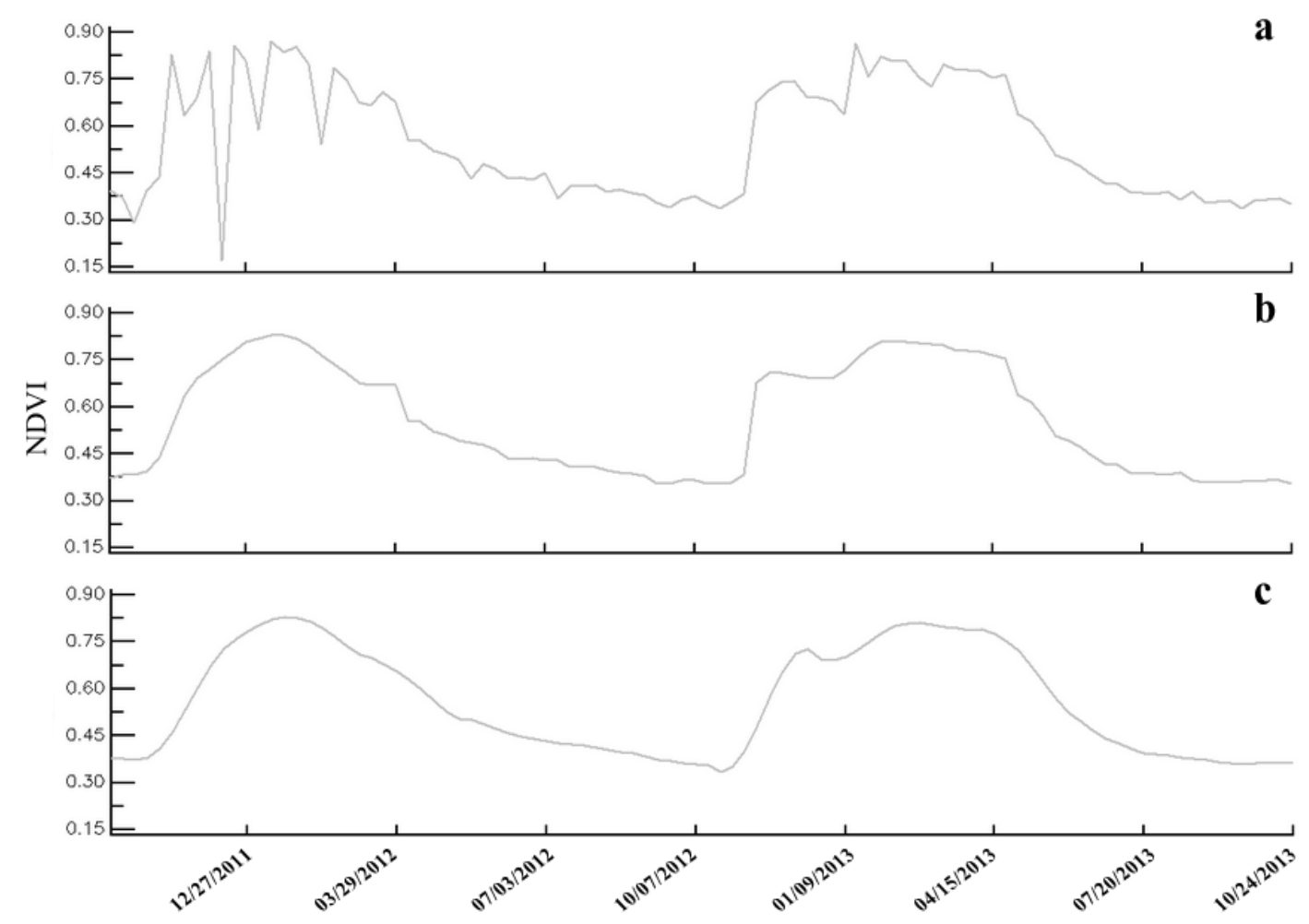

Figure 2.8. MODIS NDVI time series, (a) original data with the presence of noise, (b) time profile softened by the median filter, and (c) refined by the S-G.

\subsubsection{Temporal Signatures}

The temporal signatures of vegetation have the lowest NDVI values during the dry season (May to October) and the highest values in the rainy season (November to April). The formations with more dense canopies of Caatinga domain (Deciduous Seasonal Forest and Semi-deciduous Seasonal Forest) have NDVI values of $0.80 \pm 0.03$ during the rainy season. The lower NDVI values of the Deciduous Forest are around $0.33 \pm 0.02$ because of loss of leaves. This vegetation provides a quick recovery with the rainy season, which is more significant than the shrub-grasslands [68] (Figure 2.9a). The Semideciduous Forest has lower NDVI ranges, not reaching NDVI values lower than 0.44 (Figure 2.9b). This vegetation type is photosynthetically active throughout the year, even during periods of lower rainfall. 

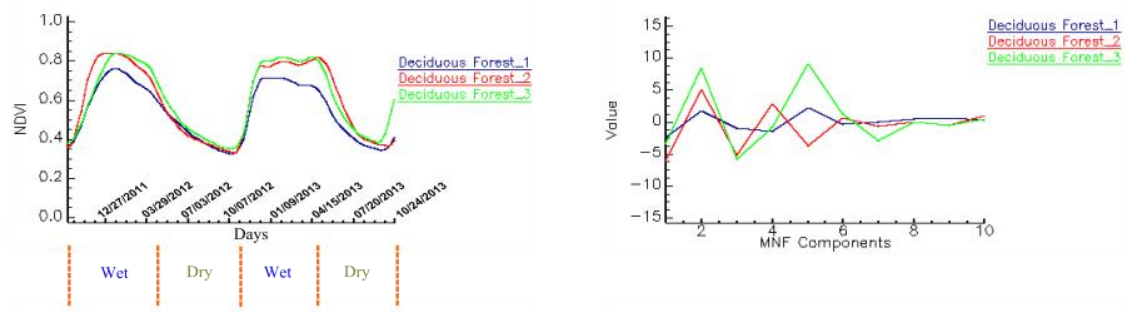

a
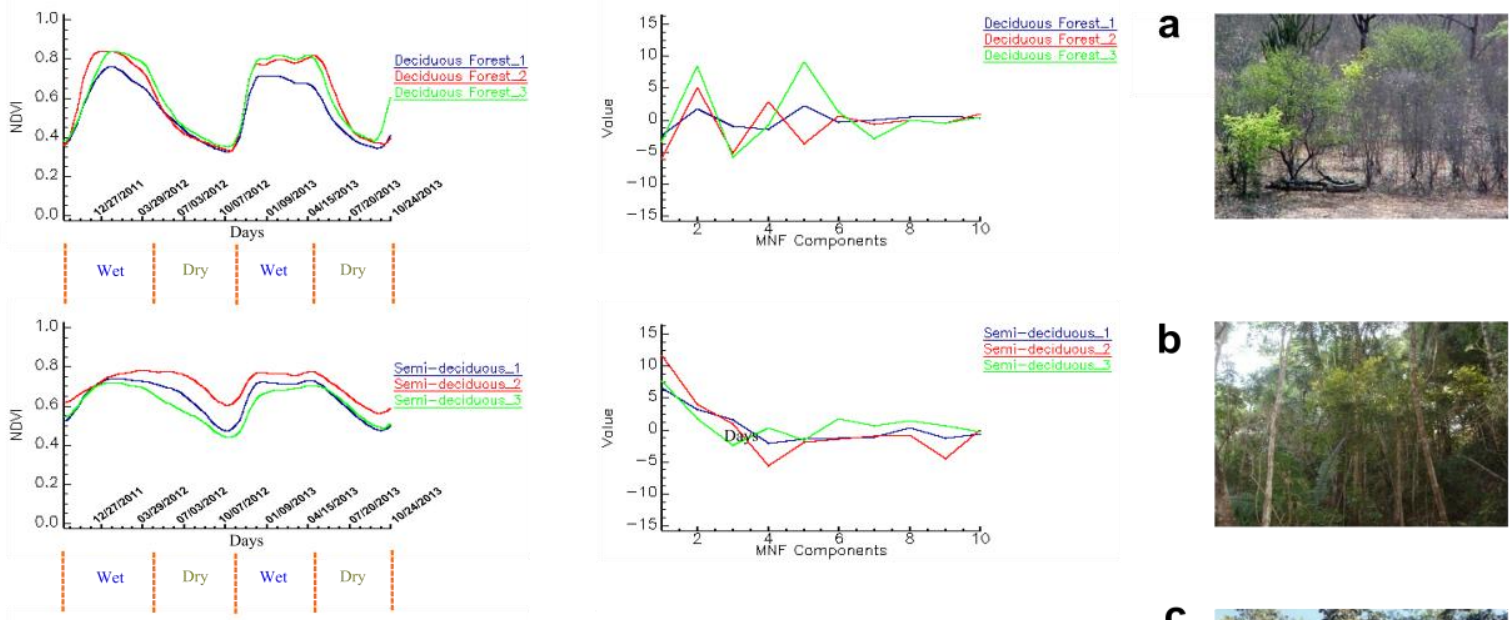

b
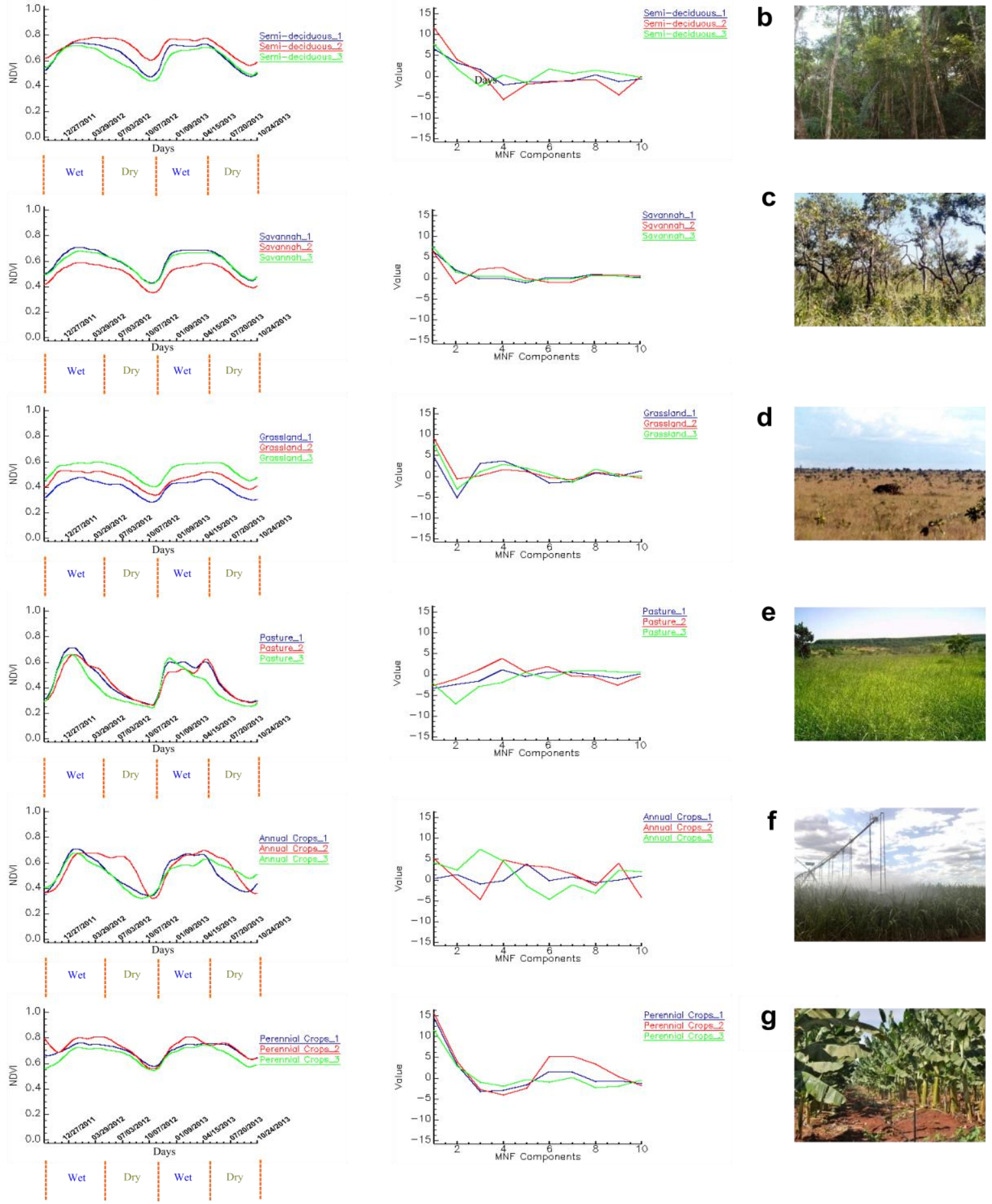

Figure 2.9. Temporal signatures from MODIS-NDVI time series and the MNF signal components: (a) Deciduous Seasonal Forest, (b) Semi-deciduous Seasonal Forest, (c) Savannah Woodland (Cerrado stricto sensu), (d) Grassland formations, (e) Pasture, (f) Annual Crops, and (g) Perennial Crops. 
The Savannah Woodland (Cerrado sensu stricto) have maximum NDVI value of 0.70 (Figure 2.9c), slightly lower than the arboreal formations of the Caatinga. The Savannah Fields (grasslands formations) have mixing behavior among its grassy and shrub, which creates difficulties in the subtypes identification [44]. Therefore, the distinction of grassland types (Savannah Grassland, Shrub Savannah and Rupestrian Fields) was not possible from temporal curves, being considered in the classification as a single class. The herbaceous scrub vegetation showed NDVI values range from 0.27 to 0.58 (Figura 2.9d), whereas the woody-herbaceous vegetation has NDVI values from 0.35 to 0.70 (Figura 2.9c) in the dry and rainy season, respectively.

The grasslands formations are quite affected by the water deficiency, leading to the lowest NDVI values among all studied native vegetation. However, the phenological behavior between native grasslands and pasture, predominantly of the genus Brachiaria [37], are possible to be differentiated. The pasture responds more quickly to the beginning of the rainy season, reaching the maximum photosynthetic activity (NDVI value equal to 0.71 ) in a range of approximately 8 days (Figure 2.9e). In the native grasslands, it occurs after approximately 24 days of the start of the rainy season. Furthermore, pastures have NDVI values higher than native grasslands for all the analyzed curves.

The distinction of temporal signatures for all types of short-cycle crops was not possible. In the same place, distinct and simultaneous short-cycle crops may occur, providing different configurations. However, Annual-cycle Crops are individualized, even when various species are grown simultaneously. These cultures maintained a maximum NDVI level (0.70) for a period of 180 days and showed a similar minimum values $(0.31 \pm 0.01)$ (Figure 2.9f). This indicates a cyclical regularity of agricultural practices, nutritional conditions and water availability, which is not happen as rigorously in nature. The Perennial Crops have deciduous nature, with maximum NDVI values similar to the Semi-deciduous Forest $(0.80 \pm 0.03)$ (Figure 2.9g). The distinction between these vegetations is the minimum NDVI values, the forest has a range from 0.44 to 0.60 , and the perennial crop has more restricted range from 0.54 to 0.57 . The crop performance compared to native vegetation is motivated by agricultural techniques that standardize the soil fertility, the number of species per unit area and water availability.

\subsubsection{Classification of the MODIS-NDVI Time-Series and MNF Signal Components}

This study evaluated different classifications of land use and land cover, considering several combinations of procedures. Table 2.2 showed the accuracy indices for the different classifications obtained by the arrangement of the following attributes: (a) number of temporal curves by class (single or multiple); (b) number of classes used in the classification (six or eight), (c) input data (NDVIMODIS time series or MNF signal components), and (d) classification measures (SAM, SCM or ED). The best result was the combination that used the multiple curves, ED on MODIS-NDVI time-series and considered six classes of land use/land cover, obtaining an Overall Accuracy of $82.25 \%$ and Kappa Index of 0.76 , representing a very good classification. The same combination using the MNF signal components also achieved a very good classification, having a Overall Accuracy of $77.68 \%$ and Kappa of 0.70 . 
Table 2.2. Accuracy assessment for the classifications from two types of input data (NDVI-MODIS time series and MNF signal components), three classification measures (SAM SCM and ED), number of curves by class (single or multiple) and the two classification with six and eight classes.

\section{One Temporal Signature per Class}

\begin{tabular}{cccccc}
\multirow{2}{*}{\begin{tabular}{c}
\multirow{2}{*}{ Methods } \\
Sets
\end{tabular}} & \multicolumn{2}{c}{ Overall Accuracy } & \multicolumn{2}{c}{ Kappa Coefficient } \\
\cline { 3 - 6 } & & $\begin{array}{c}\text { NDVI } \\
\text { MODIS }\end{array}$ & Signal MNF & $\begin{array}{c}\text { NDVI } \\
\text { MODIS }\end{array}$ & Signal MNF \\
\hline \multirow{2}{*}{ Spectral Angle Mapper } & 1 & 55,50 & 61,26 & 0,41 & 0,48 \\
& 2 & 40,99 & 39,60 & 0,32 & 0,31 \\
\hline \multirow{2}{*}{ Spectral Correlation Mapper } & 1 & 59,60 & 59,60 & 0,45 & 0,45 \\
& 2 & 40,66 & 41,66 & 0,31 & 0,33 \\
\hline \multirow{2}{*}{ Euclidian Distance Measure } & 1 & 60,79 & 67,48 & 0,46 & 0,54 \\
& 2 & 40,79 & 45,17 & 0,32 & 0,36 \\
\hline
\end{tabular}

Three Temporal Signatures per Class

\begin{tabular}{cccccc}
\multirow{2}{*}{$\begin{array}{c}\text { Methods } \\
\text { Sets }\end{array}$} & \multicolumn{2}{c}{ Overall Accuracy } & \multicolumn{2}{c}{ Kappa Coefficient } \\
\cline { 3 - 6 } & & $\begin{array}{c}\text { NDVI } \\
\text { MODIS }\end{array}$ & Signal MNF & $\begin{array}{c}\text { NDVI } \\
\text { MODIS }\end{array}$ & Signal MNF \\
\hline \multirow{2}{*}{ Spectral Angle Mapper } & 1 & 63,18 & 75,29 & 0,53 & 0,67 \\
& 2 & 55,63 & 66,29 & 0,47 & 0,59 \\
\hline \multirow{2}{*}{ Spectral Correlation Mapper } & 1 & 59,54 & 75,36 & 0,49 & 0,67 \\
& 2 & 46,49 & 66,36 & 0,38 & 0,59 \\
\hline \multirow{2}{*}{ Euclidian Distance Measure } & 1 & 82,25 & 77,68 & 0,76 & 0,70 \\
& 2 & 73,25 & 68,81 & 0,68 & 0,62
\end{tabular}

The use of multiple temporal curves in the classification showed better accuracy than the use of a single time curve (Table 2.2). Figure 2.10 shows the results from the single or three temporal curves per class, compared with NDVI-MODIS images, signal components of the MNF transform, and Landsat-TM.

Figure 2.11 illustrates the classified images using the distance and similarity measures (SAM, $\mathrm{SCM}, \mathrm{ED}$ ) and the two data types (NDVI-MODIS and the MNF signal components). These maps consider the eight classes described in the Table 2.1. The dominance of the Cerrado in the east and the Caatinga in the western part were detected in all the classified images. Agricultural activities also had a regional division, with the annual cycle crops to the northwest and the perennial crops in the centersouth and east of the study area, mainly in the classifications from the ED algorithm.

The increase in the number of classes causes a decrease in accuracy, considering all classification measures or input data (Table 2.2). The Cerrado physiognomies have the highest loss of accuracy with the increase in the number of classes. The vegetation types of the Cerrado biome with shrub and 
herbaceous vegetation have a high interannual variability amending phenology and so hinder its detection with only a temporal signature. Unlike the Cerrado, the subclasses of Caatinga were well defined. The Deciduous Forest presents temporal signatures with specific shapes and with few variations (Figure 2.9a), enabling an accurate classification, irrespective of the adopted algorithm. Some classification errors happened near fragment edges, which occurs spectral mixing with their surroundings. However, the deciduous formation showed the best accuracy among all evaluated native vegetation types. The Semi-deciduous Forest did not achieve the accuracy of deciduous formation due its deciduous nature, which causes confusion with the Cerrado tree formations and permanent crops, mainly forestry located in the southeast of the study area.

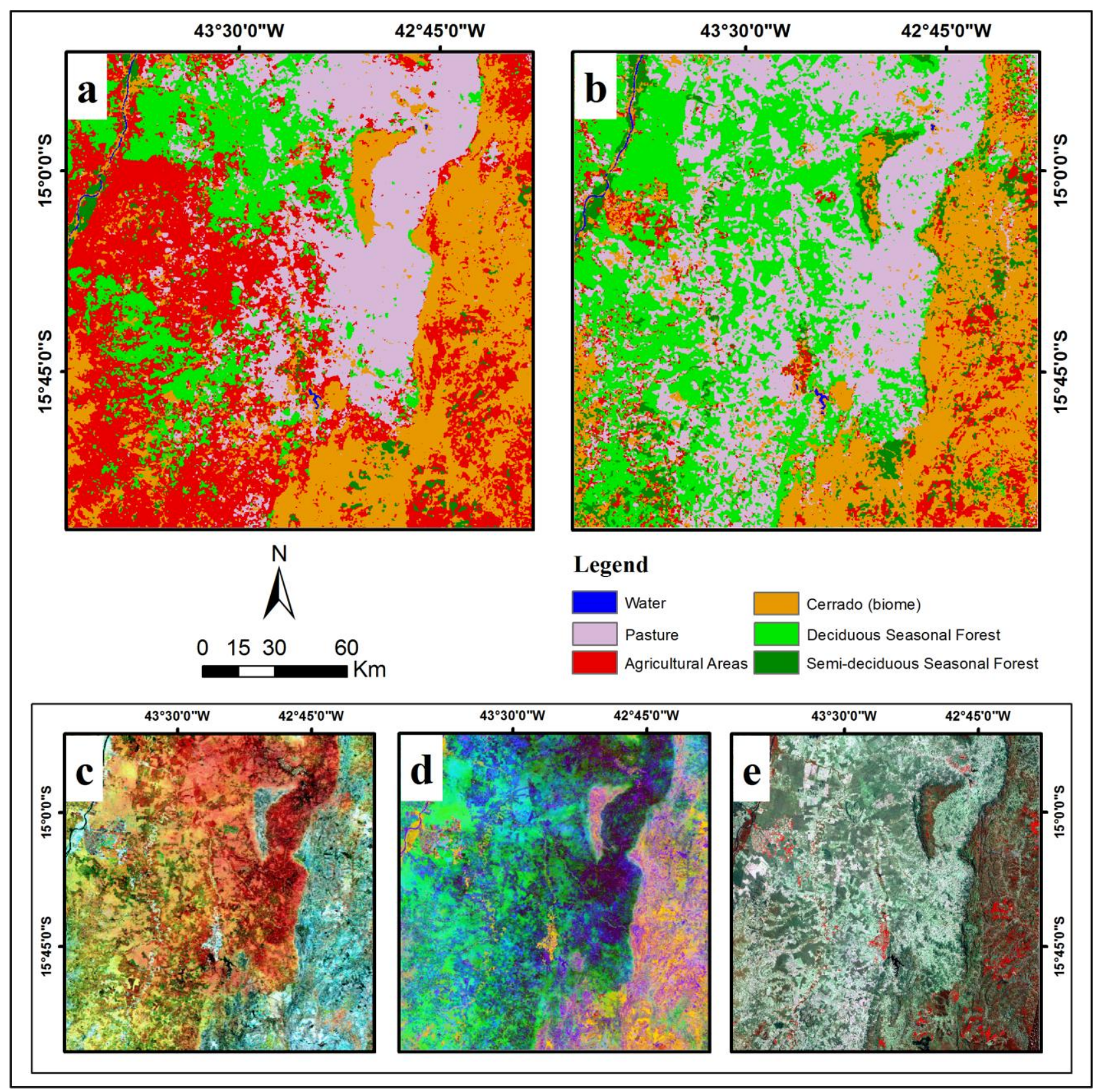

Figure 2.10. Classified maps elaborate from one (a) or three temporal curves (b), considering the other factors remain constant: Euclidian distance, six classes (land-use and land-cover), and NDVI-MODIS input data. Color composite (RGB) 12-28-44 of NDVIMODIS images (c), 1-2-4 signal fraction of the MNF (d) and 4-5-3 Landsat-TM (e). 


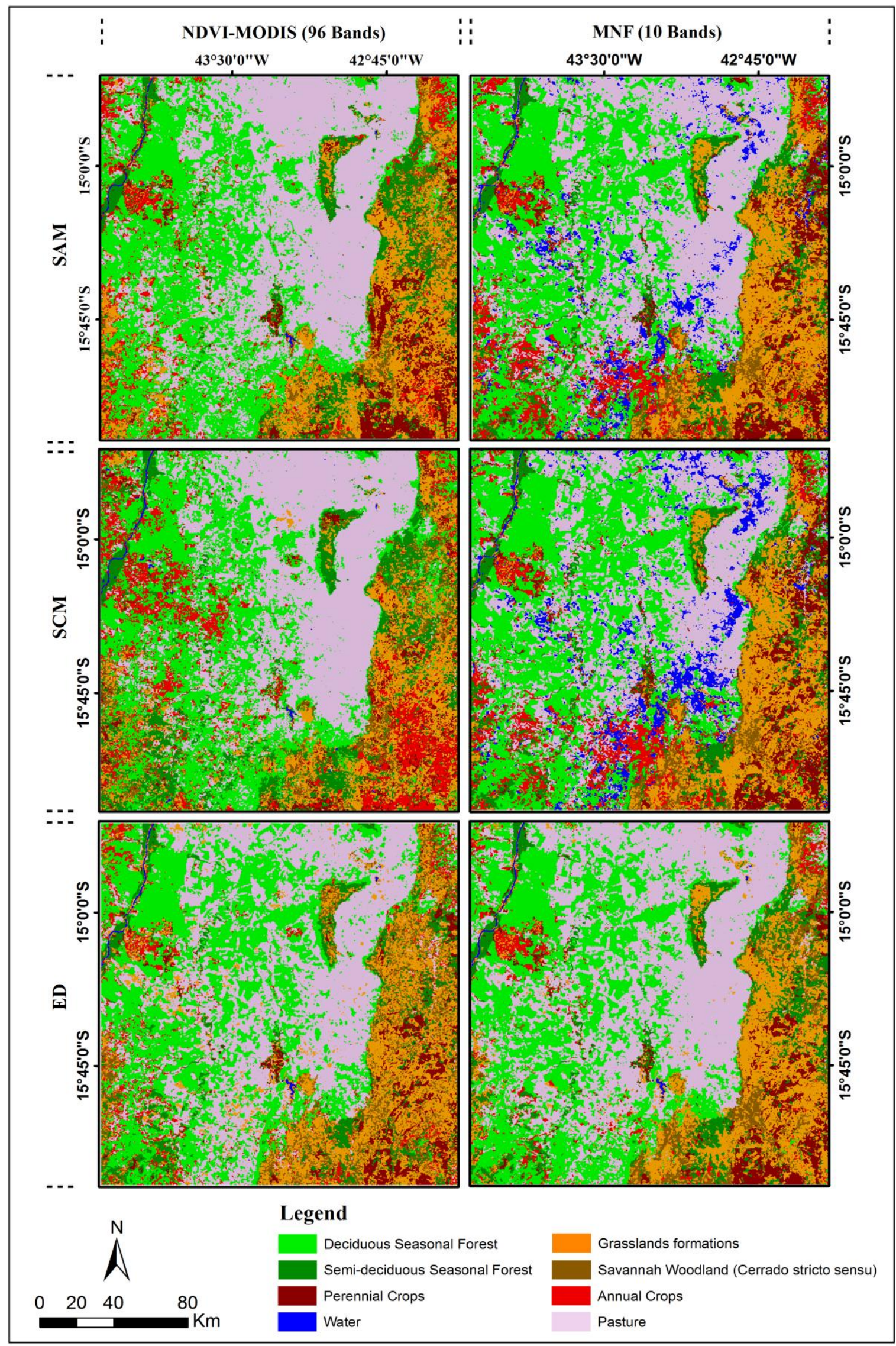

Figure 2.11. Classified images considering two types of input data (NDVI-MODIS time series and MNF signal components), three types of similarity and distance measures (SAM SCM and ED), and the more specific set of use classes (eight classes). 
The distinction between annual and perennial crops occurred only in monoculture areas over large areas, where prevailing crops irrigated by center pivot. Small farms with intercropping or small-scale monocultures present difficulties in the separation among the crops types. In addition, the high dynamic and multiple land-uses cause confusion in the image classification.

Among the classification measures, the ED showed the best results for both the NDVI-MODIS time series and the MNF signal components (Table 2.2). The SCM method had the worst result for the NDVI-MODIS data considering the eight classes, with Overall Accuracy of $46.49 \%$ and Kappa of 0.38. SAM reached slightly better values with Overall Accuracy of 55.63\% and Kappa of 0.47. This worse performance for the similarity measures was expected due to the interference of the seasonal behavior of vegetation, which gives a similar behavior among the targets of vegetation after canceling the effects of gain and offset [69]. Despite the classes of Semi-deciduous Forest, Savannah Woodland and Savannah Fields having distinct NDVI values, have temporal curves with similar shapes, making it difficult to detect through similarity measures (Figures 2.9b, 2.9c e 2.9d).

The accuracies of SAM and SCM methods show a significant improvement with the use of MNF signal components, which make it closer to the ED results [47,69]. However, the SAM and SCM classification on MNF signal fraction overestimated the area of water bodies over to pastures. On the other hand, the ED results were adversely affected when applied to the MNF signal fraction.

\subsection{Discussion}

A wide range of densities of the woody and herbaceous layers characterizes the vegetation types in the Brazilian Cerrado-Caatinga boundary. The vegetation gradates to other vegetation types, both within its own biome and along the border to neighbouring biomes. Thus, an accurate classification using coarse resolution satellite imagery becomes a challenge. The spectral separation of the vegetation from a single date is difficult due to large seasonal variability. A large improvement is achieved from temporal information that describes the different phenological behavior. The temporal trajectories have been used to characterize and classify different vegetation and land-use.

Numerous comparisons were made in order to identify the optimal image processing for land-cover and land-use mapping in the study region. One reason for the decreased accuracy of phenological classification can be explained by the different responses to the same type of vegetation caused by environmental variations (precipitation, temperature, soil and hydrological conditions). Thus, a single temporal signature for each class is not sufficient to represent the changes in the vegetation phenology or land-use in semi-arid environment. In such regions, the natural climatic variability presents isolated events in a short distance, such as rain, wind and fire [69-74]. This variability of physical events cause different behaviors for a same vegetation type, such as regeneration, vegetative growth, flowering, fruiting and seed dispersal. Therefore, the classification efficiency increases when more than a temporal signature is applied for describes each land-use/land-cover class. The number of temporal signatures per class should correspond to different temporal patterns described by the analyzed classes. In this approach, the endmember-detection method, widely use in the hyperspectral imaging, can be adapted for time series.

The MNF transform causes a data reduction by approximately $10 \%$. The use of signal components of MNF transform instead of MODIS-NDVI data did not improve the classification accuracy of the Euclidian distance. However, this input data causes a significant change when used with the similarity 
metrics (SCM and SAM). Since there was no significant difference in the classifications obtained from signal MNF components, we recommend the use of MODIS-NDVI data and Euclidian distance in the classification.

The separation between annual and perennial crops has limitations, especially in areas with family farming. This agricultural occupation develops multiple activities and high dynamics in smaller territorial extensions, which affects the quality on detection using MODIS data [29]. Another constraint is to differentiate the savanna types, because it consists of a nearly continuous grass layer, overlaid by a discontinuous tree layer. The boundaries between the savanna physiognomies are usually gradual and fragmented on the landscape, which hampers the proper detection from the 250-m resolution images due to its high spectral mixture. This difficulty has already been pointed out by other authors [75,76], even combining MODIS time series and climate data (precipitation, humidity, soil moisture, light intensity, day length). The application of high spatial and temporal resolution images as the RapidEye can be a possible solution for an accurate detection [77].

Another test that can be performed as future work is to evaluate the time-series interval for phenological classification. Alcântara et al. [78] recommend the inclusion of at least two years of MODIS-NDVI data to conduct the abandoned agriculture mapping. Huttich et al. [28,79] suggest to improve the accuracy of the native vegetation classification in savanna environments the use of vegetation-index time series more than two years and a temporal resolution of less than 16 days.

\subsection{Conclusion}

This study defines a method for the native and exotic vegetation mapping in the transition region of semi-arid ecosystems (Cerrado-Caatinga) from comparison of different time-series processing. The different factors that can compose the classification highlight the importance for studying dynamics in dry savanna ecosystems. The range of the kappa statistics for classification sets is between 0.38 and 0.76. Improved accuracies were achieved by the integration of following parameters: Euclidian Distance, use of more than a reference curve per class, and the adoption of six mapping classes (Water, Farming, Pasture Deciduous Forest, Semi-deciduous Seasonal Forest e Cerrado). This configuration obtained Overall Accuracy of $82.25 \%$ and Kappa coefficient of 0.76 . The innovative adoption of the signal components of the Minimum Noise Fraction (MNF) improved the accuracy indices of the SAM and SCM, which had Overall Accuracy greater than 73\% and Kappa equal or higher than 0.64. This study noted a significant improvement in accuracy with the use of more than one reference curve by class, in all tested models. This is due to spatial variations of the climatic factors in semi-arid environment that cause a gap between the phenological curves of same vegetation. Therefore, slightly different temporal signatures can represent the same target, which differs from the spectral classification. The limitation of the spatial resolution of the MODIS sensor hinders the identification of the arboreal and herbaceous physiognomies and the activities on small family farms. Future work using other time intervals and images at a periodicity less than 16 days can get better results.

\section{References}

1. Werneck, F.P. The diversification of eastern South American open vegetation biomes: historical biogeography and perspectives. Quaternary Sci. Rev. 2011, 30, 1630-1648. 
2. Pinheiro, M.H.O.; MONTEIRO, R. Contribution to the discussions on the origin of the Cerrado biome: Brazilian savanna. Braz. J. Biol. 2010, 70, 95-102.

3. Mayle, F.E. Assessment of the Neotropical dry forest refugia hypothesis in thelight of palaecological data and vegetation model simulations. J. Quaternary Sci. 2004, 19, 713-720.

4. Pennigton, R.T.; Lavin, M.; Oliveira-Filho, A. Woody plant diversity, evolution, and ecology in the tropics: perspectives from seasonally dry tropical forests. Annu. Rev. Evol. Sust. 2009, 40, 437-457.

5. Hoekstra, J.M.; Boucher, T.M.; Ricketts, T.H.; Roberts, C. Confronting a biome crisis: global disparities of habitat loss and protection. Ecol. Lett. 2005, 8, 23-29.

6. Portillo-Quintero, C.A.; Sánchez-Azofeifa, G.A. Extent and conservation of tropical dry forests in the Americas, Biol. Cons. 2010, 143, 144-155.

7. Boori, M.S.; Amaro, V.E. Land use change detection for environmental management: using multi-temporal, satellite data in the Apodi Vallery of northeastern Brazil. Appl. GIS, 2010, 6, 115.

8. Ministério do Meio Ambiente (MMA); Instituto Brasileiro do Meio Ambiente e dos Recursos Naturais Renováveis (IBAMA). Monitoramento do Bioma Caatinga 2008-2009. In Monitoramento dos Desmatamentos nos Biomas Brasileiros por Satélite. 2011; pp. 1-46. Available online: http://siscom.ibama.gov.br (accessed on 23 December 2014).

9. Sano, E.E.; Rosa, R.; Brito, J.L.S.; Ferreira, L.G. Land cover mapping of the tropical savanna region in Brazil. Environ. Monit. Assess. 2010, 166, 113-124.

10. Furley, P.A.; Metcalfe, S.E. Dynamic changes in savanna and seasonally dry vegetation through time. Prog. Phys. Geog. 2007, 31, 633-642.

11. Werneck, F.P.; Costa, G.C.; Colli, G.R.; Prado, D.E.; Sites, J.W., Jr. Revisiting the historical distribution of seasonally dry tropical forests: new insights based on palaeodistribution modelling and palynological evidence. Global Ecol. Biogeogr. 2011, 20, 272-288.

12. Justice, C.O.; Townshend, J.R.G.; Vermote, E.F.; Masuoka, E.; Wolfe, R.E.; Saleous, N.; Roy, D.P.; Morisette, J.T. An overview of MODIS land data processing and product status. Remote Sens. Environ. 2002, 83, 3-15.

13. Clark, M.L.; Aide, T.M.; Riner, G. Land change for all municipalities in Latin America and the Caribbean assessed from 250-m MODIS imagery (2011-2010). Remote Sens. Environ. 2012, 126, 84-103.

14. Hammer, D.; Kraft, R.; Wheeler, D. Alerts of forest disturbance from MODIS imagery. Int. J. Appl. Earth Obs. Geoinf. 2014, 33, 1-9.

15. Jia, K.; Liang, S.; Wei, X.; Yao, Y.; Su, Y.; Jiang, B.; Wang, X. Land cover classification of Landsat data with phenological features extracted from time series MODIS NDVI data. Remote Sens. 2014, 6, 11518-11532.

16. Senf, C.; Pflugmacher, D.; van der Linden, S.; Hostert, P. Mapping rubber plantations and natural forests in Xishuangbanna (Southwest China) using multi-spectral phenological metrics from MODIS time series. Remote Sens. 2013, 5, 2795-2812.

17. Van Leeuwen, W.J.; Davison, J.E.; Casady, G.M.; Marsh, S.E. Phenological characterization of desert sky Island vegetation communities with remotely sensed and climate time series Data. Remote Sens. 2010, 2, 388-415. 
18. Zhao, X.; Xu, P.; Zhou, T.; Li, Q.; Wu, D. Distribuition and variation of forests in China from 2001 to 2011: a study based on remotely sensed data. Remote Sens. Environ. 2013, 4, 632-649.

19. Bernardes, T.; Moreira, M.A.; Adami, M.; Giarolla, A.; Rudorff, B.F.T. Monitoring biennial bearing effect on coffee yield using MODIS remote sensing imagery. Remote Sens. 2012, 4 , 2492-2509.

20. Breunig, F.M.; Galvão, L.S.; Formaggio, A.R.; Epiphanio, J.C.N. Variation of MODIS reflectance and vegetation indices with viewing geometry and soybean development. An. Acad. Bras. Ciên. 2012, 84, 263-274.

21. Couto Júnior, A.F.; de Carvalho Júnior, O.A. Martins, E.S.; Vasconcelos, V. Characterization of the agriculture occupation in the Cerrado biome using MODIS time-series. Rev. Bras. Geofis. 2013, 31, 393-402.

22. Galford, G.; Mustard, J.F.; Melillo, J.; Gendrin, A.; Cerri, C.C.; Cerri, C.E.P. Wavelet analysis of MODIS time series to detect expansion and intensification of row-crop agriculture in Brazil. Remote Sens. Environ. 2008, 112, 576-587.

23. Pan, Y.; Li, L.; Zhang, J.; Liang, S.; Zhu, X.; Sulla-Menashe, D. Winter wheat area estimation from MODIS-EVI time series data using the crop proportion phenology index. Remote Sens. Environ. 2012, 119, 232-242.

24. Sakamoto, T.; Yokozawa, M.; Toritani, H.; Shibayama, M.; Ishitsuka, N.; Ohno, H. A crop pehnology detection method using time-series MODIS data. Remote Sens. Environ. 2005, 96, 366-374.

25. Ferreira, L.G.; Fernandez, L.E.; Sano, E.E.; Field, C.; Sousa, S.B.; Arantes, A.E.; Araújo, F.M. Biophysical properties of cultivated pastures in the Brazilian savanna biome: an analysis in the spatial-temporal domains based on ground and satellite data. Remote Sens. 2013, 5, 307-326.

26. Le Maire, G.; Marsden, C.; Nouvellon, Y.; Stape, J.L.; Ponzoni, F.J. Calibration of a speciesspecific spectral vegetation index for leaf area index (LAI) monitoring: example with MODIS reflectance time-series on eucalyptus plantations. Remote Sens. 2012, 4, 3766-3780.

27. Sánchez-Azofeifa, G.A.; Quesada, M.; Rodríguez, J.P.; Nassar, J.M.; Stoner, K.E.; Castillo, A.; Garvin, T.; Zent, E.L.; Calvo-Alvarado, J.C.; Kalacska, M.E.R.; Fajardo, L.; Gamon, J.A.; Cuecas-Reyes, P. Research priorities for neotropical dry forests. Biotropica, 2005, 37, 477-485.

28. Hüttich, C.; Gessner, U.; Herold, M.; Strohbach, B.J.; Schimidt, M.; Keil, M.; Dech, S. On the suitability of MODIS time series metrics to map vegetation types in dry savana ecosystems: a case study in the Kalahari of NE Namibia. Remote Sens. 2009, 1, 620-643.

29. Baldi, G.; Houspanossian, J.; Murray, F.; Rosales, A.A.; Rueda, C.V.; Jobbágy, E.G. Cultivating the dry forests of South America: diversity of land users and imprints on ecosystem functioning. J. Arid. Environ. 2014, doi: 10. 1016/j.jaridenv.2014.05.027.

30. Portillo-Quintero, C.A.; Sánchez-Azofeifa, G.A.; Espírito-Santo, M.M. Monitoring deforestation with MODIS active fires in neotropical dry forests: an analysis of local-scale assessments in Mexico, Brazil and Bolivia. J. Arid Environ. 2013, 97, 150-159.

31. Madeira, B.G.; Espírito-Santo, M.M.; D’Ângelo Neto, S.; Nunes, Y.R.F.; Sánchez-Azofeifa, G.A.; Fernandes, G.W.; Quesada, M. Changes in tree and liana communities along a sucessional gradiente in a tropical dry forest in south-eastern Brazil. Plant. Ecol. 2009, 201, 291-304. 
32. Saadi, A.; Magalhães Júnior, A.P. A geomorfologia do Planalto do Espinhaço setentrional avaliada para a implantação de barragem: a UHE de Irapé-MG. Geonomos, 1997, 5, 9-14.

33. De Carvalho, L.M.T.; Scolforo, J.R. Inventário florestal de Minas Gerais: monitoramento da flora nativa 2005-2007, 1st ed.; Lavras: Universidade Federal de Lavras, Brazil, 2008; p. 357.

34. Dutra, V.F.; Garcia, F.C.P. Three New Species of Mimosa (Leguminosae) from Minas Gerais, Brazil. Syst. Botany, 2013, 38, 398-405.

35. Alves, R.J.V., Kolbek, J. Can campo rupestre vegetation be floristically delimited based on vascular plant genera? Plant Ecol. 2010, 207, 67-79.

36. Echternacht, L.; Trovó, M.; Oliveira, C.T.; Pirani, J.R. Areas of endemismo in the Espinhaço Range in Minas Gerais, Brazil. Flora, 2011, 206, 782-791.

37. Espírito-Santo, M.M.; Sevilha, A.C.; Anaya, F.C.; Barbosa, R.; Fernandes, G.W.; SánchezAzofeifa, G.A.; Scariot, A.; de Noronha, S.E.; Sampaio, C.A. Sustainability of tropical dry forests: two case studies in southeastern and central Brazil. Forest. Ecol. Manag. 2009, 258, 922-930.

38. Zappi, D. Fitofisionomia da Caatinga associada à Cadeia do Espinhaço. Megadiversidade, 2008, 4, 34-38.

39. Instituto Brasileiro de Geografia e Estatística (IBGE). Sistema IBGE de Recuperação Eletrônica (SIDRA), 2012. Available online: http://www.sidra.ibge.gov.br (accessed on 29 August 2014).

40. Domingues, S.A.; Karez, C.S.; Biondini, I.V.F.; Andrade, M.A.; Fernandes, G.W. Economic environmental management tolls in the Serra do Espinhaço biosphere reserve. J. Sust. Dev. 2012, 5, 180-191.

41. Dos Santos, R.M.; Vieira, F.A.; Fagundes, M.; Nunes, Y.R.F.; Gusmão, F. Floristic richness and similarity of eight forest remnants in the north of Minas Gerais state, Brazil. Rev. Árvore, 2007, 31, 135-144.

42. Justice, C.O.; Townshend, J.R.G.; Vermote, E.F.; Masuoka, E.; Wolfe, R.E.; Saleous, N.; Roy, D.P.; Morisette, J.T. An overview of MODIS land data processing and product status. Remote Sens. Environ. 2002, 83, 3-15.

43. Guindin-Garcia, N.; Gitelson, A.A.; Arkebauer, T.J.; Shanahan, J.; Weiss, A. An evaluation of MODIS 8- and 16-day composite products for monitoring maize leaf are index. Agric. For. Meteorol. 2012, 161, 15-25.

44. Lisenberg, V.; Ponzoni, F.J.; Galvão, L.S. Analysis of the seasonal dynamics and spectral separability of some savanna physiognomies with vegetation indices derived from MODIS/TERRA and AQUA. Rev. Árvore, 2007, 31, 295-305.

45. Rouse, J.W.; Haas, R.H.; Schell J.A.; Deering, D.W. Monitoring vegetation systems in the Great Plains with ERTS. In Proceedings of the Third Earth Resources Technology Satellite-1 Symposium, Greenbelt, MD, USA, 10-15 December 1973, pp. 301-317.

46. De Carvalho Júnior, O.A.; Hermuche, P.M.; Guimarães, R.F. Identificação regional da floresta decidual na bacia do rio Paranã a partir da análise multitemporal de imagens MODIS. Rev. Bras. Geofis. 2006. 24, 319-332.

47. De Carvalho Júnior, O.A.; Sampaio, C.S.; da Silva, N.C.; Couto Júnior, A.F.; Gomes, R.A.T.; de Carvalho, A.P.F.; Shimabukuro, Y.E. Classificação de padrões de savana usando assinaturas 
temporais NDVI do sensor MODIS no parque nacional Chapada dos Veadeiros. Rev. Bras. Geofis. 2008, 26, 505-517.

48. Savitzky, A., Golay, M.J.E. Smoothinbg and differentiation of data by simplified least squares procedures. Anal. Chem. 1964, 36, 1627-1639.

49. Ataman, E.; Aatre, V.K.; Wong, K.M. Some statistical properties of median filters. IEEE T. Acoust. Speech, 1981, 29, 1073-1075.

50. De Carvalho Júnior, O.A.; da Silva, N.C.; de Carvalho, A.P.F.; Couto Júnior, A.F.; Silva, R.S.; Shimabukuro, Y.E.; Guimarães, R.F.; Gomes, R.A.T. Combining noise-adjusted principal components transform and median filter techniques for denoising MODIS temporal signatures. Rev. Bras. Geofis. 2012, 30, 147-157.

51. Schefer, R.W. What is a Savitzky-Golay filter? IEEE Signal Process. Mag. 2011, 28, 111-117.

52. Chen, J.; Jönsson, P.; Tamura, M.; Gu, Z.; Matsushita, B.; Eklundh, L. A simple method for reconstructing a high-quality NDVI time-series data set based on the Savitzky-Golay filter. Remote Sens. Environ. 2004, 91, 332-334.

53. Li, L.; Friedl, M.A.; Xin, Q.; Gray, J.; Pan, Y.; Frolking, S. Mapping Crop Cycles in China Using MODIS-EVI Time Series. Remote Sens. 2014, 6, 2473-2493.

54. Vrieling, A.; de Leeuw, J.; Said, M.Y. Length of Growing Period over Africa: Variability and Trends from 30 Years of NDVI Time Series. Remote Sens. 2013, 5, 982-1000.

55. Geng, L.; Ma, M.; Wang, X.; Yu, W.; Jia, S.; Wang, H. Comparison of Eight Techniques for Reconstructing Multi-Satellite Sensor Time-Series NDVI Data Sets in the Heihe River Basin, China. Remote Sens. 2014, 6, 2024-2049.

56. Boardman, J. W., 1993, Automating spectral unmixing of AVIRIS data using convex geometry concepts. In Summaries of the Fourth Annual JPL Airborne Geosciences Workshop, Jet Propulsion L aboratory, Pasadena, 25-29 October 1993 (Pasadena, California: JPL Publication), 93-26, 11-14.

57. Craig M. Minimum-volume transforms for remotely sensed data. IEEE Trans. Geosci. Remote Sens. 1994, 32, 542-552.

58. Boardman, J.W.; Kruse, F.A. Analysis of imaging spectrometer data using n-dimensional geometry and a mixture-tuned matched filtering approach. IEEE Trans. Geosci. Remote Sens. 2011, 49, 4138-4152.

59. Green, A.A.; Berman, M.; Switzer, P.; Craig, M.D. A transformation for ordering multispectral data in terms of images quality with implications for noise removal. IEEE Trans. Geosci. Remote Sens. 1988, 26, 65-74.

60. Dickson, B.L.; Taylor, G.F. Maximum noise fraction method reveals detail in aerial gamma-ray surveys. Explor. Geophys. 2000, 31, 73-77.

61. De Carvalho Júnior, O.A.; Maciel, L.M.M.; de Carvalho, A.P.F.; Guimarães, R.F.; Silva, C.R.; Gomes, R.A.T.; Silva, N.C. Probability Density Components Analysis: A New Approach to Treatment and Classification of SAR Images. Remote Sens. 2014, 6, 2989-3019.

62. Kruse, F.A.; Lefkoff, A.B.; Boardman, J.W.; Heidebrecht, K.B.; Shapiro, A.T.; Barloon, P.J.; Goetz, A.F.H. The spectral imageprocessing system (SIPS) - interactive visualization and analysis of imaging spectrometer data. Remote Sens. Environ. 1993, 44, 145-163. 
63. De Carvalho Júnior, O.A.; Meneses, P.R. Spectral correlation mapper (SCM): an improving spectral angle mapper. In Proceedings of Annual JPL Airborne Earth Science Workshop, Pasadena, CA, USA, 23-25 February 2000; pp. 65-74.

64. De Carvalho Júnior, O.A.; Guimarães, R.F.; Gillespie, A.R.; Silva, N.C.; Gomes, R.A.T. A new approach to change vector analysis using distance and similarity measures. Remote Sens. 2011, 3, 2473-2493.

65. De Carvalho Júnior, O.A.,; Guimarães, R.F.; Silva, N.C.; Gillespie, A.R.; Gomes, R.A.T.; Silva, C.R.; de Carvalho, A.P.F. Radiometric Normalization of Temporal Images Combining Automatic Detection of Pseudo-Invariant Features from the Distance and Similarity Spectral Measures, Density Scatterplot Analysis, and Robust Regression. Remote Sens. 2013, 5, 2763 2794.

66. Congalton, R.; Green, K. Assessing the Accuracy of Remotely Sensed Data: Principles and Practices; CRC/Lewis Press: Boca Raton, FL, USA, 1999.

67. Miglani, A.; Ray, S.S.; Vashishta, D.P.; Parihar, J.S. Comparasion of two data smoothing techniques for vegetation spectra derived from EO-1 Hyperion. J. Indian Soc. Remote Sens. 2011, 39, 443-453.

68. Ratana, P.; Huete, A.R.; Ferreira, L.G. Analysis of Cerrado physiognomies and conservation in the MODIS seasonal-temporal domain. Earth Interact. 2005, 9, 1-22.

69. De Carvalho Júnior, O.A.; Couto Júnior, A.F.; da Silva, N.C.; Martins, E.S.; Carvalho, A.P.F.; Gomes, R.A.T. Distância Euclidiana e Spectral Correlation Mapper em séries temporais NDVIMODIS no campo de instrução militar de Formosa (GO). Rev. Bras. Cartogr. 2009, 61, 399412.

70. Oliveras, I.; Meirelles, S.T.; Hirakuri, V.L.; Freitas, C.R.; Miranda, H.S.; Pivello, V.R. Effects off fire regimes on herbaceous biomass and nutrient dynamics in the Brazilian savanna. Int. J. Wildland Fire. 2013, 22, 368-380.

71. Pinheiro, M.H.O; Monteiro, R. Contribution to the discussions on the origin of the Cerrado biome: Brazilian savanna. Braz. J. Biol. 2010, 70, 95-102.

72. Singh, K.P.; Kushwaha, C.P. Diversity of flowering and fruiting phenology of trees in a tropical deciduous forest in India. Ann. Bot. 2006, 97, 267-276.

73. Araújo, F.M.; Ferreira, L.G.; Arantes, A.R. Distribution patterns of burned areas in the Brazilian biomes: an analysis based on satellite data for the 2002-2010 Period. Remote Sens. 2012, 4, 1929-1946.

74. Daldegan, G.A.; de Carvalho Júnior, O.A.; Guimarães, R.F.; Gomes, R.A.T.; Ribeiro, F.F. McManus. C. Spatial patterns of fire recurrence using remote sensing and GIS in the Brazilian savanna: Serra do Tombador Nature Reserve, Brazil. Remote Sens. 2014, 6, 9873-9894.

75. Archibald, S.; Scholes, R. Leaf green-up in a semi-arid African savanna-separating tree and grass responses to environmental cues. J. Veg. Sci. 2007, 18, 583-594.

76. Higgins, S. I.; Delgado-Cartay, M. D.; February, E. C.; Combrink, H. J. Is there a temporal niche separation in the leaf phenology of savanna trees and grasses? J. Biogeogr. 2011, 38, 2165-2175.

77. RapidEye AG. Satellite imagery product specifications. Available online: www.rapideye.net/upload/RE_Product_Specifications_ENG.pdf (acessed on 20 November 2014). 
78. Alcântara, C.; Kuemmerle, T.; Prishchepov, A.; Radeloff, V.C. Mapping abandoned agriculture with multitemporal MODIS satellite data. Remote Sens. Environ. 2012, 124, 334-347.

79. Hüttich, C.; Herold, M.; Wegmann, M.; Cord, A.; Strohbach, B.; Schmullius, C.; Dech, S. Assessing effects of temporal compositing and varying observation periods for large-area landcover mapping in semi-arid ecosystems: Implications for global monitoring. Remote Sens. Environ. 2011, 115, 2445-2459. 


\section{CAPITULO 3 - CONSIDERAÇÕES FINAIS}

Os avanços alcançados nas últimas décadas pelos ramos do conhecimento que envolvem o sensoriamento remoto, os sistemas de informações geográficas (SIG) e os sistemas de posicionamento global (SPG) têm proporcionado uma verdadeira revolução nos estudos orientados ao entendimento do meio ambiente. Com essas ferramentas é possível, por exemplo, entender os padrões de cobertura da terra, as alterações e uso do solo e o comportamento fenológico da vegetação.

Acontece que até o início dos anos 2000, esse avanço somente foi significativo para regiões de clima temperado no mundo. De lá para cá, os inúmeros protocolos firmados por vários líderes de várias nações, a crescente importância que vem sendo dada à preservação da Floresta Amazônica, o acesso gratuito aos produtos do sensor MODIS, dentre outras medidas, acabaram direcionamento parte das pesquisas que se utilizam do geoprocessamento às Florestas Tropicais Úmidas.

Hoje instituições científicas e centros de excelência acadêmica ponta internacionais e nacionais, tais como o Instituto Nacional de Pesquisas Espaciais (INPE) e o Instituto Nacional de Pesquisas da Amazônia (INPA), dedicam parcela significativa dos seus esforços ao desenvolvimento de ferramentas, metodologias e dados que permitam o conhecimento e a preservação desses ambientes.

Embora esse aspecto seja positivo, deve-se ressaltar a pesquisa científica direcionada à compreensão dos ecossistemas semiáridos ainda é deficitária. Ao sensoriamento remoto ainda falta o desenvolvimento de aplicações de rotina que permitam a observação e geração de dados desses ambientes, que reconhecidamente são mais heterogênios e, consequentemente, mais complexos do que os ambientes temperados e úmidos. Tal medida é urgente, haja vista que, apesar de possuírem diversidade tão significativa quanto os ambientes úmidos, os ambientes secos, englobados, dentre outros pelo Cerrado e a Caatinga, vêm passando por uma forte pressão antrópica.

Neste trabalho buscou-se, então, o desenvolvimento de uma sistemática no âmbito do sensoriamento remoto que sirva de referência para o desenvolvimento de rotinas de estudo, monitoramento e preservação dos ambientes de Caatinga e Cerrado do Brasil. Evidentemente que o conjunto de técnicas abordadas no Capítulo 2 não foi suficiente ao encerramento do assunto. Reconhece-se que ajustes melhorias devem ser feitas principalmente no que se refere 
à distinção das formações campestres do bioma Cerrado e das atividades múltiplas desenvolvidas pela agricultura familiar.

Porém, foi provado que o estudo da fenologia e a distinção de alvos vegetais naturais e exóticos em ambientes de alta complexidade de espécies são possíveis através da utilização de séries temporais NDVI-MODIS oriundas do produto MOD09, combinados com uma técnica filtragem dupla, utilizando os métodos de mediana e Savitzky-Golay, e da aplicação de algoritmos de classificação orientados a análise de variância dos alvos, tais como o Euclidian Distance Measure.

É importante ressaltar que o êxito do procedimento está amparado no fato de que a caracterização de cada um das formações vegetais avaliadas deve ser feita por curvas temporais múltiplas, definidas através de análise de variância. Essas curvas representam, em conjunto, a variabilidade do comportamento de alvos de tal natureza em ambientes cujos aspectos climáticos propiciam a forte sazonalidade.

Tem-se, portanto, um fluxo metodológico a partir do qual novas investigações visando à compreensão dos ambientes semiáridos são viabilizadas. Esse fluxo pode ser reproduzido em trabalhos cujos elaboradores disponham de imagens com melhor resolução espacial e temporal ou pode ser melhorado através de inúmeros experimentos. Cita-se, por exemplo, o estudo que visando determinar os melhores índices de identificação de alvos vegetais na região ora avaliada; a comparação de desempenho do NDVI oriundo dos produtos MOD09 e MOD13; a consorciação de imagens com resoluções temporais e espaciais distintas; ou até mesmo o desenvolvimento de novos algoritmos de classificação capazes de detectar as especificidades da sazonalidade da vegetação existente em ecossistemas de precipitação pluviométrica reduzida. 